Nova Southeastern University NSUWorks

2018

\title{
A Knowledge Management System (KMS) Using a Storytelling-based Approach to Collect Tacit Knowledge
}

Nicholas Shaw

Nova Southeastern University, doc@docharley.com

This document is a product of extensive research conducted at the Nova Southeastern University College of Engineering and Computing. For more information on research and degree programs at the NSU College of Engineering and Computing, please click here.

Follow this and additional works at: https://nsuworks.nova.edu/gscis_etd

Part of the Computer Sciences Commons

\section{Share Feedback About This Item}

\section{NSUWorks Citation}

Nicholas Shaw. 2018. A Knowledge Management System (KMS) Using a Storytelling-based Approach to Collect Tacit Knowledge. Doctoral dissertation. Nova Southeastern University. Retrieved from NSUWorks, College of Engineering and Computing. (1033)

https://nsuworks.nova.edu/gscis_etd/1033.

This Dissertation is brought to you by the College of Engineering and Computing at NSUWorks. It has been accepted for inclusion in CEC Theses and Dissertations by an authorized administrator of NSUWorks. For more information, please contact nsuworks@nova.edu. 


\title{
A Knowledge Management System (KMS) Using a Storytelling-based Approach to Collect Tacit Knowledge
}

\author{
By
}

Nicholas James Shaw

\begin{abstract}
A dissertation submitted in partial fulfillment of the requirements for the degree of Doctor of Philosophy

in

Computer Information Systems
\end{abstract}

College of Engineering and Computing

Nova Southeastern University

December 2017 
We hereby certify that this dissertation, submitted by Nicholas Shaw, conforms to acceptable standards and is fully adequate in scope and quality to fulfill the dissertation requirements for the degree of Doctor of Philosophy.

Peixiang Liu, Ph.D.

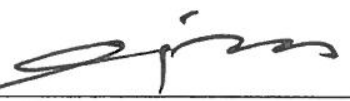

Chairperson of Dissertation Committee

\section{$2 / 2 / 2018$}

Date
Gurvirender Tejay, Ph.t.

Dissertation Committee Member

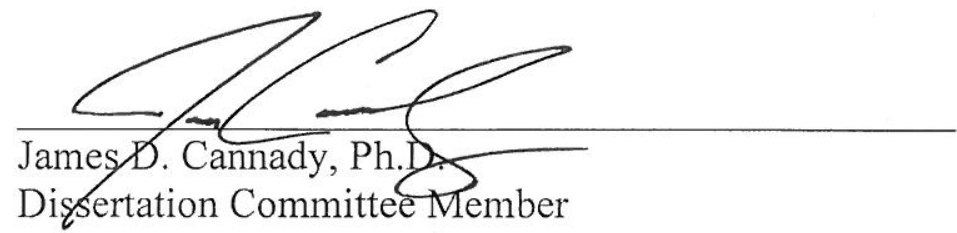

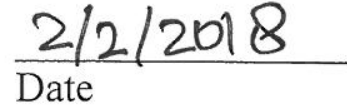

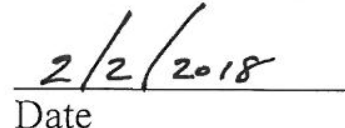

Approved:

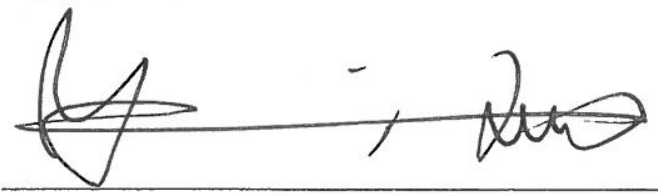

Yong X. Tao, Ph.D., P.E., FASME

Dean, College of Engineering and Computing

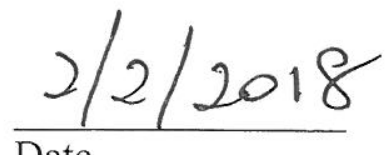

College of Engineering and Computing

Nova Southeastern University 


\begin{abstract}
An Abstract of a Dissertation Submitted to Nova Southeastern University In Partial Fulfillment of the Requirements for the Degree of Doctor of Philosophy

A Knowledge Management System (KMS) Using a Storytelling-based Approach to Collect Tacit Knowledge
\end{abstract}

By

Nicholas J. Shaw

December 2017

Since the 1990s, Knowledge Management Systems (KMS) have been largely unsuccessful in the collection of tacit knowledge. The process, whether through direct input by the holder of the tacit knowledge or through an intermediary such as the collection of tacit knowledge through interviews and videos, has not succeeded. Reasons encompass the organizational (such as culture of the organization), the technological (example: poor tools), and the individual (example: knowledge is power, i.e. where experts with rare knowledge results in knowledge hoarding instead of transfer). The purpose of this study was to demonstrate that tacit knowledge could be successfully and consistently collected from the participants themselves and placed into a KMS using a storytelling-based approach. This study extended past research that collected stories for KMS' using interviews and videos by having participants directly entering their data, as stories, into a KMS. This was a new approach and it was posited that having participants use stories to enter their tacit knowledge themselves into a KMS would overcome their reluctance to provide tacit knowledge thus overcoming barriers to providing tacit knowledge into a KMS.

The validation methodology was based upon three elements: the deep-dive research element, the issues and solution element, and the dissertation proposition element. The deep-dive research element was the extensive research for the study into knowledge management, storytelling, and other various methods for collection of tacit knowledge. The issues and solution element consisted of issues about tacit knowledge that were identified from the deep-dive research element, i.e. general arguments constructed about knowledge management which were backed by data from research into knowledge management systems and storytelling. Theoretical solutions to the issues regarding the capture of tacit knowledge were then constructed which included the storytelling-based approach and a KMS framework for the collection of tacit knowledge. Lastly was the dissertation proposition element which consisted of a thorough analysis of the survey data against each of the dissertation propositions. There were three propositions. Proposition 1 was sharing of knowledge and the storytelling-based approach. Proposition 2 was about the framework, the scenarios, guiding questions, and Communities of Practice (CoP), and Proposition 3 was about participant knowledge and interaction with forums. Each proposition was evaluated independently. 
The study was successful and validated propositions 1 and 2. For proposition 1, $81 \%$ of the participants responded positively to the eight study questions directed towards this proposition. For all eight questions across all 21 participants, the mean was 29.952 against a target test mean of 24 with a range of 27.538-32.367. For proposition 2, $76.19 \%$ of participants scored this section positive. For all six questions across all 21 participants, the mean was 23 against a target test mean of 18 with a range of 21.39424.606. However, the results for proposition 3 were inconclusive and must be considered a failure. Most of the respondents either scored 'no change' to at least $50 \%$ of the questions or they stated they had never been to a forum. For all four questions across all 21 participants, the mean was 12.905 against a target mean of 12 with a range of 11.89613.914. Based upon propositions 1 and 2, the null hypothesis was disproved.

Participants liked the storytelling-based approach, providing their tacit knowledge, and they liked the framework. 


\section{Acknowledgements}

I consider it a privilege to have completed this dissertation under the guidance of three of the finest individuals and scholars that I have ever had the pleasure of working with.

First, I want to offer my sincere thanks and gratitude to Dr. Peixiang Liu, my committee chair and professor, who literally taught me the meaning of good research through his wisdom, his feedback, and his advice on other topics that I believed to be important. He helped me get a conference paper published through the IEEE on the topic of my dissertation.

Dr. Gurvirender Tejay, one of my professors and committee members, who always helped improve the content of my dissertation with his insightful input and excellent suggestions.

Dr. James Cannady, one of my professors and committee members, for his excellent advice for necessary changes in my dissertation.

Mrs. Lisa Shaw, my loving wife, who encouraged me to get another Doctorate and then put up with all of my long hours in the course work and working on this dissertation. And she still managed to give me her love and encouragement. She truly understands the level of effort and commitment a Doctoral program requires from everyone; I could not have done this without her support.

I would also like to thank Mr. Umesh Phuyal who developed the web-based knowledge management system that was used to conduct the experiments. I had spent a great deal of time learning the PHP programming language, HTML 5 programming, and the MySQL relational database but was still falling behind. I reached out to Mr. Phuyal and he had the system up-and-running in a few weeks.

Finally, I want to express my gratitude to the entire faculty and staff who have made my studies and research at Nova Southeastern University one of the best experiences of my life. 


\section{Table of Contents}

\section{Abstract 2}

Table of Contents 5

List of Tables 8

List of Figures 9

Chapter 1: Introduction 10

Background 10

Dissertation Goal 18

Problem Statement 20

Research Questions 23

Relevance and Significance 24

Barriers and Issues 26

Assumptions, Limitations and Delimitations 29

Limitations 29

Delimitations 29

Definition of Terms 30

Summary 33

Chapter 2: Review of the Literature 36

Knowledge Sharing 36

Knowledge Management Systems 37

Forums 40

KMS Approaches 41

KMS Architectures 41

Database Management Systems 41

Case-Based Reasoning (CBR) 42

Ontology-based KMS' 42

Storytelling 42

Summary 45

Chapter 3: Methodology 48

Overview of the Quantitative Approach 52

Overview of the Qualitative Approach 57

Design and Implementation of the KMS 58

Conduct of Experiments 67 
Physical host: 68

Virtual Machine: 68

Success Criteria 70

Chapter 4 Results 79

Data Analysis 79

Findings 83

Framework 83

Means to Solicit Participants 84

Participation 84

Summary of Results 88

Chapter 5 Conclusions, Implications, and Recommendations 90

Conclusions 90

Scientific Research Contribution 92

Implications 92

Limitations/Recommendations 93

Summary 95

Appendices 96

Appendix A Waiver of Documentation of Informed Consent 98

Appendix B Study Information Sheet 102

Appendix C Participant Data and Survey 107

Appendix D Story Guiding Questions 114

DOMAIN: Migration 114

Subdomain: Application and/or Database 114

Subdomain: Data Center Migration 115

Subdomain: Servers 116

Subdomain: Storage 116

Subdomain: System Software 117

DOMAIN: Provisioning 117

Subdomain: Cloud 117

Subdomain: Networks 118

Subdomain: Servers 118

Subdomain: Storage 119

Subdomain: Virtualization 119

DOMAIN: Design System 119

Subdomain: Hardware/Software 119

DOMAIN: Decommission 120

Subdomain: Application 120 
Subdomain: Servers 120

Subdomain: Storage 121

Appendix E Actual Story Example 122

Appendix F Participant Response Scoring 123

Appendix G KMS Screen Captures 126

Appendix H Survey Code Book 138

References 143 


\section{List of Tables}

\section{Tables}

Table 1 - IT Domains/Subdomains utilized within the study 67

Table 2 - Example of an Unsuccessful Research Hypothesis ( $h a$ ) for Proposition 173

Table 3 - Participant Age Breakdown 85

Table 4 - Participant Region Breakdown 85

Table 5 - Summary of Results 86

Table 6 - Participant Survey Response Table 123

Table 7 - Demographics \& Participant Status 124

Table 8 - Survey Code Book 138 


\section{List of Figures}

\section{Figures}

Figure 1 - Information systems are interrelated systems of technical and organizational elements 19 Figure 2 - Use Cases for KMS 53

Figure 3- End-to-End Participant Process 53

Figure 4 - Overall System Architecture 61

Figure 5 - KMS Schema Model 62

Figure 6 - Guiding Questions Table Structures 65

Figure 7 - Minitab 17 Sample $t$ Test for the Mean of Proposition 1 Summary Report 81 Figure 8 - Minitab 17 Sample $t$ Test for the Mean of Proposition 2 Summary Report 81 Figure 9 - Minitab 17 Sample $t$ Test for the Mean of Proposition 3 Summary Report 82 Figure 10 - Minitab 17 Sample t Test Diagnostic Report for the Mean of Proposition 187 Figure 11 - Minitab 17 Sample t Test Diagnostic Report for the Mean of Proposition 287 Figure 12 - Minitab 17 Sample $t$ Test Diagnostic Report for the Mean of Proposition 388

Figure 13 - KMS Home Screen 126

Figure 14 - Contributor Password Screen 127

Figure 15 - Contributor Initial Screen 128

Figure 16 - Contributor Status/Edit/View Stories Screen Capture 129

Figure 17 - Selecting a domain and subdomain pair of a story 130

Figure 18 - Answering guiding questions screen capture 131

Figure 19 - Continuing the creation of a story screen shot 132

Figure 20 - Lessons learned screen shot 133

Figure 21 - Collaboration between contributor and reviewer screen shot 134

Figure 22 - Completed story being reviewed screen shot 135

Figure 23 - Reviewer Accept or Decline Story screen shot 136

Figure 24 - Logging out of the KMOS system 137

Figure 25 - BPMN KMS Framework Model 142 


\section{Chapter 1: Introduction}

\section{Background}

Knowledge management systems (KMS) refer to any kind of Information Technology (IT) system that stores and retrieves knowledge, improves collaboration, locates knowledge sources, mines repositories for hidden knowledge, captures and uses knowledge, or in some other way enhances the knowledge management (KM) process (Becerra-Fernandez, 2000; Frost, 2013; Jimenez-Jimenez, Martinez-Costa, \& Sanz-Valle, 2014; Rance \& Hanna, 2007). Chen, Xiao, Ren, and Shi (2011) defined knowledge management $(\mathrm{KM})$ as the process that enterprises use to identify and organize knowledge and then effectively use the knowledge to competitive advantage. Fanfan (2012) described $\mathrm{KM}$ as any process or practice of creating, acquiring, capturing, sharing, using and evaluating knowledge wherever it resides.

There are two fundamental types of knowledge - explicit and tacit. According to the Cambridge dictionary, explicit knowledge is knowledge that can be expressed in words, numbers, symbols, and stored. The Law Dictionary states it is knowledge that is recorded and expressed; it is easy to share and store and is the opposite of tacit knowledge. Tacit knowledge, according to the Cambridge Dictionary, is knowledge you get from personal experience. The Law Dictionary states that tacit knowledge is unspoken, unwritten, and hidden stores of knowledge based on experiences, emotions, institutions, insights, and observations. Examples of tacit knowledge include the knowledge of how to ride a bicycle, how to knead bread, and how to use a word processor (Linde, 2001). In short, tacit knowledge is the knowledge that resides in our heads and is far more difficult to represent in a knowledge management system (KMS) 
due to the reluctance of the owners of the knowledge to allow it to be placed into a KMS (R. O. Weber, 2007). Researchers who have attempted to populate KMS' with tacit knowledge concede that there are two fundamental obstacles - fear (fear among employees that sharing knowledge reduces job security) and power (keeping information to oneself enhances job security) (Disterer, 2001; R. O. Weber, 2007). The power factor is, stated simply, knowledge is power and keeping that knowledge to oneself contributes to organizations retaining them and forces people to come to them for their knowledge contributing to self-worth (Benbya \& Alstyne, 2008; Fanfan, 2012; Kankanhalli, Tan, \& Wei, 2005). Other researchers are not convinced that either fear or power is a primary factor. Okoroji, Velu, and Sekaran (2014) determined that the key factor was appropriate motivation. Okoroji, et al. did note that in every organization, there are individuals who are willing to share their knowledge, and there are those who prefer not to. Their research sought to understand why some are willing while others are not, i.e. what initiatives encourage knowledge sharing and what are the barriers to knowledge sharing. Riege (2005) suggested there are three primary barriers - individual, organizational, and technological. According to Riege, the individual barriers include lack of communication skills, lack of social networks, differences in culture, lack of time, lack of trust, lack of motivation, and fear of not receiving recognition. He stated that "knowledge sharing practices often seem to fail because companies attempt to adjust their organizational culture to fit their KM, instead of implementing knowledge sharing practices that fit their culture" and the technology (hardware and software tools) necessary to implement successful solutions; Riege included in this a shortage of appropriate software tools. Ling, Sandhu, and Jain (2009) supported Riege but their research was limited to the opinions of executives; no individual participants were part of their study. Sandhu, Jain, and Ahmad (2011) picked up where Ling, Sandhu, and Jain left off and this time went 
directly to the employees. Their findings showed that individual, organizational, and technological barriers do exist.

This researcher asserts that most domain experts do share their tacit knowledge willingly with others on a day-to-day basis. They share their knowledge with junior members who are learning their craft, they share their knowledge with other domain experts as they recount lessons they have learned over time or from specific incidents and/or challenges and they share their tacit knowledge with management in briefings or as concerns to management or other domain experts. This is supported by Guechtouli, Rouchier, and Orillard (2012) and Ariffin, Arshad, Shaarani, and Shah (2007) in their discussions on direct knowledge transfer and by Sandhu, Jain, and Ahmad (2011) in their research into knowledge sharing. Based upon the three barriers of Riege, this research targeted the barriers of individual and technology.

Early KMS efforts in the 1990s to capture tacit knowledge of employees were geared towards employees ready to retire or leaving the organization on their own for other employment opportunities. The concerns were the loss of valuable lessons learned while at the organization. The research of Benbya and Alstyne (2008) at HP and Siemens demonstrated that fear can be overcome with the right motivation. This supports the issue of motivation discussed in Okoroji, Velu, and Sekaran (2014). HP developed an incentive program based on frequent flyer mile certificates; however, after 90 days, only $20 \%$ of the target audience had participated. HP elected to continue the program without change, primarily due to the large number of mile certificates they still had on hand. Siemens, another global company, took a different approach by rewarding the country that produced the knowledge and to the countries that consumed it and the countries rewarded the individuals. Siemens rewarded both producers and consumers of the 
knowledge with corporate stock shares and the financial value of the shares were based upon the type of contribution. However, over time, managers found it difficult to continue the incentive program as those who received the financial shares were not turning them in for the money but keeping them. This was still considered a success as those who received the shares considered the number of shares a badge of sorts, i.e. the more you had, the greater was your importance.

Weber (2007) identified nine reasons why KMS' may fail. In evaluating these, this researcher determined that three are relevant to this study because they relate in one way or another to the collection or failure to collect tacit knowledge (see below).

Examples of non-applicable reasons were: KM approaches may fail when they attempt to create a monolithic organizational memory and another was KM approaches may fail when they are outside the process context. The following reasons were applicable to this study:

- KMS' often fail due to the nature of the KMS, i.e. there are no bounds on what a domain expert can enter or how.

- KMS' may fail when users are afraid of the consequences of their contributions; this is related to job security. Users may even feel that withholding their knowledge may be a way to secure influence.

- KMS' may fail when they do not integrate humans, processes, and technology

In the context of Riege's three barriers (individual, organizational, and technological), Weber's reasons fall within the technological and individual.

It is in the area of tacit knowledge collection that KMS' have not been successful. Specifically, as noted earlier, for reasons that span individual, organization, and 
technology, people do not want to provide their tacit knowledge. In research as late as 2014, researchers considered tacit knowledge as not being able to be codified (Qiu, Want, \& Nian, 2014). In 2015, Rumanti, Hidayat, and Suputro (2015) stated that tacit knowledge is the most difficult to transfer to others and in 2017, Patalas-Maliszewska, Krebs, and Dudek (2017) stated that tacit knowledge is difficult to attain in KMS'; however, Pratt-Whitney Rocketdyne's (PWR) Goldfire KMS had some success (Chun, Sohn, Arling, \& Granados, 2008). Goldfire was essentially a two-part implementation where the first part, the AskMe portion, was fundamentally a forum where individuals identified themselves as experts in one or more areas and people could present questions to them. This encouraged experts to share their knowledge. The second part, the Goldfire KMS, searched for data throughout the many KMS' or knowledge within PWR. Thus, the Goldfire KMS became the single source of information. While not all information resided within Goldfire, Goldfire was able to search out and find information throughout the many repositories within PWR.

In addition to types of knowledge, there are two types of knowledge transfer direct and indirect (Guechtouli et al., 2012). Direct knowledge transfer is one-on-one, one-on-many, or many-to-many (such as a meeting) but face-to-face such as mentoring or coaching. Ariffin, Arshad, Shaarani, and Shah (2007) used the example of a domain expert (DE) guiding a novice user through a procedure - the DE transfers their tacit knowledge to the user and, in this case, the tacit knowledge is used to improve the work activities of the novice user. In this example, the DE is using direct communications (personalization) and direct knowledge transfer versus a tool. Indirect knowledge transfer can be through any means where different people at different times can view the 
artifacts of the acquired knowledge. Examples of indirect knowledge are written documents, videos, forums and KMS'.

Companies have created internal Wiki's for knowledge sharing and there are forums on almost any topic where knowledge sharing takes place as well as within other social media such as Facebook (indirect knowledge transfer). On any given day, there are knowledgeable employees sharing their knowledge with less knowledgeable employees to help them learn (direct knowledge transfer). This was a finding of the Goldfire team at PWR (Chun et al., 2008) as well as studies on direct and indirect knowledge transfer referenced earlier. It is supported by Okoroji, Velu, and Sekaran (2014) and Sandhu, Jain, and Ahmad (2011). Thus, the transfer of tacit knowledge does occur.

Wasko and Faraj (2005) researched electronic forums into why participants participated since there is no immediate benefit to them and free-riders are able to acquire the same knowledge as everyone else. The research of Wasko and Faraj showed that those seeking knowledge have no control over who responds to their questions or the quality of the responses and participants have no assurances that those they are helping will ever return the favor. The researchers concluded that individuals contribute knowledge to electronic media when they perceive that it enhances their professional reputations, and to some extent, it is enjoyable to help others. Individuals who contribute knowledge do not seem to expect help in return.

The collection of tacit knowledge into KMS' was the point of research by Coffey and Hoffman (2003) who tied the collection of tacit knowledge to the organizational need to retain institutional knowledge in order to advance the mission of the organization, avoid making the same mistakes over again and to leverage the accomplishment of 
departing employees. But they also noted the challenges of eliciting knowledge as did Benbya and Alstyne (2008) and others (Orth, Smolnik, \& Jennex, 2009; Pumareja \& Sikkel, 2005; Vizcaino, Soto, Portillo, \& Piattini, 2007).

The focus of this research targeted the technological and individual obstacles as noted by Riege through the collection of tacit knowledge into a KMS by those who possess the knowledge using a storytelling-based approach. As seen up to this point, the transfer of tacit knowledge through direct and indirect methods does occur; however, the elicitation of tacit knowledge into a KMS by those who have the knowledge is still considered a major challenge. Whyte and Classen (2012), in the Journal of Knowledge Management did collect tacit knowledge for a KMS using stories; however, it was via face-to-face interviews with the data later inserted, by the researchers, into the KMS. This is not an efficient approach as it takes much longer to conduct the interviews and then to insert the data into a KMS as well as make updates. This study proposed having the DE contribute their tacit knowledge into the KMS themselves with the vehicle of elicitation being stories. The literature either says it cannot be done (Fanfan, 2012) or it is done through interviews and recordings. In 2001, Swap, Leonard, Shields, and Abrams (2001) explored storytelling to transfer knowledge in the workplace and, like Whyte and Classen in 2012, they used interviews to collect the tacit knowledge (as did Schank (2010)). This research proposed using the KMS itself to collect the tacit knowledge with no intermediary.

A storytelling-based approach is different in that it utilizes mechanisms employed in direct knowledge transfer. Storytelling has been used to record issues and lessons learned in project management (Buttler \& Lukosch, 2012b), education (Sugathan \& Kalid, 2009), requirements elicitation (Boulila, Hoffmann, \& Herrmann, 2011) and 
capturing tacit knowledge at MITRE (Kalid \& Mahmud, 2008). Like earlier research using stories to collect tacit knowledge, the work at MITRE was through interviews (direct knowledge transfer).

The goal of this study was to determine if, based upon the research, the use of storytelling within a KMS, by the participant, could be successful in the collection of tacit knowledge. When individuals pass along their tacit knowledge to others, they often do it through stories. Thus, the right condition for the collection of tacit knowledge was the ability to tell a story using a KMS. Researchers across the social sciences as well as KMS researchers have noted that people love a good story (Linde, 2001; Schank, 2010; Sugathan \& Kalid, 2009; Whyte \& Classen, 2012). Through storytelling and a KMS, it was hypothesized that the barrier of technology and individual would be overcome.

People, telling verbal stories, often make assumptions about the listener that can result in lost details and misunderstanding to the reader or listener, i.e. the person telling the story assumes that the listener knows what they're talking about. Even though they may be in the same field (Information Technology) and both are UNIX administrators, that assumption can easily be invalid. Assumptions could be as simple as one systems administrator talking to another systems administrator where one is talking IBM UNIX and its' virtualization technology while the other is an HP UNIX administrator and the technologies are not the same so the HP UNIX administrator doesn't understand. Another example might be a systems administrator talking about RAID 10 but the second administrator knows RAID 1 (mirroring) and RAID 0 (stripping) but has never heard the term RAID 10 so doesn't understand.

To create stories that are productive and meet a need, a framework must exist for telling the story. This study proposed a framework that consisted of the basic elements of a narrative story (Linde, 2001) and guiding questions that were asked based upon a 
selected domain and subdomain to ensure that critical information was captured. Guiding questions provide a frame of reference for the reader and a sort of fill-in-the-blanks to reduce the occurrence of assumptions. Using the RAID example above, the guiding questions might include a definition of RAID 10. Think of domains/subdomains as categories such as provisioning (domain) and servers (subdomain). The collected information is then merged into a story. The basic elements of the knowledge framework were the separate components of the guiding questions, who, what, when, where, why, how, the impacts, the obstacles encountered, and the lessons learned. This aided in extracting the story from the DE and ensured that sufficient information was provided to the reader. Once the tacit knowledge was placed into the KMS, the tacit knowledge became explicit knowledge.

\section{Dissertation Goal}

The goal of the study was to demonstrate that the use of storytelling could be successful in the collection of tacit knowledge by participants who directly entered their tacit knowledge, through stories, into a KMS. It, thus, demonstrated a solution to the obstacle of technology and individual in knowledge sharing.

The research addressed the relevant issues identified by Weber (2007) in the problem statement using a 'KM in the small' based approach (Orth, Smolnik, \& Jennex, 2009). It extended this to incorporate the application of Schank's (2010) and Whyte and Classen's (2012) storytelling-based approach using scenarios. Scenarios utilize communities-of-practice $(\mathrm{CoP})$ thus helping to reduce assumptions on the part of the participants regarding the reader. This approach integrates humans, processes, and technology (Figure 1), is intuitive to DE, is consistent, and it enhances knowledge sharing. According to Kroenke (2011), information systems are interrelated systems of 
technical and organizational elements. The technology is the hardware (network, servers, and storage) that supports the KMS (the software/tool) and the data (the information contained within the KMS). The approach is consistent from the standpoint that storytelling is a widely used mechanism to convey knowledge to others. DE found the KMS more intuitive to use based upon earlier research into stories and storytelling thus enhanced the sharing of their tacit knowledge with others through a structured database management KMS architecture. As noted earlier, Whyte and Classen (2012) felt storytelling to be the best way to transfer tacit knowledge and storytelling makes the information meaningful. They further noted that stories have a common language or taxonomy. Within a KMS, the taxonomy should be KM specific and that, in general, it should be industry immaterial, i.e. the story in one industry can be applied with success to another industry within the same CoP.

Figure 1 - Information systems are interrelated systems of technical and organizational elements

\section{Technology}

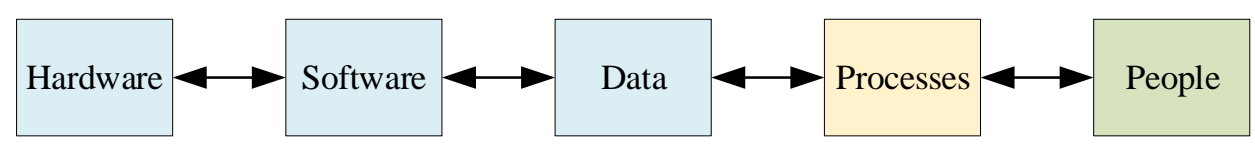

Success was measured against whether or not domain experts were willing to contribute their tacit knowledge to a KMS developed for the study.

It is acknowledged that not all tacit knowledge is best collected through an indirect knowledge transfer approach such as the implemented storytelling-based approach. Examples where this indirect knowledge transfer approach can be successful includes IT, law enforcement, and many others. This study concentrated on one CoP - 
IT. Lastly, the goal was to demonstrate that organizations, using a storytelling-based approach, will achieve greater collection of viable tacit knowledge into a KMS.

\section{Problem Statement}

Domain experts (DE) are willing to share their personal (tacit) knowledge with others using direct knowledge transfer to help them learn but they are less willing to provide the same knowledge into a Knowledge Management Systems (KMS).

The research of Chun, Sohn, Arling, and Granados (2008) at Pratt-Whitney Rocketdyne supports the willingness of DE to share their knowledge with others either by being asked or being presented with the opportunity to showcase and share their knowledge. The Pratt-Whitney Rocketdyne KMS consisted of two components - the first was 'Askme' that consisted of chats, blogs, a forum, and 'Goldfire' that was an advanced search engine to perform searches across the company's numerous sources. The research of Ko, Kirsch, and King (2005) further supports the willingness of DE to transfer tacit knowledge. In the research of Ko, et al., the research was in the transference of tacit knowledge between consultants and clients in Enterprise Resource Planning (ERP) systems implementation - not into a KMS. Wasko and Faraj (2005) noted that in Communities of Practices (CoP), a field of shared interests, knowledge flows easily within that $\mathrm{CoP}$ and enables the participants to create social networks to support the exchange of knowledge. In electronic CoPs, such as the 'Goldfire' forum, knowledge participants had no assurances that the people they were helping would reciprocate in kind when the participant needed help.

The research of Kalid and Mahmud (2008) concentrated on capturing tacit knowledge through stories with videos being the end result. They recognized that storytelling was a powerful mechanism within organizations and that stories were used to 
transfer tacit knowledge (direct knowledge transfer) but they were not being captured into a KMS (indirect knowledge transfer). Kalid and Mahmud looked at storytelling from the perspective of verbal descriptions of information. According to Pumareja and Sikkel (2005), applications can be designed to collect tacit knowledge; however, if domain experts are unwilling to contribute, the KMS will fail. Weber (2007) went further and provided several reasons why KMS' fail:

- KMS' often fail due to the nature of the KMS, i.e. there are no bounds on what a domain expert can enter or how. Haller and Abecker (2010) considered the reliance on highly structured semantic meta data as a major challenge for KMS'.

- KMS' may fail when they do not integrate humans, processes, and technology. This is justified by the limitations and importance of each of these components (Abecker, S., \& Maurer, 2000).

- KMS' may fail when users are afraid of the consequences of their contributions; this is related to job security. Users may also feel that withholding their knowledge may be a way to secure influence (Disterer, 2001).

Orth, Smolnik and Jennex (2009) described the different KMS approaches as ITbased systems that combine content, organizational processes, users and technical solutions which supports Weber (2007) who stated that KMS' fail when humans and processes are not integrated with technology. This also supports Riege (2005) who identified three key barriers to knowledge share - individual, organizational, and technology. 
Weber and Gunawardena (2008) and Benbya and Alstyne (2008) looked at repository-based KMS' that utilized database management systems with data in a variety of formats. They noted that KMS information was often difficult to find, was not vetted prior to being made available to users and users found it difficult to relate the information to their problems.

Ariffin, et al. stated that it was difficult to motivate users to contribute their tacit knowledge to a KMS while Fanfan's (2012) research indicated that tacit knowledge could not be stored using a KMS. The issue of motivation was also noted by Sandhu, Jain, and Ahmad (2011) and Okoroji, Velu, and Sekaran (2014). Yao, Kam, and Chan (2007) also noted the issue of motivation, i.e. lack of motivation and/or reward for employees. Smuts, Merwe, Loock, and Kotze (2009) considered that while the collection of tacit knowledge is difficult to codify, tacit knowledge could be used to create new explicit knowledge; however, their research indicated that tacit knowledge cannot be easily articulated which corresponds to Fanfan (2012) and Patalas-Maliszewska, Krebs, and Dudek (2017).

The research into KMS' and tacit knowledge has clearly shown that the reasons for the inability of KMS' to capture tacit knowledge are still largely unknown and, in essence, marked by a high degree of variation. Some research such as Weber's (2007) considers the KMS as the primary issue (technology). The majority of Weber's issues dealt with the KMS such as how data was entered and the type of KMS framework. Others considered failure of KMS' as more people-centric, i.e. why people do not want to enter or cannot enter data (Ariffin et al., 2007; Disterer, 2001; Fanfan, 2012; Smuts et al., 2009); this spans the individual and organizational barriers noted by Riege. People issues 
include the lack of a CoP, the difficulty in codifying tacit knowledge, and motivating DE to contribute their tacit knowledge.

a KMS framework was developed for this study that addressed the three issues identified by Weber utilizing a storytelling approach. The study also addressed Riege's issues of technology and people using a storytelling approach that was expected to motivate DE to contribute their tacit knowledge.

\section{Research Questions}

1. Proposition 1: Domain experts will be willing to provide their tacit knowledge into a KMS using a storytelling-based approach. The storytelling approach is how tacit knowledge is elicited from domain experts and how that knowledge is then communicated to users of the KMS. Instead of a simple fact-based approach, a story is created that is more interesting to both the participant and the reader of the story who is searching for information. This proposition goes to the research of Schank (2010) and Whyte and Classen (2012) who noted that telling a story is more interesting than just static dictation, Qiu, et al. (2014) who stated that tacit knowledge cannot be codified and can only be observed and Rumanti, Hidayat, and Saputro (2015) who considered tacit knowledge to be one of the most crucial factors in small and medium enterprises yet also considered the most difficult to transfer to others. As noted earlier, the issues with tacit knowledge are not with direct knowledge transfer but with indirect knowledge transfer.

2. Proposition 2: The use of scenarios, defined CoPs, domains and subdomains, and guiding questions in a semi-structured format will resolve the issue that KMS' often fail due to the nature of the KMS, i.e. there are no bounds on what a domain expert can enter or how. The semi-structured format is one where the participant is free to tell their story as they feel it should be told; however, a structure exists 
to ensure all aspects are covered. The purpose of the guiding questions was to provide clarity and to reduce or eliminate assumptions the participant may make about the reader's knowledge. Domains and subdomains provide for easy retrieval by those who seek the information. The CoP aspect was designed to address the issue of Weber (2007) that KMS' fail because they are not designed to support communities of practice and Orth, et al. (2009) whose approach, based on processes or tasks (KM in the small), concentrated on employee usage of knowledge in a task, process, or project that already possessed a common context of understanding, i.e. a CoP.

3. Proposition 3: People are more willing to provide their tacit knowledge in forums versus provide their tacit knowledge in corporate $K M S^{\prime}$. The literature clearly demonstrates that people do not like to provide their tacit knowledge into corporate KMS'; however, the literature also clearly demonstrates that people do provide their tacit knowledge into forums and like it. The Goldfire KMS has had some success (Chun et al., 2008). Goldfire was essentially a two-part implementation where the first part, the AskMe portion, was fundamentally a forum. This proposition sought to identify a motivation for why participants are willing to provide their tacit knowledge to forums but not KMS'.

\section{Relevance and Significance}

The key relevance of this research is that the participants enter stories directly into the KMS themselves unlike prior research using stories where tacit knowledge was acquired from interviews and videos and then entered into the KMS by the interviewers. The storytelling approach of Azudin, Ismail, and Taherali (2009) documented the use of storytelling at lunch and other methods such as forums to enhance knowledge sharing and 
collaboration. Furthermore, this research utilized domains and subdomains to catalog the stories into CoPs making it easier for those requiring the knowledge to find it.

The use of stories in this context is a variation of an approach that has demonstrated great success through interpersonal communications but has not been incorporated successfully into a KMS where the DE contribute their tacit knowledge directly into the KMS.

For this study, tacit knowledge from DE was collected as stories based upon scenarios under a relevant domain and subdomain within a CoP. An example of a domain/subdomain within the IT CoP and this study was provisioning hardware or software (domain) and servers (subdomain), i.e. hardware/software provisioning or the provisioning of hardware and/or software. In this way, not only did the tacit knowledge get stored but it was a valid mechanism for other DE to, in essence, peer review the input knowledge for relevancy and currency and to evaluate other potential domains/subdomains where the knowledge might be applicable. Using this approach, it was believed by this researcher that users would be able to find relevant data quickly in much the same way that forums use catalogs such as Cameras/Canon/Bodies or Cameras/Canon/Lens. The solution set encompassed the technology, the processes and the people as noted in Weber (2007) and covered the content as noted in Orth, Smolnik and Jennex (2009). For this study, domains/subdomains went no further than two levels deep although in a real system they could go four or more levels deep.

While the use of storytelling within the context of knowledge management to capture tacit knowledge is not unique, the use of storytelling as a means of populating a KMS by the holders of that knowledge directly into the KMS is. This study captured participant knowledge as well as lessons learned that were related to specific issues 
encountered by the participant and learned as a result of some task that was well planned and went well.

The significance of this research was the demonstration that relevant tacit knowledge from domain experts could be acquired without the long, drawn out approach of interviews and videos that is time consuming and difficult to ensure currency. Thus, this research extended the storytelling approach from one-on-one interviews to direct input by the holders of the tacit knowledge using stories. The use of tacit knowledge through indirect communications has been used in forums and wikis.

This study provides researchers and implementers of KMS' another approach to capturing and making available to users the individual (tacit) knowledge of DE. Lastly, this study dispelled past research that stated that tacit knowledge cannot be successfully entered into KMS'.

\section{Barriers and Issues}

Several barriers affected this study. These are identified below along with resolutions:

1. As will be presented in the 'Approach' section, the creation of stories involves the use of multiple tables that break a story down into small bytes of data that, in the end, are consolidated into the creation of a single story. A story consists of two major components - freeform data and response data with both being entered by the DE (participant). Response data addresses guiding questions. The guiding questions are not the story but provide a framework to elicit specific information regarding the story that is often lost due to assumptions on the part of DE. This will be discussed in greater detail under the approach section. The challenge was the parsing of the input data into a 
story that would be understood by others. As will be discussed in Chapter 3, this issue was resolved through formatting within the framework.

2. As noted in the first part of the literature review, storytelling has, in the past, been a video or face-to-face action while in this study, data was entered directly into the KMS by the participant. Thus, a key challenge was the development of a KMS with the necessary framework and processes to successfully elicit a story related to a point the participant was trying to make. As noted in Kalid and Mahmud (2008), the technical language used by contributors might not be understood by everyone within the same CoP. This could be especially problematic when the story is read by non-technical readers. Thus, the framework of the CoP, domains and subdomains must be to a level generally understood by the intended audience. Resolution was through use of the CoP, guiding questions, and the domains/subdomains and integration into the final story.

3. Once the KMS was developed and internally tested, participants needed to be identified to participate in the study. Finding participants was a major challenge. Initially, it was thought that participants would come from large companies with large Information Technology (IT) divisions. Thus, packets were prepared and sent to five major technology firms. This proved less than satisfactory in obtaining participants. This barrier was overcome by soliciting participants on university web sites, knowledge management forums, and technical organizations in Facebook. While the desire was for the majority of participants to have some prior KMS knowledge enabling the comparison of this approach with past approaches, it was determined that a comparison of the approach itself could be done with participants who did not have prior 
KMS experience. Another concern was that participants with prior KMS experience may be reluctant to participate for the same reasons they do (or did) not want to participate in their company KMS'. These reasons go back to the cultural barriers noted by Disterer (2001) and Weber (2007). Disterer noted that cultural traditions tend to discourage knowledge sharing. One cultural barrier he noted was 'knowledge is power' where experts with rare knowledge results in knowledge hoarding instead of transfer. McDermott and O’Dell (2001), however, believed that such barriers could be overcome. McDermott and O'Dell felt that you do not change the culture to match the knowledge management initiatives but adapt the approach to knowledge management to fit the culture. This was the approach taken in this study.

4. The framework would be a critical factor to success. The framework defines how a story is told. It defines the various attributes that ultimately lead to a complete story. Telling a story as a scenario that is not filled with useless information ("I started my day off with a bowl of cereal, I really like cereal and then...") or making assumptions about reader knowledge, even within a CoP, was challenging.

Two paths were considered - written and audio. Each has important arguments. Audio is more natural and reduces the overall number of attributes (columns) within the story table for stories-in-development; however, the audio requires storing files to disk increasing complexity and has the potential of reducing anonymity because someone may recognize the voice. Audio also injects significant challenges if the participant wishes to make changes to the story. Writing is more time consuming and stories-indevelopment must be broken down into more, and smaller, attributes to assist 
in the development of the story. Then there is the challenge of participants being poor writers. On the other hand, making changes to a story is relatively easy. In the end, writing was chosen as the mechanism for the framework as it is easier to control the creation of the story.

\section{Assumptions, Limitations and Delimitations}

- It was assumed that participants who like telling stories would have a higher number of contributions to the KMS than those who do not like telling stories. This assumption was not validated as no participant entered more than one story.

\section{Limitations}

- The literature review will show that the issues of tacit knowledge are global. This research, however, relied solely on participants located within the United States. While some participants may originate from other countries, it is likely that most participants will be American or have considerable time within the United States. For clarity in stories, all participants were required to write in English. Global cultural differences could affect how participants interact with the KMS thus potentially altering the results positively or negatively.

- This research conducted a limited comparison to social media data collection, i.e. forums. However, an in-depth analysis of the differences was beyond the scope of the study. This topic is covered in more detail in Chapter 3, under 'Design of the KMS'.

\section{Delimitations}

- The study focused on the area of IT. There were two primary reasons for focusing on IT: my primary skill sets are in IT and, IT is an area rich in communities of practice. 
By limiting the bounds of the study, it was easier to gather participants and conduct analysis of the data. Thus, for the purpose of this study, IT was the high-level CoP.

- Within IT, the study focused on a limited number of domains and subdomains. The chosen domains and subdomains are relatively common within IT and thus aided in obtaining participants for the study.

- In the study, collected data relating to social media forums was considered 'micro' knowledge vs. 'macro' knowledge used in traditional KMS'. In this way, comparisons between forums and traditional KMS' became clearer. Definitions for 'micro' and 'macro' knowledge are provided in the 'Definition of Terms'.

\section{Definition of Terms}

Case-Based-Reasoning (CBR) - Reasoning by analogy

Community of Practice (CoP) - The members share the same interests within the community.

Content Management Systems (CMS) - A content management system is software or a group or suite of applications and tools that enable an organization to seamlessly create, edit, review and publish electronic text.

Database Management Systems (DBMS) - Software that handles the storage, retrieval, and updating of data in a computer system (Dictionaries, 2017)

Domain Experts (DE) - the same as subject matter experts (SME), i.e. individuals who are considered experts with expertise in one or more areas.

Domain - In the context of this study, a primary category denoting some activity such as migrating something or provisioning something. 
Enhanced Entity Relationship (EER) Model - Provides the detailed view of the table structure for the KMS

E-Learning - Electronic learning

Explicit Knowledge - Explicit knowledge is that knowledge that can be expressed in words, numbers, and symbols, and stored. It is knowledge that is recorded and easily expressed.

FOC - Failover Cluster - where two servers exist with one being the primary and the other being the backup; both servers are always running and failover is automatic.

IP - The Internet Protocol (IP) is the principal communications protocol in the Internet protocol suite for relaying datagrams across network boundaries (Tanenbaum \& Wetherall, 2011). study.

IRB - Institutional Review Board - required when human subjects are used in a

Knowledge Management (KM) in the large - An approach based on infrastructure or generic systems (KM in the large) - concentrates on usage of knowledge where users do not have a common context of understanding (not a CoP).

$\mathrm{KM}$ in the small - An approach based on processes or tasks (KM in the small) concentrates on employee usage of knowledge in a task, process, or project that already possesses a common context of understanding (a $\mathrm{CoP})$. KM.

KMS - Knowledge Management System, i.e. the technology used to implement

LB - Load-Balanced (usually for LB clusters for use in webs). A LB cluster balances users across n number of web servers thus ensuring an even load. If a server 
fails, the remaining servers, if architected properly, will be sufficient to support the anticipated load.

Macro Knowledge - Knowledge that typically exists in KMS'. Reusable knowledge that is likely to be needed by others.

Micro Knowledge - Knowledge that typically exists in forums and other social media. Knowledge needed by one person for a specific task that is likely to be discarded knowledge.

Datacenter Migration - Migration of data from one data center to another. An example is closing a data center and migrating hardware and software to another data center.

Application Migration - Migration of an application from test into production or to another server; includes software updates and patches.

Ontology - In the context of computer and information sciences, an ontology defines a set of representational primitives with which to model a domain of knowledge (Liu \& Ozsu, 2009)

Scenario - A scenario is a situation in which a story takes place. It could be a problem that occurred and was resolved or lessons learned as a result of a well-planned activity.

Story - The real-life experiences and lessons learned of domain experts in their area of expertise.

○ Characters - Individuals involved in the story

○ Plot - The problem or solution 
- Setting - Where, and when

○ Theme - How, why, conflicts encountered, and lessons learned

Subdomain - A sub category of a domain. Within IT, if a domain is migration, a subdomain could be servers, i.e. the migration of servers. Subdomains are merely subcategories of the higher level, i.e. domains.

Tacit Knowledge - Tacit knowledge, according to the Cambridge Dictionary, is knowledge you get from personal experience. The Law Dictionary states that tacit knowledge is unspoken, unwritten, and hidden stores of knowledge based on experiences, emotions, institutions, insights, and observations.

Virtualization - Virtualization is an abstraction of the logical to the physical. An example is a virtual machine which is not a physical system but logical within a physical entity. Virtualization can encompass servers and operating systems, storage, and networks.

\section{Summary}

Traditional KMS', while experiencing some successes (mostly with explicit knowledge), have, for the most part, been unsuccessful when it comes to capturing the tacit knowledge of domain experts. Several reasons have been put forth in the research as to why this is such as knowledge is power, and poor technology.

For this study, a limited-use KMS was developed that facilitated the input of tacit knowledge through storytelling, implemented guiding questions to reduce the likelihood of assumptions, and operated within a community of practice. The structure of the knowledge management system was built around a framework designed to elicit tacit knowledge through a semi-structured approach using narrative stories. 
The framework addressed the issue of assumptions about reader knowledge through guiding questions; the framework and guiding questions are covered in-depth in Chapter 3, Methodology. The framework was the fundamental mechanism that ultimately resulted in a story that was readable, and correctly covered a scenario such that the reader gained what they desired from the story. Thus, it was critical to success. The specifics of the framework followed characteristics of a narrative story discussed in Linde (2001).

In general, people like to tell stories. Many cultures have used stories to pass on their histories and lessons from generation-to-generation. Many domain experts use stories to pass on information to other experts in order to get a point across. They often use stories as a way to communicate critical issues and lessons learned to more junior members (direct communications) in order to help them learn their trade or to management to help them understand the issues.

Research on telling stories has been through direct communications, i.e. personto-person as noted above or through interviews. After conducting a literature search of over 100 articles spanning journals and conference proceedings, evidence strongly supports that this study was unique by extending the use of stories from a direct knowledge transfer mechanism to an indirect knowledge transfer mechanism where the DE entered the story themselves into the KMS without an intermediary element.

This study looked at two methods for participants telling their stories. The first was audio and the second written text. Each had specific advantages and disadvantages. This study utilized written text. While people may not write well, much of the poor writing can be corrected and people, generally, will still understand a story even if it is poorly written. On the other hand, people have a very difficult time understanding a 
story where they do not understand the speaker and the differences can be as simple as the listener being from one part of the country while the speaker is from another part of the same country. Lastly, written text was easier to control in the development of a story and much easier to make changes to. 


\section{Chapter 2: Review of the Literature}

\section{Knowledge Sharing}

There is a good deal of research into the area of knowledge sharing which includes the sharing of tacit knowledge through direct (one-to-one, one-to-many, and many-to-many) communications. Where the research fails is in the area of indirect communications (such as a KMS). Yao, Kam, and Chan (2007) investigated how culture, attitudes, and barriers affect knowledge sharing in a Hong Kong government department. Forty people responded to their surveys about organizational culture and individual approaches towards knowledge. Seventy-nine percent (79\%) either agreed or strongly agreed that knowledge was power. This can lead to knowledge hoarding but $95 \%$ indicated that they liked to share knowledge. Over seventy present (70\%) felt that lack of incentives/rewards, lack of time, and a weak culture of sharing were barriers to knowledge sharing. Okoroji, Velu, and Sekaran (2014) also found that appropriate motivation of employees is important for a successful knowledge sharing process. They found that the voluntary nature of knowledge sharing participation retards efforts of most organizations towards effective KM. The central finding of McDermott and O'Dell (2001) was that an organization may have a strong commitment and approach to KM; however, the KM approach must accommodate the organization's culture instead of trying to change the culture to fit the approach. In their research, stories also factored in, i.e. stories were used to communicate what attitudes and actions were acceptable and unacceptable. Saenz (2012) concluded that knowledge sharing is key to innovation and that sharing can come from on-line discussion forums, blogs, intranets and knowledge 
repositories; however, personal interaction between individuals is another mechanism for sharing tacit knowledge such as in CoPs, coaching, and mentoring.

\section{Knowledge Management Systems}

Knowledge Management (KM) addresses the process of acquiring, creating, distributing and using knowledge in organizations and knowledge management systems (KMS) are the technological mechanism for implementing knowledge management (BecerraFernandez, 2000; Frost, 2013; Jimenez-Jimenez et al., 2014; Rance \& Hanna, 2007) .

Chatti, Schroeder, and Jarke (2012), in their research into KM and TechnologyEnhanced Learning (TEL), stated that since the introduction of KMs in the early 1990s, KMS's have failed to address the challenge of increasing knowledge worker productivity due to rapid changes in knowledge. The rapid change in knowledge is one of the reasons that the collection of tacit knowledge through interviews and videos is impractical. Knowledge is the primary resource for individuals. They attributed the challenges to different and incompatible concepts and tools for KM and TEL. They also highlighted that the relationship between KM and TEL needs to be closer. Kulkarni, Ravindran and Freeze (2007) stated that knowledge consists of explicit and tacit knowledge; both cannot be managed in the same manner. Their research indicated that the strategy for knowledge transfer of tacit knowledge is direct contact such as apprenticeship and mentoring; however, their research focused on explicit knowledge.

Thalmann, et al. (2010) considered the variety of knowledge work environments at different organizations and considered the many environments as a negative factor affecting productivity, i.e. the lack of standards in KM while Dingsoyr, Djarraya, and Royrvik (2005) looked at how existing tools were being used in organizations. They 
identified two strategies - those that focus on codifying relevant knowledge (technology) and those that count on communications between people with relevant tacit or explicit knowledge (personalization). Their research looked at tools to enhance personalization and found that many companies had developed KM tools to survey what type of knowledge people had and then index it. The indexing was a use of ontologies. The development of ontology's was supported by Lee (2012) whose research concluded that accessing the appropriate knowledge can be difficult, time consuming and frustrating. His research showed that many organizations suffer not from the lack of knowledge but from ways of accessing and exploiting existing knowledge. Wu (2008) also looked at ontology models that identified documents and other explicit and tacit knowledge, i.e. how to find the knowledge. His research, like Lee, looked at maps to show where the knowledge is. Abdullah, Eri, and Talib (2011), while not specifically addressing explicit or tacit knowledge, discussed the importance of CoPs. Their main contribution was to propose a model to manage and facilitate CoP knowledge using KMS techniques; Abdullah, et al. used Yellow Pages as an example (explicit knowledge). Makolm, Weiss and Reisinger (2007) found that knowledge workers require a certain degree of freedom in structuring their own tasks which often conflicts with the organization's needs for standardization.

Yordanova (2007) looked at common features of KM and E-learning. In Content Management Systems (CMS), the author described Learning Objects (LOs) that were used for presentation of learning content and knowledge. LOs, small independent units of information that could be combined in different contexts, were used for development and exchange of different types of information. Marshall, et al. (2003) developed a system, GetSmart, designed to apply KM techniques and integrate search tools with 
concept mapping. The goal was preservation of data. Similar to Schank (2010), Eales (2004) sought a different approach. His approach looked at situated learning potential from the perspective of collaborative support provided by colleagues. He argued that we need to move beyond knowledge management and instead move to sharing expertise. Guechtouli (2012) looked at transference of tacit knowledge from experts to newcomers needing the knowledge. She investigated the use of CoP's and concluded that the impact of communicating knowledge is based on how the recipient views the contributor who is providing the knowledge. Guechtouli also noted two different types of knowledge transfer - direct and indirect. Direct transfer correlates to personalization (person-toperson) while indirect transfer correlates to persistent mechanisms, i.e. forums, wikis, and other similar methods. Her research supported that indirect communication enables more powerful knowledge transfer and can be used by different people which increases the ability of the knowledge to spread. Purcell and O'Brien (2015) noted, like others, that tacit knowledge is aligned with competitive advantage. Khan, Prasad, Selvi, et al. (2015) noted that tacit knowledge is difficult to capture or share while Khalid, Shehryar, and Arshad (2015) stated that tacit knowledge cannot be shaped and transported between organizations because of cultural, structural, and goal differences.

Xinxiang and Xiaohui (2011) noted that in a Delphi Group survey, $42 \%$ of respondents considered tacit knowledge more important than explicit knowledge and one of the goals of KM to be the transfer of individual (tacit) knowledge into group (explicit) knowledge. Chen, Xiao, Ren and Shi (2011) did not consider knowledge sharing as the ultimate goal of KM, simply a means. They understood that the acquisition of tacit knowledge is not simple and requires a comprehensive extraction process. Thus, their research goal was to eliminate the obstacles of knowledge exchange. Hsu and Sabherwal 
(2011) contended that academia and practitioners consider the importance of intellectual capital (tacit knowledge) as a major source of sustained competitive advantage. Thus, they considered the externalization of one's tacit knowledge into a KMS a major issue.

\section{Forums}

The definition of a forum chosen for this study was given in Morzy (2010) when he wrote that an Internet forum is a Web application for publishing user-generated content under the form of a discussion. Usually, the term forum refers to the entire community of users with discussions on particular subjects called topics or threads. Posted messages are displayed chronologically (topics or threads).

Cerulo and Distante (2013) noted that even with forums that are organized and moderated by topics, discussions 'tended' to host messages on related subjects while Morzy's (2010) research showed that discussions on forums are often shallow, emotional, inconsistent, lacking discipline and manner; they rarely contain useful practical knowledge or specialized information. Sani, Kardan, and Cohan (2013) concluded that due to the large amount of information in forums, finding appropriate answers is becoming more time consuming and there is no suitable mechanism to measure the reliability of the answers being provided. Wasko and Faraj (2005) stated similarly when their research found that those seeking knowledge have no control over who responds to their questions or the quality of the responses. Sani, et al. also concluded that search engines are unable to process queries to questions. Ni and $\mathrm{Li}$ (2012) found that in online forums, a user's interests are reflected via the contents generated by them, the users they exchange opinions with and the topics of discussions they participate in. 


\section{KMS Approaches}

Orth, Smolnik and Jennex (2009) describe the different KMS approaches as ITbased systems that combine content, organizational processes, users, and technical solutions. They describe the types of implementations as:

- Approaches that are based on infrastructure or generic systems (KM in the large) - they concentrate on employee usage of knowledge where users do not have a common context of understanding (not a $\mathrm{CoP})$.

- Approaches that are based on processes or tasks (KM in the small) - they concentrate on employee usage of knowledge in a task, process, or project that already possesses a common context of understanding (a CoP).

- Integrated approaches which attempt to combine both KM in the large and $\mathrm{KM}$ in the small.

\section{KMS Architectures}

Different architectures have also been proposed for KMS' that include Database Management Systems (DBMS), Case-based Reasoning (CBR) and ontology's.

\section{Database Management Systems}

Weber and Gunawardena (2008) and Benbya and Alstyne (2008) looked at repository-based KMS' that utilized database management systems with data in a variety of formats. Repository-based KMS' are used for knowledge sharing and leveraging of knowledge. Both papers noted that information was difficult to find, was not vetted prior to being made available and users found it difficult to relate the knowledge to solving their problems. 


\section{Case-Based Reasoning (CBR)}

Maalel, Mejri, Mabrouk, and Ghezela (2012) and Weber and Gunawardena (2008) looked at CBR. CBR is applying past situations that are similar to a current situation to help resolve the current situation; $\mathrm{CBR}$ is a form of reasoning by analogy. Three types of CBR knowledge were discussed:

- Procedural - how a problem may be solved

- Declarative - what is known about a problem

- Heuristic - knowledge usually discovered through experience that has specific applicability (tacit knowledge)

\section{Ontology-based KMS,}

The research of Maalel, et al. (2012) considered that ontology-based KMS' could significantly reduce the effort of acquiring knowledge and could help to establish a common vocabulary for describing a situation and be used to model the knowledge necessary for indexing and organizing events. An ontology-based KMS uses a rigid structure based upon a library of keywords. Nasir and Noor (2010) developed an ontology-based KMS approach for e-applications on the web. Basically, ontology takes knowledge into another level where it gives meaning to content. This fits well with Chakraborty, Nayek, Basak, Ghosh and Debnath (2010) who saw a KMS as a simple query-response model used to extract tacit knowledge. Chakraborty, et al. saw an ontology-based KMS being faster than a DB-based KMS.

\section{Storytelling}

Sole and Wilson (2002) stated in their Harvard paper that organizations and their leaders are paying increasing attention to the role and value of narrative and anecdotal 
information conveyed in the form of stories. They stated that knowledge cannot be completely abstracted into categorical and analytical forms and is inadequately conveyed in such forms. Schank (2010) discussed the art and importance of storytelling and tied that to the actions of a company that collected video stories of their best people. Some of the stories were applicable to specific situations and Schank was working to index the stories to enable employees to find the video stories when doing something specific. Schank (2010) observed that in the age of the Internet, companies have too many electronic documents. Due to the large volume of documents, many e-mail recipients often do not open their files. The large volume of electronic data contributes to challenges of KMS'. Schank further observed that before the Internet, knowledge was passed on by stories. Whyte and Classen (2012) also researched the use of storytelling to elicit tacit knowledge from subject matter experts (SME). Whyte and Classen collected their story data through one-on-one interviews and felt that stories make information meaningful and are the best way to transfer tacit knowledge. They collected their information through interviews using guided questions (not to be confused with guiding questions in this study); SMEs were presented with a prompt card containing a brief array of story types to help them recall stories. Their intent was to identify a common language or taxonomy, identify a taxonomy that was KM specific and that was not specific to any industry. In the 1990s, Xerox field employees, through direct communications, were found to be passing on their tacit knowledge at water coolers on how to repair equipment better. Thus, the tech reps went from being independent workers to social learning units (Sole \& Wilson, 2002). Azudin, Ismail, and Taherali (2009) researched knowledge 
sharing and storytelling to encourage knowledge workers to use stories to 'sell' knowledge management internally, share knowledge, and facilitate collaboration. Again, this storytelling was direct communications versus the indirect communications of a KMS.

Wu and Zhou (2008) concluded that in a good knowledge-sharing culture, collaboration and communication are key factors that influence the effective management of tacit knowledge. Their research looked at the creation of knowledge maps (models) that identify documents and other explicit knowledge but could also identify tacit knowledge. In this case, as in others, the knowledge maps do not actually contain the knowledge but are an ontology as discussed in Gruber (1995; 1993). Berry and Nelson (2009) discussed the efforts at MITRE to improve the presentation of analysis and information through structured storytelling. The plan implemented at MITRE demonstrated that effective storytelling is tied to the achievement of specific and actionable results; however, many staff associated storytelling with fictional writing or telling tall tales. Experts who helped MITRE develop its program stressed that effective stories in a business setting must be based on truth. In the research of Kalid and Mahmud (2008), they concentrated on capturing tacit knowledge through storytelling. Their perspective was verbal descriptions of information and their goal was the development of a framework. They recognized that storytelling was a powerful mechanism within organizations and that stories were used to transfer tacit knowledge but the stories were not being captured. Their research addressed one of the main challenges of KM which is the capturing tacit knowledge. They saw this as critical due to the mobility of the

\footnotetext{
${ }^{1}$ The term 'sell' here means to get others to want to use the KMS, i.e. to sell others on the benefits of KM. It does not refer to a financial transaction.
} 
workforce through retirements and staff transfers which resulted in lost knowledge. Sugathan and Kalid (2009) studied the use of face-to-face storytelling in higher education versus the use of just PowerPoint and speeches. Their research supported that stories generate vivid and detailed memorable imagery. Boulila, Hoffmann, and Herrman (2011) noted that $30 \%$ of software defects are the result of incorrectly recorded requirements. They performed experiments using two groups eliciting requirements on the same subject - one group used brainstorming and the other used stories. The result was that the group using storytelling developed more elements, had a higher number of use cases covering all requirements, more specific details were revealed that were not observed in the brainstorming session and the use cases were clearly stated and related issues were solved. Buttler and Luosch (2012b) used stories to capture information related to projects. They noted that individuals could be moved from project to project to transfer lessons learned in earlier projects; however, should they leave the organization the knowledge was lost. Buttler, et al. considered tacit knowledge to include relevant technical issues, achievements, process knowledge and soft topics such as social interactions and building commitment. They further recognized that stories must be related to a CoP to improve user understanding. Buttler and Luosch (2012a) also noted that stories are not just a means to communicate an experience; they are also a means to make sense of a situation.

\section{Summary}

This chapter examined the literature related to knowledge management - the reasons/need for KMS', the different types of KMS', their implementation, the different 
mechanism for communications (knowledge transfer), knowledge sharing, and stories to collect tacit knowledge for KMS'.

Companies do not want to lose the tacit knowledge their people have. People leave a company or are transferred to other departments and the knowledge is lost. The research identified that the approach to knowledge management needs to be supportive of the organizational culture and not the other way around, i.e. successful KMS' should not force an organization to function in a way that is contrary to its culture.

The current method of collecting tacit knowledge is through one-on-one interviews; however, this process is impractical as it takes trained interviewers preparing the questions then processing the data before putting the data into a KMS. With the rapid change in knowledge, this is expensive and almost requires immediate turn around to be useful to other employees.

The research supported three aspects of knowledge management: the individual, the organization, and the technology. The research established that the lack of knowledge within an organization is not an issue - the issue lies in the collection of tacit knowledge in a way that the knowledge can be made available to others quickly and responds to the changing nature of knowledge. Thus, the research supports two fundamental methods of knowledge transfer - direct and indirect. Direct is person-toperson while indirect is any method that retains data for use by others at a later time. KMS' and forums are indirect.

The implementation of KMS' follow three basic approaches - KM in the large which concentrates on employee usage of knowledge, $\mathrm{KM}$ in the small which is employee usage of knowledge in a task, process, or project, and an approach that 
integrates both. It also identified three basic KMS types: database management systems (DBMS) that are repository-based KMS', case-based reasoning $(\mathrm{CBR})$ that is reasoning by analogy, and ontology-based KMS' that use a rigid structure based upon a library of keywords. 


\section{Chapter 3: Methodology}

Stories are the real-life experiences of DE and what they have learned over time. Acquiring the tacit knowledge of DE who have learned lessons and gained knowledge over years is a desire and goal of all organizations as supported in literature from the 1990s on (Anantatmula \& Kanungo, 2007; Burrows, Drummond, \& Martinsons, 2005; Disterer, 2001; Okoroji et al., 2014; Qiu et al., 2014; Rumanti et al., 2015; Swap et al., 2001). The objective of this research was to extend the prior research into stories that utilized interviews to elicit tacit knowledge. Tacit knowledge transfer does take place but as direct knowledge transfer as described in Sole and Wilson at Xerox (Sole \& Wilson, 2002). This study demonstrated that a storytelling-based approach can be successful in the elicitation of tacit knowledge by a participant who directly enters their tacit knowledge into a KMS.

This chapter includes an overview of the differences between this research and other research in the collection of tacit knowledge. It will then discuss the approach that was taken in the study. Following the approach, the chapter will cover the following:

- An overview of the qualitative approach used in the study,

- An overview of the quantitative approach used in the study,

- The design of the KMS,

- How the experiments were conducted,

- The success criteria that were utilized in the research and,

- Evaluation of the experiments against other KMS research 
In a storytelling-based approach, the DE are using stories to get a point across such as providing lessons learned after performing some operation. The stories are wrapped around a scenario in which something occurred. Prior storytelling research was not directed towards populating a KMS in real time; it used direct knowledge transfer (interviews) which was later transferred into a KMS by the interviewers. This research, on the other hand, utilized indirect knowledge transfer in the collection of tacit knowledge. All stories were reviewed by the principle investigator. This means that while earlier storytelling research was conducted in face-to-face (one-on-one, one-onmany, or many-to-many) interviews, key to this research was the tacit knowledge being directly entered into the KMS by the DE. These are major differences as they address the noted failures of earlier research in the field of KMS'.

Stories based upon scenarios and solutions are likely applicable to more than one specific domain or subdomain thus potentially extending the usefulness of the knowledge.

The technology was the KMS where the stories were collected and stored. While this study did not go beyond the collection of tacit knowledge from participants, the rudimentary KMS built for this study did possess the ability for users to participate in later studies. The processes affected by this research referred to the process of participants entering their tacit knowledge through stories and then evaluating, through surveys, changes in their willingness to provide their tacit knowledge. For those who were willing to share their tacit knowledge prior to the experiment (such as in a forum), the study tested their thoughts regarding the storytelling approach itself. The content was the collected tacit knowledge that once entered into the KMS became explicit knowledge. 
The author used a combination of a descriptive approach (to obtain information regarding current state and issues), quantitative (for conducting the experiments) and a qualitative approach for interactions with subjects through the surveys (Creswell, 2009; Wilson, 1990). Each research question (proposition) was answered based upon the postexperiment, online, surveys. The post-experiment survey is in Appendix D. No followon interviews were conducted; the study relied on participants entering one or more stories and the post-experiment survey. In fact, while participants were provided the opportunity and mechanism to enter in multiple stories, no participant entered more than one. A detailed discussion of each research question and what constituted success and/or failure is in the section 'Success Criteria'.

Current research can be broken down into two areas - traditional KMS' that are used within businesses to capture long-term (macro) knowledge of their workforce and social media which includes forums designed to primarily address short-term (micro) information. The short-term nature is due in large part to the fact that forum data is structured as discussions that often digresses from the topics (Morzy, 2010) into many different areas (Sani et al., 2013; Wasko \& Faraj, 2005) thus making the finding of data, even using search engines within the forum, challenging (Morzy, 2010; Wasko \& Faraj, 2005). One can consider web-based forums as a simple form of KMS. In traditional KMS', the objective is to capture knowledge that is needed by many versus forums where the knowledge may be needed by a single person only once. Thus, one could say the difference between traditional KMS' and social media forums is the difference of macro versus micro knowledge. In this study, micro knowledge is defined as knowledge needed 
by the few ${ }^{2}$ for specific tasks that is unlikely to be needed by others. It is targeted towards a specific, generally short term, need such as 'I'm having a problem getting this piece of code to work' or 'I do not understand how this camera function works'. These types of questions are ill-suited to traditional KMS'. Macro knowledge, on the other hand, is defined here as reusable knowledge that is likely to be needed by many over a longer term. An example of macro knowledge is setting up a virtualization environment. Companies often implement both.

All knowledge has the potential to become dated over time thus reducing or eliminating its usefulness. However, in macro knowledge, the knowledge will generally become dated at a slower rate. Micro knowledge may have a useful lifespan of days, weeks or months versus months or years for macro knowledge. Another challenge with social media forums is the lack of vetting for accuracy, relevancy or currency. This challenge goes back to the quality of data identified in Wasko, et al. (2010) and Sani, et al. (2013).

Accuracy, relevancy and currency are critical to traditional KMS'. Is the information accurate? Is the information relevant to the audience? And is it current? Traditional KMS' must be vetted for accuracy, currency, and relevancy. An example is knowledge that is accurate and current but is not relevant to the business such as knowledge that relates to aircraft propeller design for a clothing company. This research targeted traditional KMS'.

2 There are occasions where knowledge contained within a forum is, in fact, macro knowledge; however, even in this instance, it is difficult to extract through searches. 
The qualitative portion consisted of participant selection, and the post-experiment, online, survey (discussed in the 'Overview of Qualitative Approach' section). The quantitative portion encompassed the design of the KMS tool, the processes, and the experiment (discussed in the 'Overview of Quantitative Approach' section).

\section{Overview of the Quantitative Approach}

Quantitative studies make use of statistical analysis to obtain their findings. Key features include formal and systematic measurement and the use of statistics (Marczyk, DeMatteo, \& Festinger, 2005).

The quantitative portion of this study consisted of the experiments where participants entered their tacit knowledge as stories into the KMS. They had the ability to review and edit their stories prior to finalizing them.

Metrics for each participant were collected. The specific data collected and the purposes are outlined below.

- An auto-incrementing integer value was created for each story a participant entered into the KMS. The purpose was twofold:

- Identify how often participants submitted stories into the KMS and

- Assist in the determination of the success of the storytelling-based approach. As noted earlier, it was assumed that participants who liked telling stories would submit more stories than participants who do not like telling stories. However, as noted earlier, no participant entered in more than one story. Thus, this assumption could not be validated. 
Figure 2 - Use Cases for KMS
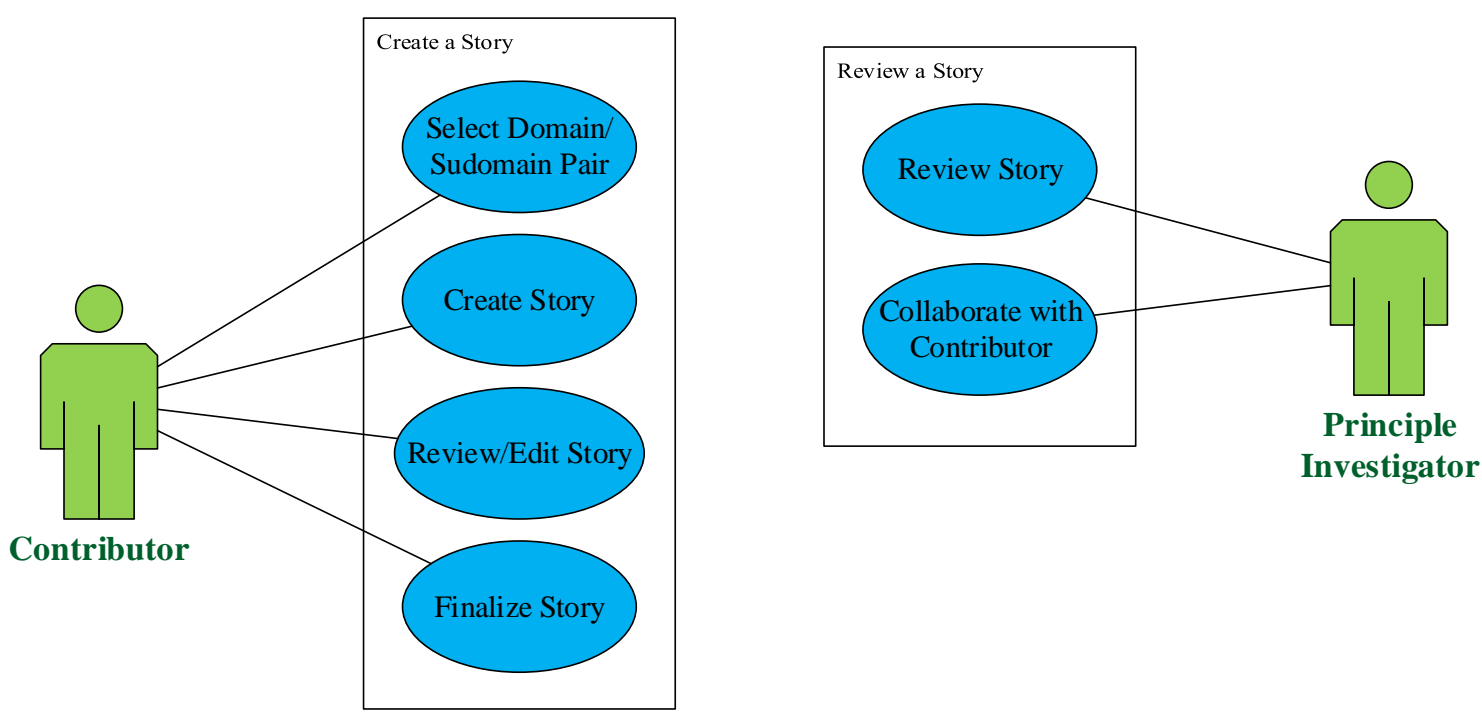

\section{Tell a Story}

Figure 2 above contains the use cases for the KMS. There was only one type of participant - contributors. Reviews were conducted by the principle investigator. The use case defined what actions each performed.

The process for obtaining participants and the process participants followed during the study is shown in figure 3 below:

Figure 3- End-to-End Participant Process

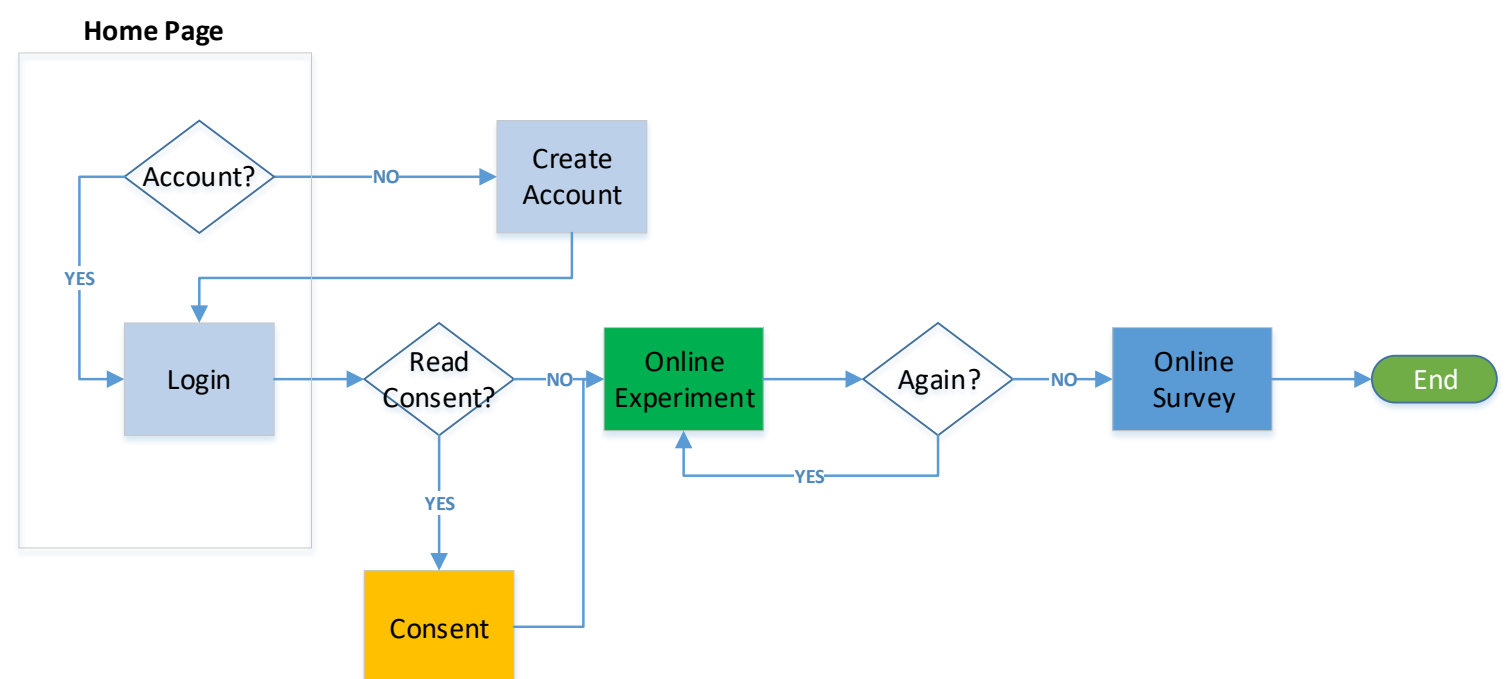


1. Study participants were required to meet the following criteria:

a. Be at least 18 years old, preferably older,

b. Have applications development and support experience for a production environment within an organization, or

c. Have information technology experience within an organization where they supported a production environment, or

d. Have responsibility for data center consolidation, or

e. Have responsibility for cloud implementation.

f. It was preferable, but not required, that they have prior KMS experience.

2. Participants for the experiment were solicited by the principle investigator through several methods:

a. By posting a short video on academic school sites: the Institute of Electrical and Electronics Engineers (IEEE) Computer Society Facebook page, the Association of Computing Machinery (ACM) Facebook page, and three university Facebook pages:

i. Nova Southeastern University's College of Engineering and Computing (CEC) Facebook page

ii. The Johns Hopkins University Whiting School of Engineering Facebook page

iii. The Colorado Technical University Facebook page

b. By posting a short video on knowledge management forums.

c. By going to two online survey sites (paid and free) - the participant requirements noted above were included. 
d. By sending requests to IT and application people known to the principle investigator and asking them to pass the request to their IT departments.

3. The video provided the academic email address of the principle investigator and provided a link to the online experiment/survey web site. The video was later replaced with a one-paragraph statement about the study. When registering, participants were provided the opportunity to view the waiver of informed consent form. Participants did not have to review the consent; it was available for them to review throughout the exercise. Participants were asked for the following information:

a. A personal email address (requested that business emails not be used)

b. An age range from 18-30, 31-40, 41-50, 51-60, and 60+

c. The region where they live from the Northwest (Washington, Oregon, Idaho, Montana, and Wyoming), West ${ }^{3}$ (California, Nevada, Utah, and Colorado), Southwest (Arizona and New Mexico), North Central (North Dakota, South Dakota, Minnesota, and Wisconsin), Central (Nebraska, Iowa, Illinois, Kansas, and Missouri), South Central (Oklahoma, Arkansas, Texas, and Louisiana), and Northeast (Maine, Vermont, New Hampshire, Massachusetts, New York, Connecticut, Pennsylvania, New Jersey, Delaware, Maryland, Ohio, Indiana, and Michigan), Central East (Kentucky, Tennessee, West Virginia, Virginia, and North Carolina), Southeast (Mississippi, Alabama, Georgia, South Carolina, and Florida) 
f. And, lastly, how many years they had been at their current company (what company they worked at was specifically not requested)

An example of the data collected for statistical analysis was: there were 28 participants of which 5 were from the west. Of the participants, 6 were in the age range of $18-30$.

The consent form should be considered as a frequently asked questions or FAQ that covered, in clear language, the data being collected, why it was being collected, how it is protected, and other aspects of the study a participant may wish to know.

The database consisted of several tables. One table contained the participant information to include their start and end date and, if applicable, the date they dropped. One table was used for the creation of the participant's stories. One was for the actual KMS. One table was used for the survey data. The story and survey tables did not use the participants email address but a randomly generated number to refer to the participant. This same number was used to relate the demographic table to the other tables. Then there were the tables for the guiding question responses and tables for the domains and subdomains.

The participants were assisted in the entering of their stories through explanatory text at each section of the story-creation process and through guiding questions specific to the domain/subdomain selected by the participant (Appendix D). This was to ensure the participant covered all aspects of the story for the purpose of clarity and understanding for the readers of the story. Guiding questions were merely to reduce situations where assumptions were made on the part of the participant about the readers 
of their stories or where information was needed by the reader to provide context. An example is where servers were migrated into production - how many servers were migrated? Across how many data centers did the migration occur? These simple questions might be of interest to the reader. For this study, participants were limited to the domains/subdomains listed in Table 1 on page 67 . The key aspect of the story was, in the words of the participant, what happened, why it happened, what was tried to resolve the issue(s) (if issues/problems were involved), what was successful, what was not, what obstacles did they encounter, and what, if any, lessons were learned. Participants were encouraged not to just enter data but to think of what happened and how they would relate what happened to someone else, e.g. create a story.

Once the participant completed the entry of their story, they selected 'Finished'. After the participant selected 'Finished', they were asked if they wished to do another story or go to the survey.

This is as far as this study went; however, future research could incorporate users to gain their insights into the process.

\section{Overview of the Qualitative Approach}

Qualitative research involves studies that do not attempt to quantify their results through statistical summary or analysis. Qualitative studies typically involve interviews and observations without formal measurement (Marczyk et al., 2005). The qualitative portion of the study consisted of the post-experiment survey.

The post-experiment survey documented participant experiences with this KMS approach and compared participant experiences to forums if forums had been utilized by 
the participants. The ideal situation was to have $100 \%$ of the participants with prior KMS experience. However, realistically, if a participant did not have prior KMS experience, their thoughts on the storytelling-based approach to providing tacit knowledge into a KMS were valuable. The study explored if their attitudes changed, how they changed, why they changed, and explored the influence of stories on their changes of attitude.

Based upon the post-experiment survey responses, each research question was addressed (see 'Success Criteria' below). Key was how responses aligned to issues identified in Benbya and Alstyne (2008) which discussed the studies at HP and Siemens, Chun, et al. (2008) and their work at Pratt-Whitney Rocketdyne on the Goldfire KMS and the research of Weber (2007) of which three earlier noted reasons for KMS' failure were applicable to this study.

\section{Design and Implementation of the KMS}

Design of the KMS was based upon the following requirements:

1. Stories were based upon the Information Technology Community of Practice.

2. Stories were created by participants who were domain experts and had knowledge in the specified domain and subdomain pairs.

3. Participants were given a randomly generated unique identification number to identify them throughout the study.

4. Stories were comprised of components that incorporated these story elements (what happened, what was impacted, why did it happen, what was tried, what obstacles were encountered, and what lessons were learned). Once the elements were addressed, they were assimilated into a complete story by the KMS; this constituted the framework. The assimilation of stories was performed by SQL statements taking the contents of attributes in a predefined order that included the 
story attributes and the guiding questions. A simplistic example that does not include 'impacts', 'obstacles', or the 'guiding questions' is the following:

\section{a. What happened?}

i. Answer: During lunch, I received a call on my mobile by a panicked systems administrator telling me that two storage devices in a RAID 1 configuration failed at the same time.

b. Why did it happen?

i. Answer: After listening to him tell me of the symptoms, I asked him some questions such as 'are the failed drives in the same storage enclosure (yes), are the fans still operational (yes), are there any power supply failures in the same enclosure (no), and are there any other drives being supported by the same power supply and fans (yes). Based upon the discussion, it was determined that both devices had to be connected to the same controller and the controller failed.

c. What was tried:

i. Answer: the system administrator, prior to calling me, had replaced both drives. When the problem persisted, the system administrator called me as the data on the two drives was critical to the business and needed to get up-and-running as soon as possible.

\section{d. Lesson(s) learned:}

i. Answer: ensure storage devices in a RAID configuration (primary and mirror) are on different controllers. The result of replacing both drives could have resulted in hours of lost processing; 
however, once the controller was replaced, the original drives were reconnected to two different controllers and the data was recovered quickly.

5. Story Assimilation - in the above example, the contents of the attribute "what happened' was copied to the 'story' attribute using a SQL statement. The contents of attribute 'why' was appended to the end of the 'story' attribute with some formatting and then the contents of attribute 'what was tried' was appended to the end of the 'story' attribute. For a complete story, this would continue until all participant input resulted in a story. Based upon the domain and subdomain of the story, guiding questions were asked that were specific to the chosen domain and subdomain. The purpose of the guiding questions was to ensure all aspects of the story were collected that could be relevant to the reader. The various attributes were not simply appended but, as noted above, formatted as a story would be. The guiding questions were included at the top of the story to provide the reader an understanding of the environment and to address questions they would likely want to know in order to assess whether or not the story was or could be applicable to their situation. It is important to understand that in a real situation, participants would be inputting data relatively soon after an event. Thus, the guiding questions could be more extensive. However, since it is most likely that input during the study involved events that were not current, the guiding questions were abbreviated to what a participant would hopefully remember. 
The backend of the KMS was implemented using a MySQL, community version, relational database management system (RDBMS) and the frontend KMS was a webbased application with a web-based interface. Figure 4 is a graphical view of the design.

Figure 4 - Overall System Architecture

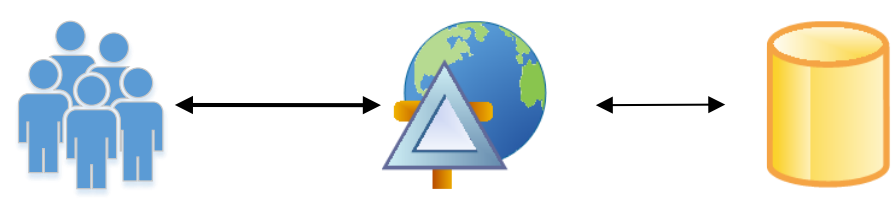

The KMS for this study was not a full-fledged KMS but contained the RDBMS to hold the data and the web-based user interface (for accessing the KMS via the web). The user interface was sufficiently detailed to reduce the interface from being a hindrance to the study, i.e. that participants were reasonably comfortable with the interface and that the interface met the needs of the study.

The complexity of the KMS was limited to addressing the study questions. While IT was designated a CoP within the confines of the study, a CoP could have been networks, databases, servers, storage, etc. Within a more global sense within an organization, there could be a contracting CoP, a program management (PM) CoP, etc. Appendix G provides screen captures of the KMS.

Figure 5 below is the KMS schema diagram that provides a detailed view of the table structure for the KMS minus the tables for the guiding questions and the domains/subdomains. Table information regarding each participant was kept to a minimum for privacy. For participants, the domain/subdomain information for each story 
was collected and stored in the story table 'Contrib_Story'. The model utilizes crowsfeet to depict the two foreign key relationships.

As noted earlier, prior to being a single attribute in the KMS, a story consisted of multiple attributes in the table 'Contrib_Story' that encompassed the various characteristics of the story. In the Contrib_Story table, GQ_Story holds the Guiding Question responses. ID in Contrib_Story and Participants is the participant ID, e.g. it is how the stories are linked back to the contributing participant (first foreign key). STORY_ID relates each unique story in Contrib_Story and the KMS (second foreign key).

Figure 5 - KMS Schema Model

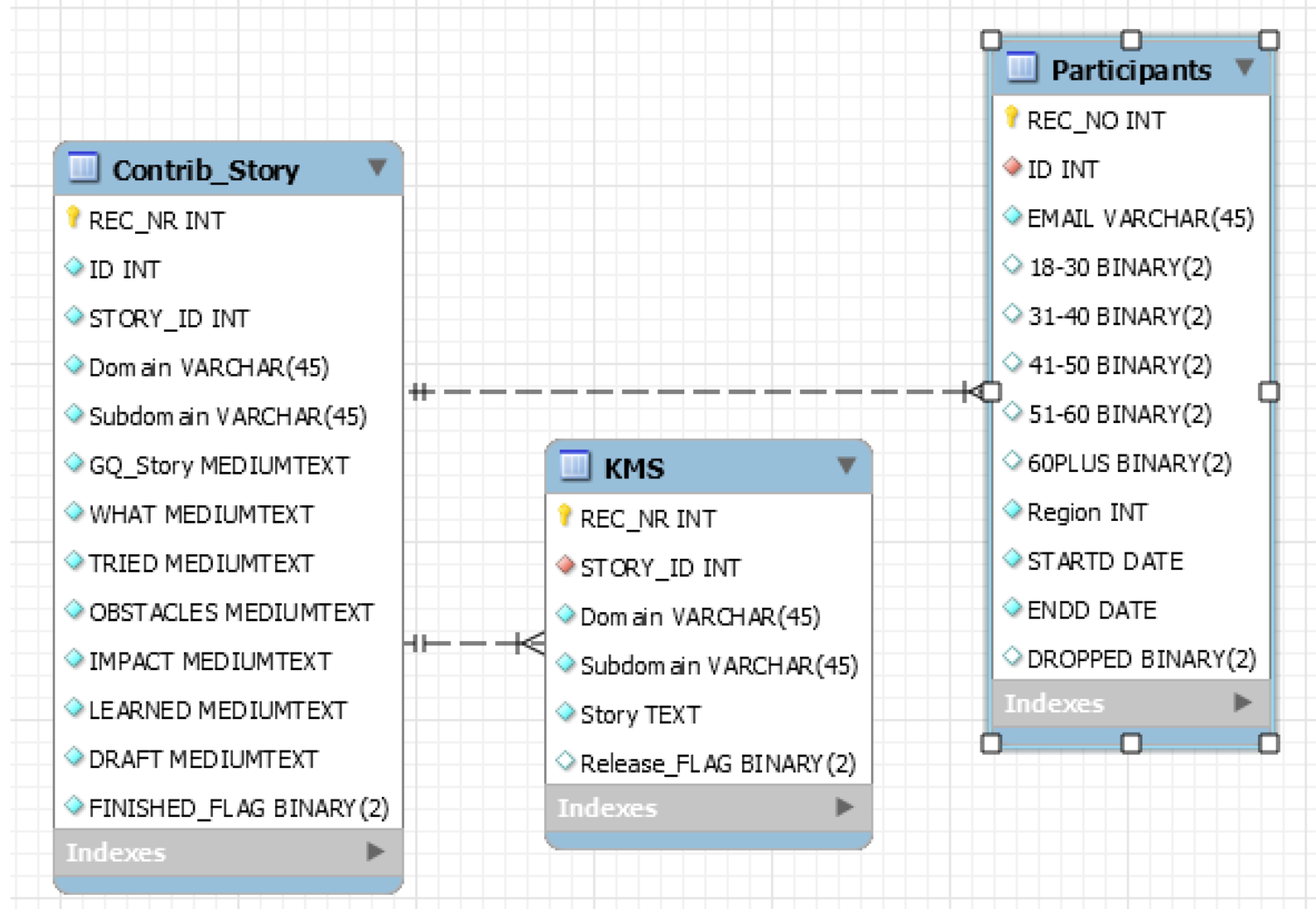

Stories were created in the table 'Contrib_Story'. The participant first selected the domain and subdomain pair from pulldown menus; for the purpose of the study, the 
CoP of IT was automatically applied. The data for the pulldown menus was not contained within a table but was an internal program construct. This was easy as no new domains/subdomains pairs would be used during the study. The participant's ID was automatically entered into a new story when the participant started a story. This was to map a story to the specific participant. A unique story ID was automatically generated for every story. The purpose of the unique story ID was to link guiding question responses to the correct story.

Once the domain, and subdomain entries were selected, the next step, based upon the domain and subdomain, was to answer the guiding questions. The tables for storing the guiding questions are shown in Figure 6 below. The majority of guiding questions were binary, i.e. yes/no. Some questions required integer values (how many of $\mathrm{x}$, for example) and a very few required text input (example: from where to where if for a data center consolidation effort). Guiding questions for the domain/subdomain pairs are in Appendix D. Once the guiding questions were answered, the participant began the actual story by freeform input into six text attributes - WHAT happened (such as a software release or hardware migration failed) and depending upon the what, how it happened, WHY something happened, what was the IMPACT (what was affected and how severely), what was TRIED to resolve a problem or issue, what were the OBSTACLES such as getting financial approval for a new storage array, and what was LEARNED. The how was not always required but it could be critical for providing steps to emulate success or understand why something was not successful. While the HOW was not always required for the story, it was required for the database to ensure that nothing was left out. Thus, a participant could enter, "N/A". The IMPACT, TRIED, OBSTACLES, and LEARNED attributes were not always applicable as not every story was the result of 
a problem. In these cases, "N/A" was input. An example might be a DE inputting information regarding a successful server migration into production or consolidating several data centers. Once the participant toggled the FINISHED_FLAG by selecting 'Finished', the completed story was assembled from the completed attributes into the attribute 'STORY' in table KMS. The sequence for the story was the guiding questions input, WHAT, WHY, IMPACT, TRIED, OBSTACLES, and LEARNED. Appendix E is an example of a story segment taken from the KMS during testing. "N/A" entries for an attribute were filtered out, e.g. they were not made part of the story - the attribute was included but a statement of "there were no obstacles", for example, was inserted. 
Figure 6 - Guiding Questions Table Structures

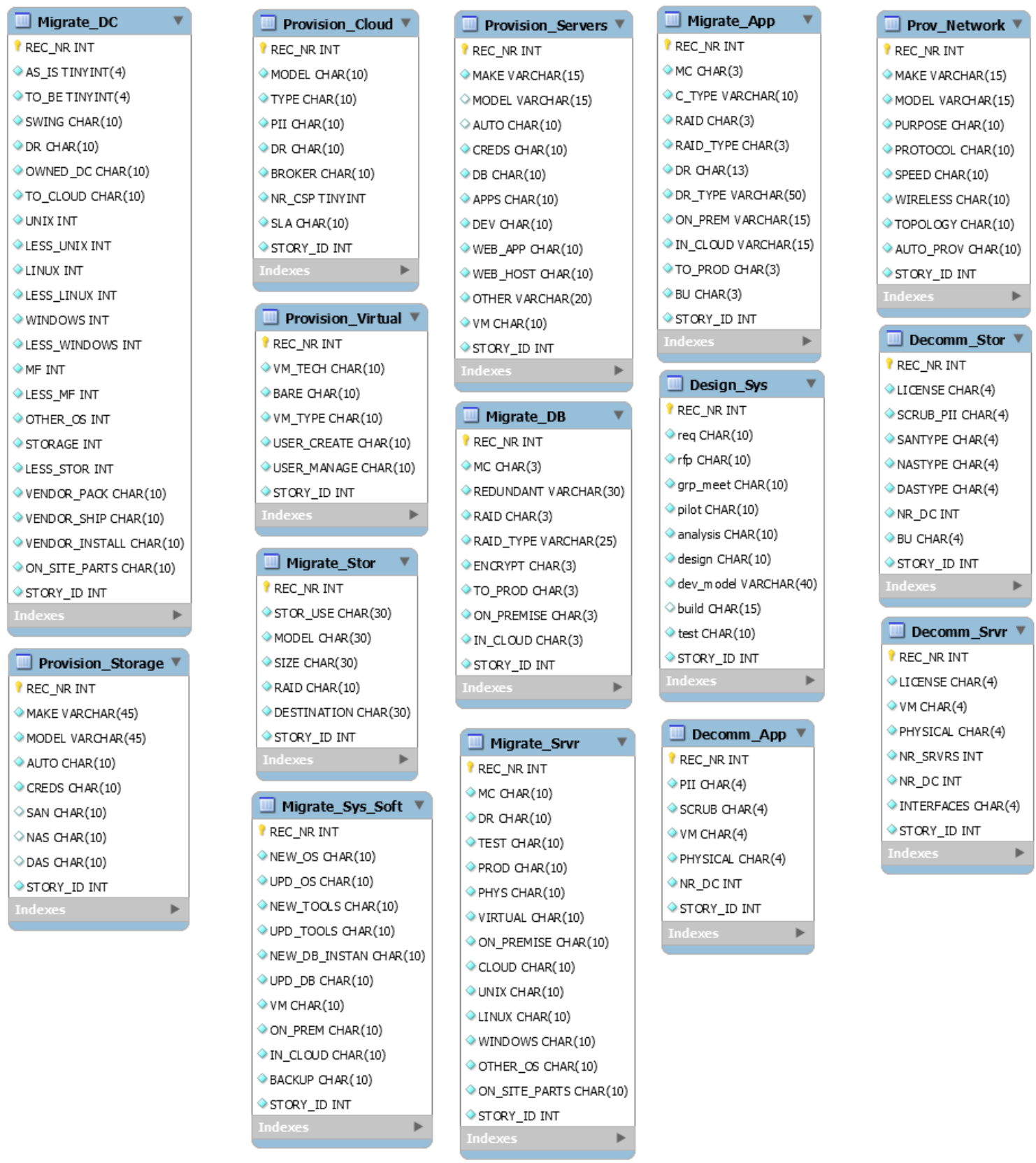

While some of the guiding questions tables look extensive, it is important to remember that the largest, such as migrating (consolidating) data centers is actually relatively easy. Example: a contributor's company supports UNIX and Windows, 
doesn't have NAS (network attached storage) or shared DAS (direct attached storage). Thus, most of the questions would be null.

The guiding questions in Appendix D are the type of questions that someone who was not directly involved in a scenario might ask someone who was. Guiding questions were developed by the principle investigator in collaboration with DEs from the specific domains/subdomains. As noted earlier, an example of a guiding question could be whether a migration involved multiple data centers. The answers from the participant became part of the story. The freeform input in table 'Contrib_Story' is the actual story. The guiding questions are specifically tied to the selected domain/subdomain pair. An example of a story input might be 'we migrated 100 servers to a new location'; however, the reader might ask 'was the new location in the same data center or in multiple data centers.' The guiding question of 'were multiple data centers involved' answers that question and enables the reader to better place the story in context. 
The table 1 contains the domains that were used: some subdomains (Applications, Servers, Storage, for example) were used across multiple domains.

Table 1 - IT Domains/Subdomains utilized within the study

\begin{tabular}{|l|l|}
\hline \multicolumn{1}{|c|}{ DOMAINS } & \multicolumn{1}{|c|}{ SUBDOMAINS } \\
\hline Decommissioning & Applications \\
\hline & Servers \\
\hline Design System & Storage \\
\hline & Hardware \\
\hline Migration & Software \\
\hline & Applications \\
\hline & Database \\
\hline & Data Center (data center consolidation) \\
\hline & Servers \\
\hline & Storage \\
\hline Provisioning & System Software \\
\hline & Cloud \\
\hline & Network Devices \\
\hline & Servers \\
\hline & Storage \\
\hline & Virtualization \\
\hline
\end{tabular}

As noted earlier, once a story was finished by the participant selecting 'Finished', the participant could no longer edit the story.

\section{Conduct of Experiments}

The test environment consisted of a single Windows 7 Virtual Machine (VM). The virtual machine environment was VMware Workstation. The Infrastructure characteristics of the physical host and of the VM were: 


\section{Physical host ${ }^{4}$ :}

- Host operating system: 64-bit Windows 7 Ultimate

- Host Processor: Dual $3 \mathrm{GHz}$ Intel i7 quadcore processors broken down into 16 logical processors, 8 per quadcore

- Memory: 64 GB of DDR3 (double data rate, $3^{\text {rd }}$ generation) RAM (random access memory) running at $1600 \mathrm{MHz}$

- Storage:

○ 1.5 TB consisting of dual RAID 0750 GB 7500rpm drives

- One $80 \mathrm{~GB}$ solid state drive (SSD) for caching

- Graphics/video: Dual NVIDIA GeForce GTX 780M cards each with 2 GB of GDDR5 video memory (VRAM); the video cards were in a Serial Link Interface (SLI) configuration, i.e. the two cards, comprising 4GB of total video memory, acted as one.

- Manufacturer and model: Alienware 18 from Dell

\section{Virtual Machine ${ }^{5}$ :}

- VMware Workstation version 9.0.4, build-1945795

- Operating system: Windows 7 Professional with latest patches

- VM Processor: 1 core / 2 logical processors

- Memory: 2 GB of DDR3 running at $1600 \mathrm{MHz}$

- Storage: $60 \mathrm{~GB}$

- Graphics: Host graphics and sound

\footnotetext{
4 The configuration ran within the Fatcow.com cloud.

5 The actual VM environment changed as a result of placing the test and production environments in a commercial cloud (Fatcow.com).
} 
- Network: Network Address Translation (NAT)

The study sought to have approximately 50 total participants from IT. As noted earlier, it was desired that a majority have prior KMS experience; however, such experience was not an absolute in order to address the question regarding the validity of the storytelling-based approach and willingness to provide tacit knowledge. This question was answered through use of the experimental KMS.

Initially, the consent form had to be agreed to and signed by the participant. However, before any participant started, this was changed to a Waiver of Documentation for Informed Consent (Appendix A). This meant that the participant could read if they wished to read the consent form or not. In either case, the consent was available to participants throughout the study. No one under the age of 18 was allowed to participate in the study.

Appendix C contains the post-experiment/exercise questionnaire that was used during the study. The purpose of the post-experiment questionnaire was to understand how contributor attitudes changed with regards to providing tacit knowledge into a KMS, gaining insight into participant thoughts and concerns with regards to the storytellingbased approach, and participant thoughts and concerns with domains and subdomains as the mechanism for supporting Communities of Practice (CoP).

Once the experimental phase ended, the data analysis phase formally began; however, minimal data analysis was conducted during the experimental phase in an attempt to identify potential emerging trends. 


\section{Success Criteria}

The study used hypothesis testing to validate or invalidate each proposition, i.e. did the data disprove the null hypothesis. The first part is related to the hypotheses (hypotheses, analysis plan, and analysis) followed by the criteria for determining success and/or failure of each proposition. Lastly, I discuss each proposition, the questions in each proposition, and how the questions relate to their respective propositions.

\section{- Hypotheses:}

○ The null hypothesis $\left(\mathrm{h}_{0}\right)$ was that no change would be seen. There were five survey choices a participant could select for each question in the survey ranging from one (1) the lowest representing significantly disagrees to five (5) the highest representing significantly agrees and with three (3), the middle, representing no change. Thus, the target value, to invalidate the null hypotheses, was to achieve greater than (>) no change, or 3. Because the target value changed depending upon the number of questions in the proposition, the target value could have two values. Let $\mu_{0}=3$ represent the absolute value of the null hypothesis and let $\mu_{1}$ represent the adjusted value of the null hypothesis calculated by $\mu_{0}$ multiplied by the number of questions in the proposition. For example, for proposition 1 , there were 8 questions. Thus $\mu_{0}=3$ and $\mu_{1}=3 * 8$ or 24 and $\mathrm{H}_{0}$ can be represented as: $\mu<=\mu_{1}$ or $\mu$ $<=24$ for proposition 1 . This was done for all propositions. 
- The research hypothesis $\left(h_{a}\right)$ was that improvement would be or $\mu>\mu_{1}$.

- Analysis Plan: due to the low sample size, a single right tail t-distribution was used with a significance level of $\alpha=.05$.

- Analysis:

○ All calculations were done in Minitab v.17.3.1.

- The mean, standard error (SE), degrees of freedom (DF), test statistic (t), and the P-value were calculated. A test statistic is a standardized value that is calculated from sample data during a hypothesis test. The test statistic is used to calculate the p-value. When the data show strong evidence against the assumptions in the null hypothesis, the magnitude of the test statistic becomes large and the test's p-value can become small enough to reject the null hypothesis. There are different hypothesis tests that use different test statistics based on the probability model such as the Z-test (the test statistic is the $\mathrm{Z}$-value) and the $\mathrm{t}$-test (the test statistic uses the t-value) (Minitab-Product-Support, 2016). This study used the ttest.

- The total sample size (n) consisted of all the participants in the study minus those who dropped from the study and did not complete the survey

$\circ \mathrm{s}$ is the standard deviation of the sample

- DF was the sample size (n) minus one (n-1).

- SE was calculated by: $S / \sqrt{n}$. 
○ The formula for the test statistic (one population mean) was: $\frac{\bar{x}-\mu_{1}}{s / \sqrt{n}}$

For the hypothesis testing, the total score of a participant's responses to all questions of a proposition (see Table 2 for Proposition 1 as an example) constituted that participants RAW attitudinal score. The RAW attitudinal score for all participants for a proposition was then totaled for a Total RAW attitudinal score. The RAW attitudinal score was used to calculate the mean, standard deviation, standard error, and t-score. Using the t-score and the t-distribution table, the p-value was determined in order to validate or invalidate the research hypothesis $\left(h_{a}\right)$ Since $h_{a}$ is a greater than (versus not equal to (two-tailed) or less than) hypothesis, success was determined if the p-value was $<0.05$. This process was utilized for all three propositions to determine success or failure (Rumsey, 2003). In the Table 2 example, the p-value does not meet this criterion. In the Table 1 example, the data was not sufficient to disprove the null hypothesis and the proposition would be rated as failed. The t-distribution has a mean of 0 and a standard deviation of 1 . If the t-test was close to 0 or at least within that range, then the null hypothesis held (Rumsey, 2003). In Table 2, the t-test was -0.535 with a P-Value of 0.303 .

The study utilized an attitudinal scale. There are three major types of attitudinal scales (Kumar, 2005):

- The summated rating scale, also known as the Likert scale

- The equal-appearing interval scale or differential scale, also known as the Thurstone scale, and

- The cumulative scale, also known as the Guttman scale 
This study utilized a Likert scale. Construction of the Likert scale followed the outline in Kumar (2005). As discussed earlier, in constructing the Likert scale, five categories were utilized to measure the intensity of the participants' attitude to a question. The responses were converted to a five-point scale $(1,2,3,4$, and 5$)$ with a one (1) assigned to the least favorable response and a five (5) assigned the most favorable response; a three (3) was assigned to responses of no change. Thus, the scoring allowed for the use of parametric methods. The Likert scale does not actually measure attitude but simply enables the rating of the participants in descending or ascending order with respect to their attitudes towards the question responses. The type of hypothesis test used was the One Population Mean. This test is used when the variable is numerical and only one population or group is being studied (Rumsey, 2003).

Table 2 - Example of an Unsuccessful Research Hypothesis $\left(h_{a}\right)$ for Proposition 1

\begin{tabular}{|l|l|l|l|l|l|l|l|l|l|l|}
\hline P \# & $\mathbf{1 - 1}$ & $\mathbf{1 - 2}$ & $\mathbf{1 - 3}$ & $\mathbf{1 - 4}$ & $\mathbf{1 - 5}$ & $\mathbf{1 - 6}$ & $\mathbf{1 - 7}$ & $\mathbf{1 - 8}$ & $\mathbf{R A W}$ & Calculations \\
\hline 001 & 5 & 4 & 3 & 3 & 2 & 2 & 4 & 3 & 26 & \\
\hline 002 & 4 & 5 & 3 & 3 & 3 & 2 & 1 & 1 & 22 & \\
\hline 003 & 1 & 2 & 3 & 3 & 3 & 2 & 1 & 1 & 16 & \\
\hline 004 & 4 & 4 & 4 & 3 & 3 & 2 & 3 & 4 & 27 & \\
\hline 005 & 1 & 1 & 2 & 2 & 3 & 3 & 3 & 3 & 18 & \\
\hline 006 & 3 & 4 & 4 & 3 & 3 & 3 & 2 & 2 & 25 & \\
\hline 007 & 4 & 3 & 4 & 3 & 4 & 2 & 2 & 2 & 24 & \\
\hline 008 & 1 & 1 & 2 & 1 & 3 & 3 & 3 & 2 & 16 & \\
\hline 009 & 5 & 5 & 4 & 4 & 5 & 3 & 3 & 4 & 33 & \\
\hline 010 & 3 & 3 & 3 & 3 & 3 & 3 & 3 & 3 & 24 & \\
\hline & & & & & & & & & 231 & Total RAW \\
\hline & & & & & & & & & 23.1 & Mean \\
\hline & & & & & & & & & 5.322 & s \\
\hline & & & & & & & & & 10 & n \\
\hline & & & & & & & & & 9 & DF \\
\hline & & & & & & & & & 1.683 & SE \\
\hline & & & & & & & & & 24 & $\mu_{1}$ \\
\hline & & & & & & & & & -0.535 & t-test \\
\hline & & & & & & & & & 0.303 & P-Value \\
\hline
\end{tabular}


All questions were close-ended, i.e. the response pattern was already provided (Rumsey, 2003). The questions in the survey were specific to addressing the propositions. Participant questions spanned the individual, organizational, and technological standpoints. The survey is located in Appendix C. Appendix H is the survey code book for all questions in the study. The questions were grouped into three segments with each segment addressing one proposition. Sharing of Knowledge and Storytelling addressed Proposition 1, Scenarios, Solutions, and COPS addressed Proposition 2, and Forums addressed Proposition 3.

Each proposition is now discussed:

1. Proposition 1: Domain experts will be willing to provide their tacit knowledge into a KMS using a storytelling-based approach.

There were eight questions to proposition 1.

a. Question 1-1 sought to understand, based upon the limited study, if the participant's opinion had changed regarding their willingness to provide their tacit knowledge into a KMS.

b. Question 1-2 sought to understand if the storytelling-based approach had an impact on the participant's willingness to provide their tacit knowledge into a KMS.

c. Question 1-3 explored the storytelling-based approach against the typical problem/resolution format used in most KMS'.

d. Question 1-4 delved into the participant's thoughts on the storytellingbased approach itself, i.e. did they like it. 
e. Question 1-5, went further on the storytelling-based approach in that it looked at the ability to tell what happened like it happened which is difficult in a problem/resolution format.

f. Question 1-6 switched gears and went to the negative of the storytellingbased approach, i.e. after reviewing their story, the participant realized that it would take a lot of work and didn't want to put the time in.

g. Question 1-7, still on the storytelling-based approach, asked if the participant would have preferred to tell their stories audibly. While this study did not test that aspect, it was interesting to see how the participants responded and is an area of future study.

h. Question 1-8 is similar to question 1-5 with the difference being flexibility, i.e. telling what happened in their own way.

2. Proposition 2: This proposition studied the technology: The use of scenarios, defined CoPs, domains and subdomains, and guiding questions in a semi-structured format will resolve the issue that $K M S^{\prime}$ often fail due to the nature of the KMS, i.e. there are no bounds on what a domain expert can enter or how.

The semi-structured format is a framework designed to enable the contributor to tell their story in a way they might tell a story of an incident they resolved while in a one-on-one, one-on-many, or many-on-many conversation at the office. The framework exists to ensure that all aspects of the story are covered.

a. Question 2-1 asked if the participant liked a KMS that was based upon scenarios and solutions. A KMS that uses solutions is one where you are 
providing a solution to a specific issue that is likely to be encountered by others in the future. A scenario is the background that led to the issue.

b. Question 2-2 was about whether or not the participant liked domains and subdomains to segment/catalog data in a KMS. Continuing with domains and subdomains, question 2-3 sought to understand if multiple levels could reduce the need to perform searches.

c. Question 2-4 sought to understand if the use of guiding questions helped improve the clarity of a story. Guiding questions provide the reader more information about something to help them place something into context or provide greater insight into what was done or why. An example is provisioning 10 servers - were they all provisioned in the same data center or in multiple data centers. Each has different issues and the reader may want to know which so they can place the solution into context.

d. Question 2-5 investigated the use of communities of practice and question 2-6 looked at the pairing of solutions and scenarios with the storytellingbased approach - is it a good match or not?

3. Proposition 3: People are more willing to provide their tacit knowledge in forums versus provide their tacit knowledge in corporate $K M S^{\prime}$. The research of Wasko and Faraj (2005) showed that contributors like contributing. As discussed earlier, the nature of forums is different than KMS' in the style of data communication, the ability to search for relevant data, the accuracy of forum data, and the type of data itself (micro-knowledge versus macro-knowledge of KMS'). This proposition sought to identify a motivation for why contributors are willing to provide their tacit knowledge to forums but not KMS'. 
a. It was hypothesized that all of the participants had participated in forums and that, as a minimum, their participation was as a user. While the study sought forum participants who were contributors, the insights of users was considered valuable as well. Question 3-1, was to determine if the participant had partaken in forums and if a participant answered that they had not been involved in forums then the study ended for the participant.

b. Question 3-2 asked if the participant liked providing their tacit knowledge in a forum while question 3-3 went further by asking the participant if they liked providing their tacit knowledge into a forum more than a KMS.

c. Questions 3-4 explored the freeform writing style of providing tacit knowledge in a forum. The freeform writing style is similar to the storytelling-based approach in that it provides the writer more flexibility.

d. Question 3-5 was related to the quality of information in a KMS versus the quality of data in a forum.

\section{Evaluation of Experiments against other KMS Research}

Comparisons of this research to past experiments using traditional KMS' was restricted to pre-2008 studies where KMS research utilizing active corporate KMS' were dominant versus the use of social media. Social media exists within many corporations today due to the issues outlined earlier with traditional KMS'. Current research either considers tacit knowledge to be unobtainable (Qiu et al., 2014), very difficult to obtain (Rumanti, 2015), or more obtainable through social media (Taherparvar, Esmaeilpour, \& Dostar, 2014). This poses a challenge as social media, while providing an opportunity to share tacit knowledge, has different goals and outcomes when compared to traditional 
organizational KMS' as discussed earlier. These differences include the scope, i.e. the target audience of each. For social media, in this case forums, the target audience is generally one-on-one and real time, i.e. a user asks a question and a DE (hopefully) responds.

For studies using KMS', comparisons were made to the studies at HP and Siemens (Benbya \& Alstyne, 2008) and Rocketdyne (Chun et al., 2008). These studies discussed the KMS' and what was used (such as awards) to motivate DEs to contribute their tacit knowledge. They further laid out reasons why the KMS' were unsuccessful. The comparison between this study and the earlier studies concentrated on the results and attempted to draw conclusions on how to make KMS' successful. 


\section{Chapter 4 Results}

\section{Data Analysis}

As noted in Chapter 3, the range of scores were one (1) to five (5) with three (3) equal to no change. The bottom two values were negative responses and the top two values were positive responses.

In the survey, there was one question, 3-1, that was a yes (value $=1$ ) or no (value $=0)$ response. The question was to determine if the participant had utilized forums in the past. During analysis, this question's value was eliminated as it had no analysis relevance; it was merely to determine if the participant would continue with the survey or if the survey was ended. If the participant answered no (they had no experience with forums), the remaining four questions were each graded 3 (no change) to ensure their previous answers retained their value. Thus, the overall results were not overly skewed negative.

The mean was 3 (no change) for this study and the total sample size was 21 (the total number of participants was 28 ; however, seven dropped before completing the survey). The mean was calculated taking the aggregate possible survey values of the set $(1+2+3+4+5=15)$ and dividing by the total number of elements in the set (5). The target mean was calculated in the same way except for each proposition, i.e. the mean multiplied by the number of questions in each proposition. For proposition 1, there were eight questions so the target mean was $3 * 8=24$. For proposition 2 , there were 6 questions for a target mean of $18(3 * 6)$. And for proposition 3 , there were 4 questions for a target mean of 12. The Alpha level, as noted in Chapter 3, was 0.05 . 
Based upon the survey results and calculations in Minitab 17, proposition 1 had a mean of $29.952(27.538-32.367)$ against a target mean of 24 . A mean value greater than 24 equated to more positive responses than negative. A right tailed hypothesis test $(\mu)$ was selected using the aggregate survey data for proposition 1 (Figure 7). For proposition 2, the mean value of 23 (21.394-24.606) was greater than the target value of 18 which equated to more positive responses than negative (Figure 8). And for proposition 3, the mean value of 12.905 (11.896-12.914) against a target mean of 12 was not sufficient to draw any conclusions (Figure 9). Appendix F contains the participant response scoring and demographic information. The aggregate was based upon the scoring of each participants questions minus question 3-1 which, as noted earlier, was a yes/no question. Based upon the survey data for propositions 1 and 2, it can be concluded that the mean was greater than the target mean at the 0.05 level of significance. 
Figure 7 - Minitab 17 Sample $t$ Test for the Mean of Proposition 1 Summary Report

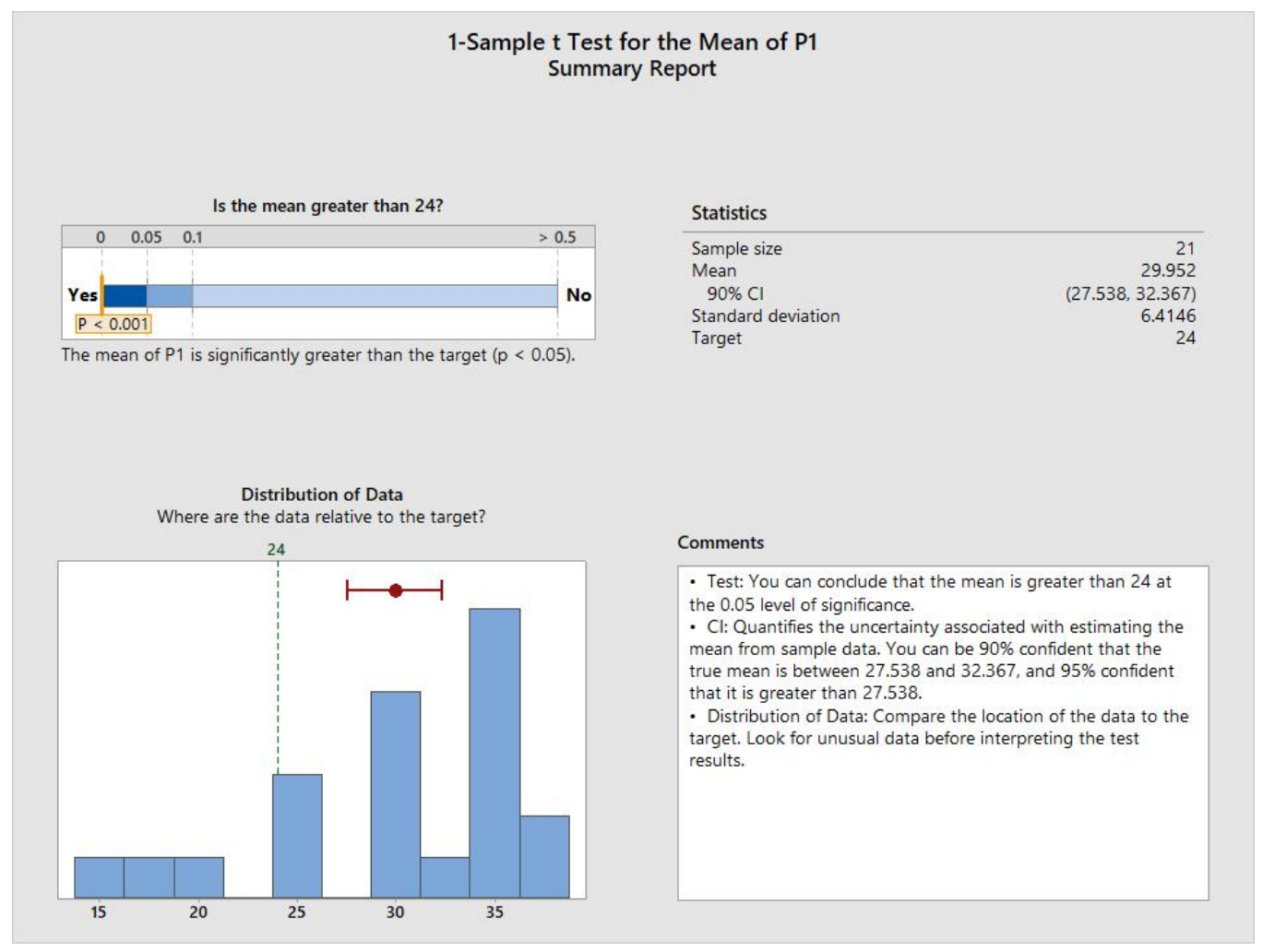

Figure 8 - Minitab 17 Sample t Test for the Mean of Proposition 2 Summary Report

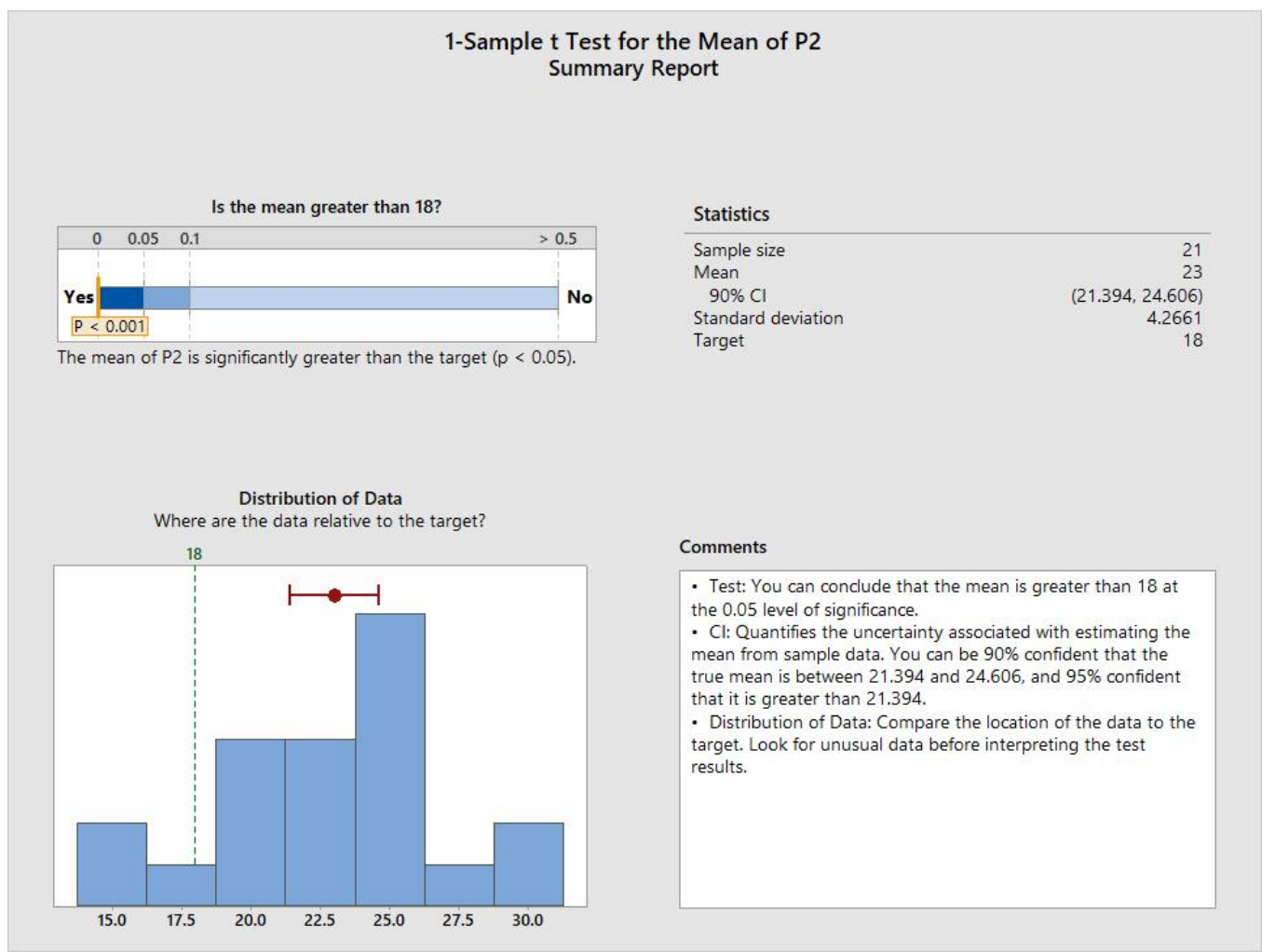


Figure 9 - Minitab 17 Sample t Test for the Mean of Proposition 3 Summary Report

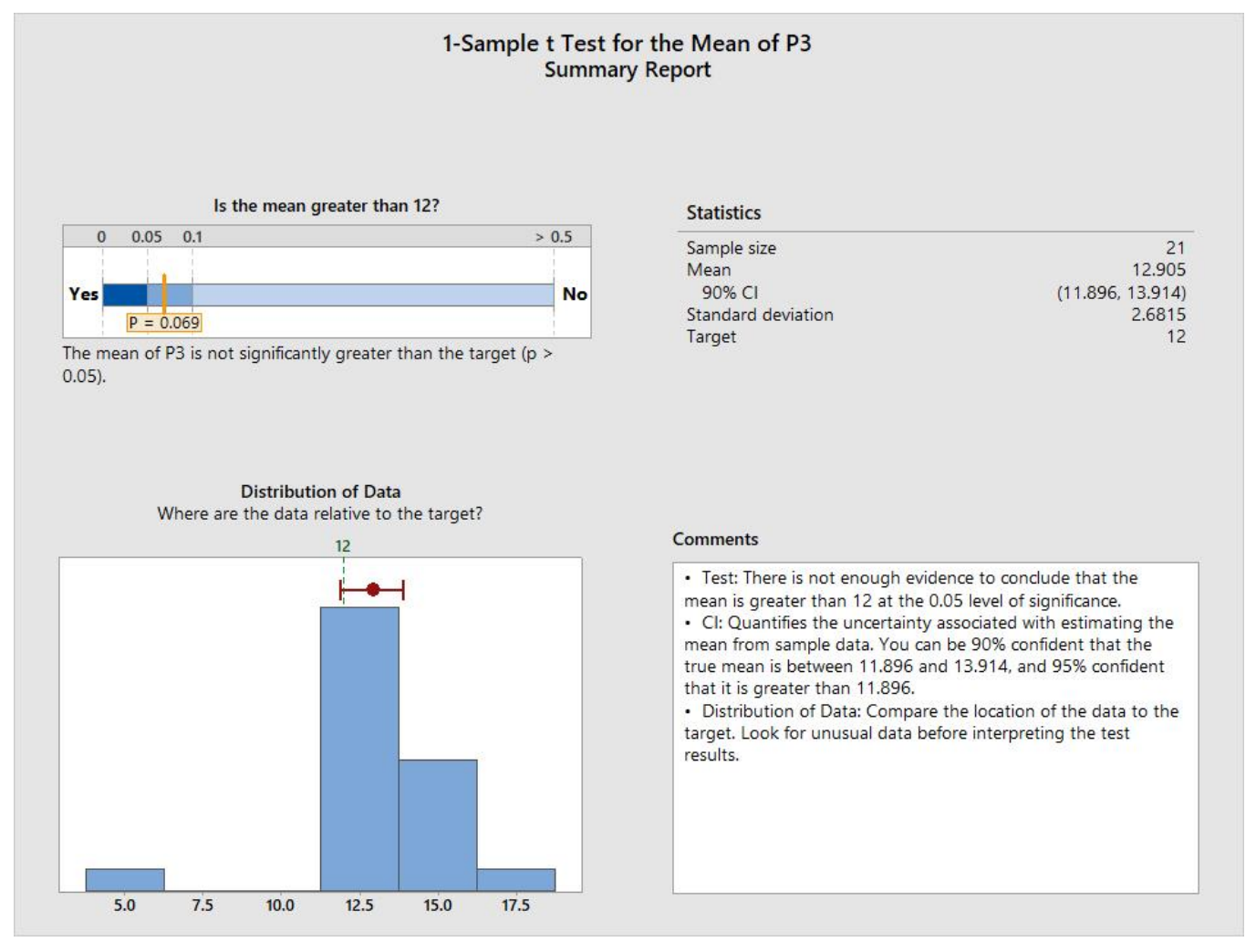

The tests were accurate with normal data ("Minitab," 2016) and the sample was sufficient to detect a difference between the sample mean and the target mean ("Minitab," 2016). The data shows that a confidence level of $95 \%$ is greater than 27.538 for proposition 1, greater than 21.394 for proposition 2, and greater than 11.896 for proposition 3. Thus, as noted earlier, it can be concluded that the sample means for propositions 1 and 2 are greater than the target means for each of these propositions at the 0.05 level of significance and the null hypothesis is rejected. The data quantifies the uncertainty associated with estimating the mean from sample data. Minitab 17 states a $90 \%$ confidence that the true mean for proposition 1 is between 27.538 and 32.367 and between 21.394 and 24.606 for proposition 2. Minitab calculated the mean to be significantly greater than the target with a P score of less than $0.05(0.001)$. 


\section{Findings}

Framework

1. It was discovered early on that the framework did not provide sufficient information to participants, i.e. what should go into each box. As a result, the framework interface was changed twice to provide additional information to participants.

2. The framework was modified to eliminate the collection of personal names during the registration process as the information was not needed.

3. The framework was modified with regards to the consent. The requirement of a signed consent form became a waiver of informed consent. This means that by participating in the exercise, the participant consents. This also required changes to the consent form itself. The participant had the opportunity to review or not review the waiver of informed consent. If the participant elected not to review the waiver of informed consent before the exercise, they were provided the opportunity to review it while in the exercise phase as a link was inserted to the waiver of informed consent at the bottom of each section. Based upon early feedback, the biggest issue was the framework. The issue was primarily what data went into each of the text blocks. Participants, even with an explanation of what the domain/subdomains were and how to select them, seemed to have difficulty in choosing a domain/subdomain pair that fit their story. This mostly occurred in the application development and support space. 


\section{Means to Solicit Participants}

Initially, a 9-minute video was prepared explaining the study end-to-end and the process of participating. However, comments came back that even though the video showed the site to go to for the exercise and survey, many who viewed the video were not really paying attention to the video at all - they just wanted to know how to do the exercise and move on. This drove a change to provide detailed information at each block of data input and resulted in the cessation of the video. This also pushed changes to how I solicited participants and resulted in a short paragraph with a link to the site and the creation of a link on the site with detailed instructions.

\section{Participation}

While the target of twenty-one participants was finally achieved after nine months of weekly posts to various universities and professional organization Facebook sites, no participant entered in more than one story. Seven participants dropped out of the study, i.e. they either did not start the survey or did not complete the survey. Feedback from one participant was she was not in Information Technology or applications development. Five participants indicated they had never participated in a forum which is curious considering that of the five, one fell in the 18-30 range and one fell in the 31-40 range and all participants were in the domains of application developers and/or Information Technology. This represented $23 \%$ of participants with no forum knowledge or experience. The remaining three were in the 51-60 range and 60+ range.

Tables 3 and 4 provide a breakdown of data contained in Appendix F. The tables are based upon the age range of participants, number of participants, and the region in 
which they live. Table 5 is a summary of results towards achieving the objectives of each proposition.

Table 3 - Participant Age Breakdown

\begin{tabular}{|l|l|l|l|}
\hline $\begin{array}{l}\text { Age } \\
\text { Range }\end{array}$ & $\begin{array}{l}\text { Age Range } \\
\mathbf{\%}\end{array}$ & $\begin{array}{l}\text { Number of } \\
\text { Participants }^{\mathbf{6}}\end{array}$ & Dropped \\
\hline $\mathbf{1 8 - 3 0}$ & 19.05 & 6 & 2 \\
\hline $\mathbf{3 1 - 4 0}$ & 9.52 & 2 & 1 \\
\hline $\mathbf{4 1 - 5 0}$ & 19.05 & 7 & 3 \\
\hline $\mathbf{5 1 - 6 0}$ & 33.33 & 8 & 1 \\
\hline $\mathbf{6 0 +}$ & 19.05 & 4 & \\
\hline
\end{tabular}

Table 4 - Participant Region Breakdown

\begin{tabular}{|l|l|l|}
\hline Region & Count* & Region \% \\
\hline Northwest (NW) & 3 & 10.71 \\
\hline West (W) & 5 & 17.86 \\
\hline Southwest (SW) & 2 & 7.14 \\
\hline North Central (NC) & 0 & 0 \\
\hline Central (C) & 4 & 14.29 \\
\hline Southcentral (SC) & 2 & 7.14 \\
\hline Northeast (NE) & 4 & 14.29 \\
\hline East (E) & 3 & 10.71 \\
\hline Southeast & 5 & 17.86 \\
\hline
\end{tabular}

*Includes all participants to include those who dropped

${ }^{6}$ The percentage is based upon the total for the age group minus those who dropped. Thus, the percentage is based upon those who fully completed the study. 
Table 5 - Summary of Results

\begin{tabular}{|c|c|}
\hline $\begin{array}{l}\text { Proposition } \\
\end{array}$ & $\begin{array}{r}\text { Results } \\
\end{array}$ \\
\hline $\begin{array}{l}\text { Proposition 1: Domain experts will be } \\
\text { willing to provide their tacit knowledge } \\
\text { into a KMS using a storytelling-based } \\
\text { approach. }\end{array}$ & $\begin{array}{l}\text { The results clearly showed that } \\
\text { proposition } 1 \text { succeeded. } 81 \% \text { of } \\
\text { the participants responded } \\
\text { positively to the eight study } \\
\text { questions directed towards this } \\
\text { proposition. For all eight } \\
\text { questions across all } 21 \\
\text { participants, the mean was } 29.952 \\
\text { against a target test mean of } 24 \text { ( } 3 \\
\text { being no change } * 8 \text { questions) } \\
\text { with a range of } 27.538-32.367 \text {. }\end{array}$ \\
\hline $\begin{array}{l}\text { Proposition 2: The use of scenarios, } \\
\text { defined CoPs, domains and subdomains, } \\
\text { and guiding questions in a semi- } \\
\text { structured format will resolve the issue } \\
\text { that KMS' often fail due to the nature of } \\
\text { the KMS, i.e. there are no bounds on } \\
\text { what a domain expert can enter or how. }\end{array}$ & $\begin{array}{l}\text { The results clearly showed that } \\
\text { proposition } 2 \text { succeeded. } 76.19 \% \\
\text { of participants scored this section } \\
\text { positive. For all six questions } \\
\text { across all } 21 \text { participants, the mean } \\
\text { was } 23 \text { against a target test mean } \\
\text { of } 18 \text { (3*6 questions) with a range } \\
\text { of } 21.394-24.606 \text {. }\end{array}$ \\
\hline $\begin{array}{l}\text { Proposition 3: People are more willing to } \\
\text { provide their tacit knowledge in forums } \\
\text { versus provide their tacit knowledge in } \\
\text { corporate KMS' }\end{array}$ & $\begin{array}{l}\text { The results for proposition } 3 \text { were } \\
\text { inconclusive and must be } \\
\text { considered a failure. Most of the } \\
\text { respondents either scored 'no } \\
\text { change' to at least } 50 \% \text { of the } \\
\text { questions or they stated they had } \\
\text { never been to a forum. For all four } \\
\text { questions across all } 21 \\
\text { participants, the mean was } 12.905 \\
\text { against a target mean was } 12(3 * 4) \\
\text { with a range of } 11.896-13.914 \text {. }\end{array}$ \\
\hline
\end{tabular}


Figure 10 - Minitab 17 Sample $t$ Test Diagnostic Report for the Mean of Proposition 1

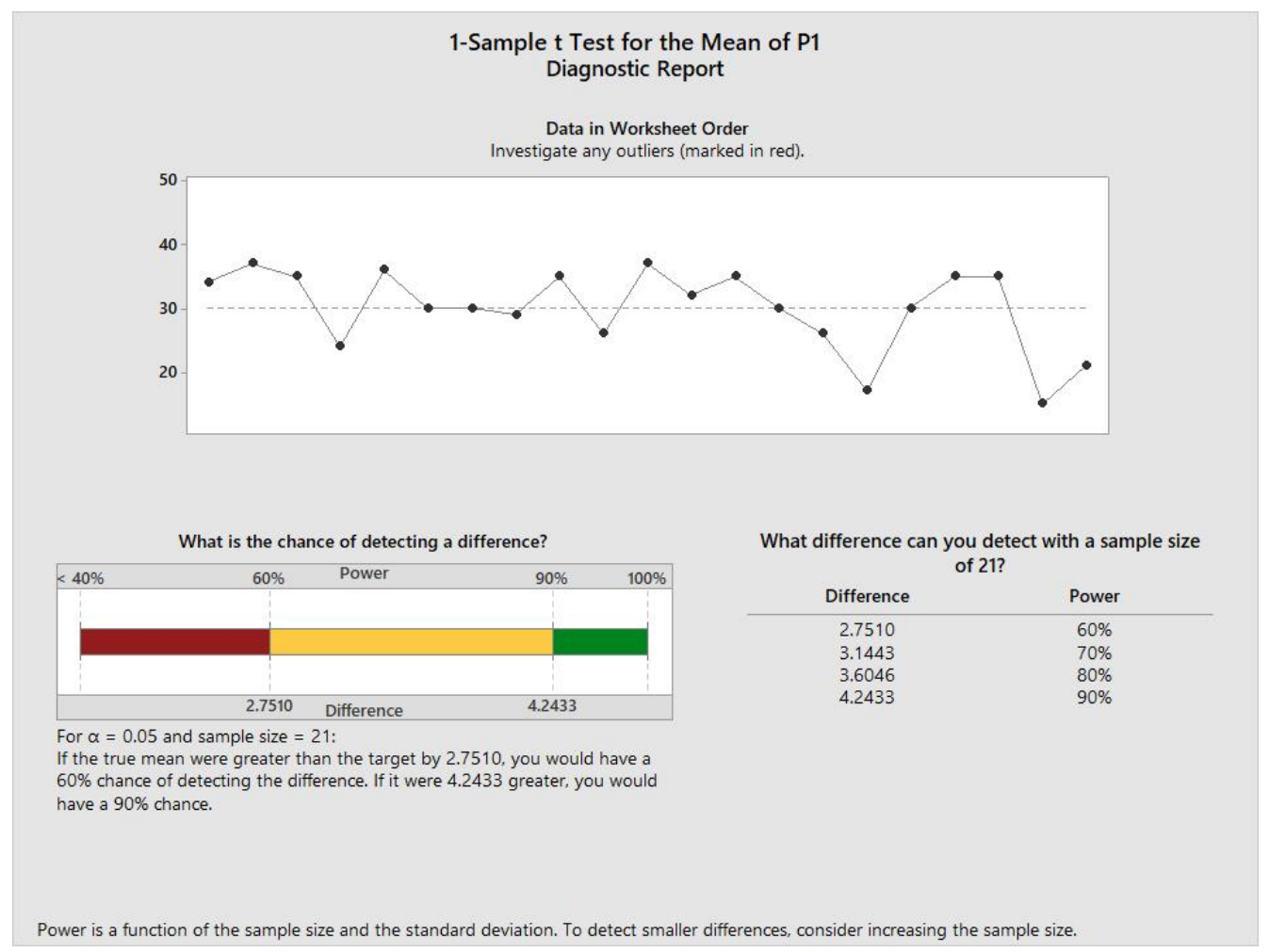

Figure 11 - Minitab 17 Sample t Test Diagnostic Report for the Mean of Proposition 2

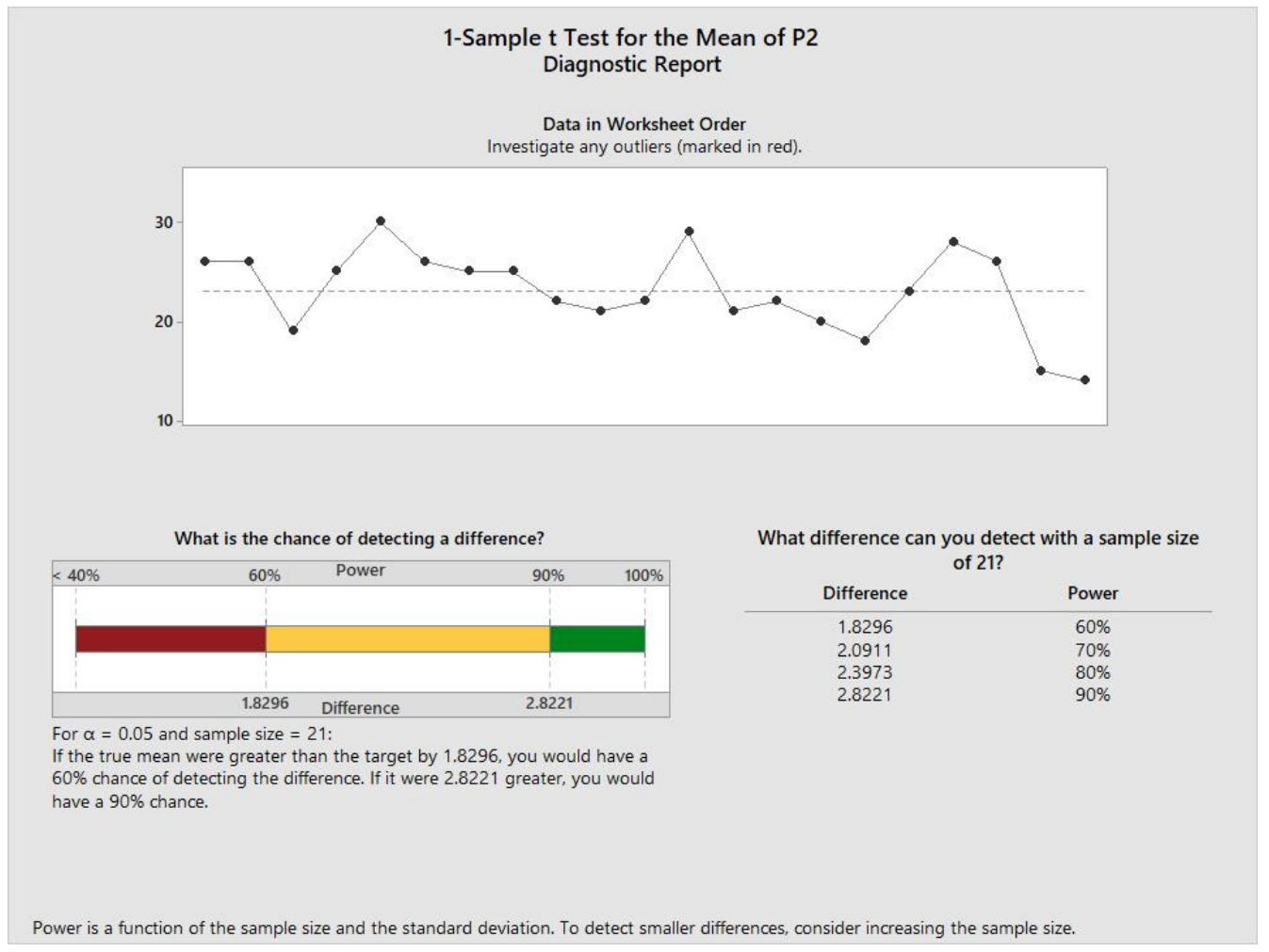


Figure 12 - Minitab 17 Sample t Test Diagnostic Report for the Mean of Proposition 3

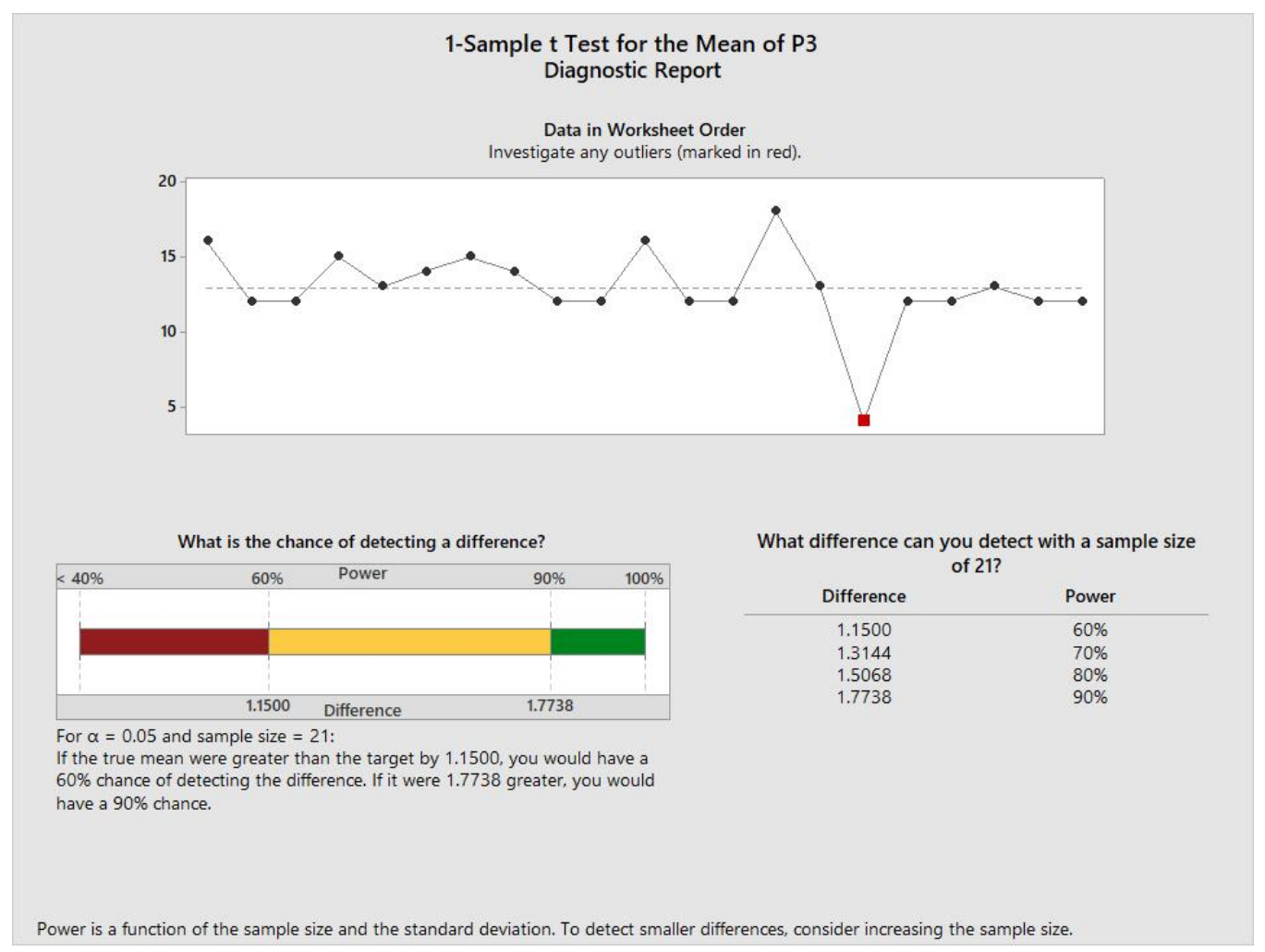

\section{Summary of Results}

The primary goal of this study was to demonstrate that domain experts would be willing to provide their tacit knowledge into a KMS using a storytelling-based approach. That goal was achieved with $81 \%$ scoring positively the eight questions for proposition 1 . The next goal in which Weber (2007) stated was a major issue to KMS' failing was the framework (Communities of Practice (CoPs), Scenarios, domains/subdomains, guiding questions). While the framework could improve (see recommendations below), it did meet the needs of the study with $76.19 \%$ of respondents scoring the questions in proposition 2 favorably.

Based upon the results of the study, it can be stated that this storytelling-based approach is a better approach than other, existing, approaches including interview-based 
story's. There are still challenges that are discussed in Chapter 5,

'Limitations/Recommendations'. The desire to collect tacit knowledge (learned knowledge) from employees has been around for decades. There is a story that talks about a man who retired from an electrical plant. One day, the plant suffered a significant outage and after two days the problem still hadn't been found. Thousands of homes were without electricity and the plant manager called the retiree and asked if he would take a look. The man said no, he was retired. The plant manager begged and said he'd pay whatever the man wanted. The man said ok and on the way to the plant stopped off at a hardware store and bought some white chalk for 99 cents. When he got to the plant, he received a briefing. He immediately grabbed a hard hat and walked outside. $\mathrm{He}$ walked over to a column and with the chalk, make an X. He said, "the problem is here and will be easy to fix". He was right, the engineers had the problem fixed within 30 minutes and the man went back home. That is tacit knowledge. 


\section{Chapter 5 Conclusions, Implications, and Recommendations}

This chapter provides the conclusions of the study along with limitations and recommendations for future areas of research. The chapter concludes with a summary.

\section{Conclusions}

The purpose of the study was to explore if the use of a storytelling-based approach for knowledge management systems would be more successful in the collection of tacit knowledge than approaches currently in use. As discussed early on, direct tacit knowledge transfer (one-on-one, one-on-many, and many-on-many) is used daily to verbally communicate tacit knowledge. Could the storytelling-based approach in KMS' provide a similar level of success? The study was broken down into three propositions.

The first proposition, would domain experts be willing to provide their tacit knowledge into a KMS using a storytelling-based approach, went directly to the heart of the study. The studies of Schank (2010) and Whyte and Classen (2012) noted that telling a story is more interesting than just static dictation. Qiu, et al. (2014) stated that tacit knowledge cannot be codified and can only be observed. $81 \%$ of the participants responded positively to the eight study questions directed towards this proposition. Thus, this proposition supports Schank, and Whyte and Classen. It demonstrated a solution to the obstacle of technology and individual in knowledge sharing. As the goal of the study was to demonstrate that the use of storytelling could be successful in the collection of tacit knowledge by participants who directly enter their stories into a KMS, this proposition was concluded successful. One participant, $4.76 \%$, rated questions 1-3 (the storytelling-based approach is a better mechanism to communicate information into a 
KMS than the problem/resolution format typically used in KMS') and 1-4 (I enjoyed the process of creating stories) negatively; however, 1-2 (the storytelling-based approach contributed to my willingness to provide my tacit knowledge into a KMS) and 1-5 (I felt like the storytelling-based approach allowed me the ability to tell it like it happened) were both positive. The differences indicate that the framework may have been an issue as this participant was one of $33.33 \%$ who felt voice would be a better format than text. While this answer does not support one or the other, it does indicate that an issue may exist with the framework itself. $14.29 \%$ did not like the storytelling-based approach. $76.19 \%$ were positive on question 1-8 (the storytelling-based approach allowed me more flexibility to tell what happened in my own way, in a way that my peers will understand). $14.28 \%$ were negative on question 1-8 while $4.76 \%$ had no change in their opinion. Based upon the limited survey of 21 participants who utilized a storytelling-based approach to enter data into a limited-use KMS, the studies of Qiu, et al. (2014) who stated that tacit knowledge is not able to be codified and Fanfan (2012) who simply said the collection of tacit knowledge cannot be done, are disproved.

The second proposition was on the use of scenarios, defined CoPs, domains and subdomains, and guiding questions in a semi-structured format to resolve the issue that KMS' often fail due to the nature of the KMS. $76.19 \%$ of participants scored this section positive. Thus, the issues identified by Weber (2007), i.e. the framework, CoPs, domains and subdomains are valid and this proposition is concluded a success. One participant, $4.76 \%$, rated all questions covering this proposition as no change while $14.29 \%$ rated this proposition as negative. 
Proposition 3, people are more willing to provide their tacit knowledge in forums versus provide their tacit knowledge in corporate KMS', targeted the use of forums. Studies have shown that contributors are willing to provide their tacit knowledge in forums so this question sought out participant thoughts. $38.10 \%$ stated they had not used a forum before. Of those who had, $42.86 \%$ had two or more out of four questions as 'no change' responses. Thus, it is concluded that proposition 3 failed due to lack of sufficient data.

\section{Scientific Research Contribution}

The contributions of this study were as follows:

- It adds the use of a storytelling-based approach to KMS' in the collection of tacit knowledge

- Unlike earlier attempts at implementing storytelling in KMS' that utilized interviewers, this approach has the holder of the knowledge entering the information themselves into the KMS as a story; this is a significant departure from what exists today and what has been tried in the past

\section{Implications}

The implications of this study support the implementation of a story-telling-based approach for the collection of tacit knowledge into knowledge management systems. More than just the implementation of a storytelling-based approach but use of the storytelling-based approach by the contributors themselves. This gets away from past practice of stories through interviews with domain experts and then having the interviewers insert the data into a KMS. This further implies that data can be more 
readily updated reducing the likelihood of outdated information remaining in the KMS. The research clearly demonstrated that the collection of tacit knowledge is a necessity for businesses. Coffey and Hoffman (2003) tied the collection of tacit knowledge to the organizational need to retain institutional knowledge in order to advance the mission of the organization, avoid making the same mistakes over again, and to leverage the accomplishment of departing employees. A common theme throughout the literature in the collection of tacit knowledge is to gain a competitive advantage (Fanfan, 2012).

Based upon this limited-use knowledge management system, users found using this approach to be a better approach than approaches currently used in KMS'. This is not surprising as the literature on stories are clear - it is natural and people never tire of telling stories (Schank, 2010). The inverse is also true - use of a format such as the problem/resolution format may seem efficient but it is not how people think.

Considering that the primary age group of the participants was 41 and older, this could be significant as it is this age group that is likely to have actually come in to contact with KMS'. Due to the failure of KMS', most companies have moved to forums. It is hoped that based upon this study, more research will be done with the use of stories and future KMS' will be developed incorporating the technology.

\section{Limitations/Recommendations}

The greatest limitation of this study was the number of participants. While 21 met the requirement for statistical relevancy and the statistical software checked OK for Normality, a much large sampling would have been beneficial. Had a larger sampling been possible, three outliers would have been eliminated. On the other hand, with a larger sampling, it is possible that the outliers would not have been outliers but that a 
better curve would have formed. The topic of participants is an important one - any future study that seeks to use participants needs to closely examine where the participants will come from. Had this simply been a survey without the preceding exercise, it is likely that there would be more participants; however, with just a survey, there would not have been a way to know if the participants would, in fact, like what they say they liked.

As a follow-on to the survey, it is recommended that instead of a web-based KMS with follow-on survey that a web-based KMS be used but interviews be conducted afterwards to gain the most. This will require more time of the participants and will likely be more challenging to acquire participants. Thus, plan ahead. This study initially sent out requests to five large companies with no responses. The researcher must askdoess this company want to be involved with this study? If the answer is no, what is the fallback plan? If a study utilizes participants, getting the participants WILL be a major challenge.

Close examination of the framework is recommended for future studies as the framework could determine success and/or failure. While the framework used within this study met the study needs, it could have been better. Specifically, the framework had to be modified three times throughout the study. This researcher felt that each phase of the exercise would be clear to the participants. As it turned out, very few initial participants understood what was being asked of them, even with an example for each area and this was in an area where participants had expertise. A test group was used prior to the KMS going live online; however, as it turned out, the test group was too limited. If the framework is poor then expect to get poor results even if the concept is good. It is 
believed that were the framework better designed, results, even though good, might have been better.

It is also recommended that evaluation be made between text and voice for the telling of stories. This cannot be emphasized enough. Each has its benefits and drawbacks. Text is easy to edit and takes up far less space than audio files. However, if the participant isn't a fast typist or their grammar is poor then that could affect the result. This may very well be frustrating and a deterrent. Speaking is natural and many people have no issues with talking; however, if a participant hears what they recorded and wants to make changes - how will that occur without affecting the complete story? What if they have an accent - will they be understood? If they have to rerecord a portion, will it synch well with the unchanged portions? These are just some of the challenges that further studies should investigate.

Another limitation was the region in which the study occurred - it was limited to the United States and, not surprisingly, most technology participants either work in the east or west coast. Out of all 28 participants (including the seven who dropped from the study), $77.78 \%$ fell in either the west coast or east coast which included northwest, southwest, northeast and southeast. It is doubtful that this would have been overcome with more participants as the major technology industries are in the east and west coasts. Perhaps expansion outside the United States would be beneficial.

\section{Summary}

The collection of tacit knowledge is critical to businesses. Collecting tacit knowledge is critical whether to gain the knowledge of departing employees, from employees moving from one area to another, or perhaps to bring together employees 
located in different regions of a country or world. A situation occurs and an employee with expertise that few have comes up with an innovative solution. How is that information communicated such that other employees will a) be able to find it if the same or similar situation occurs in the future, b) be able to implement what was implemented before, and c) will understand it? The knowledge management system or KMS is the place most employees will go. Unfortunately, the information is not likely to be presented in a format that most employees will feel comfortable with. That's where the storytelling-based approach can help. Telling stories does not mean telling fiction. It means being truthful and telling what happened, the result of what happened, how the solution was determined, i.e. the thought process, what was done, how it was implemented, what the results were, etc. Telling this as a story helps those who need that information understand it. That was the purpose of this study. Two of three propositions were successful. The third, forums, not a main aspect of the study, was not successful; however, an interview process may have highlighted why it wasn't successful. As it was, most of the responses were 'no change' and then there were several respondents who stated they had never used a forum. In hindsight, an explanation of what a forum is might have changed that.

\section{Appendices}

Appendix A Waiver of Documentation of Informed Consent

Appendix B Study Information Sheet

Appendix C Participant Data and Survey

Appendix D Story Guiding Questions

Appendix E Actual Story Example

Appendix F Participant Response Scoring 
Appendix G KMS Screen Captures

Appendix H Survey Code Book

Appendix I Framework BPMN Model 


\title{
Appendix A Waiver of Documentation of Informed Consent
}

\author{
Waiver of Documentation of Informed Consent for Participation in the Research Study \\ Entitled
A Knowledge Management System (KMS) Using a Scenario and Solution-Based Storytelling Approach to Collect Tacit Knowledge

Funding Source: None

IRB protocol \# 12021407Exp

Principal investigator

Co-investigator

Nicholas Shaw, MS

Peixiang Liu, PhD

18952 N. Elbert Road

3301 College Avenue

Elbert, CO 80106-9401

Fort Lauderdale, FL 33314

(303) 880-3654

(954) 262-2088

For questions/concerns about your research rights, contact:

Human Research Oversight Board (Institutional Review Board or IRB)

Nova Southeastern University

(954) 262-5369/Toll Free: 866-499-0790

IRB@nsu.nova.edu

Site Information

Nova Southeastern University

Graduate School of Computer and Information Sciences

3301 College Avenue

Fort Lauderdale, FL 33314

\section{What is the study about?}

You are invited to participate in a research study. The goal of this study is to understand if domain experts will be willing to share their tacit knowledge (knowledge gained through experience) using a storytelling-based approach.

\section{Why are you asking me?}

You are being invited to participate in this study due to your expert knowledge in the community of practice (CoP) of Information Technology (IT). This expert knowledge could be in servers (includes operating systems and virtualization), storage, networking, cloud, and requirements gathering/analysis. Upon completion of the study, all data will be removed from the online system.

\section{What will I be doing if I agree to be in the study?}

First, your communications to the principal investigator will be by the personal email you used to express interest in participating in this study. The purpose of an outside email 
address is for direct communications between you and the principle investigator throughout the study and to prevent the principle investigator from knowing what company you work for. You are reading this waiver of consent on the experiment and questionnaire web site. You are required to do nothing as far as acknowledgement goes; however, you will be given the opportunity to view this waiver each time you enter the system - you can elect not to view it but it is always available for you to view should you so desire.

Upon receipt of your desire to participate, you were provided, to your personal email address, a three-page document that describes the study, a one-page document asking for information about you, and a User Guide on use of the Knowledge Management System (KMS); the link (URL) to the KMS to begin the experiment was provided upon receipt of the personal information and the creation of your account on the KMS. At the conclusion of the experiment, i.e. when you elect not to enter any more stories, you will be taken to a short electronic questionnaire where you will provide input regarding your experiment experience.

The information the study collects on you is your name, a location region that breaks the United States into several regions, an age range such as 18-30, your gender, and how long you have been at your current company (at no time will you be asked what company you work for). The questionnaire seeks to understand any changes in opinion based upon past experience and this experiment. The questionnaire covers KMS', stories, forums, and other aspects of the experiment.

During the experiment phase, communications between you and the principle investigator regarding your stories will occur directly within the KMS. The mechanism is use of a fake email address that only functions within the KMS. An example is $247 @ \mathrm{kms} . c 0 m$. The numbers are not sequential but random and all KMS emails end in kms.com. This email address is for KMS collaboration between yourself and the principle investigator who will review all submitted stories. All correspondence is private between you and the principle investigator; it is person-to-person and not visible to anyone else.

Stories are based upon the completion of a series of questions and text boxes within the KMS. When all text boxes are completed, they are integrated by the KMS into a single element that constitutes your story. You will then have the opportunity to review the completed story and make changes before it goes to the principle investigator for review. Once the review is completed, your story will be made available (published) within the KMS. The review has two purposes - is it understandable and is there too much extraneous information that takes away from the story, i.e. this is a story of an issue or lesson learned. Your name will not be attached to a story, only your User ID (UID). At the end of the experiment with the KMS and questionnaire, you are done.

\section{Is there any audio or video recording?}

This study does not include any interviews and, thus, there are no digital audio or video recordings of any type. 


\section{What are the dangers to me?}

Risks to you are minimal, meaning they are not thought to be greater than other risks you experience every day. Sharing your opinions about your experience using the KMS as well as your thoughts on what should be different is important. If you have questions about the research or your research rights, please contact Mr. Shaw at ns201@ nova.edu. You may also contact the IRB at the numbers indicated above with questions about your research rights.

\section{Are there any benefits to me for taking part in this research study?}

There are no direct benefits to you for participating; however, if you are a current user of a KMS, the outcome of this research could result in a better KMS experience for you in the future.

\section{Will I get paid for being in the study? Will it cost me anything?}

There are no costs to you except your time. It is anticipated that the study will take less than an hour (experiment + questionnaire); however, you may contribute as many stories as you wish. You will receive no payments for participating in this study.

\section{How will you keep my information private?}

This study collects your name, a personal email address, an age range, a region where you reside, how long you have worked at your current company (you will never be asked what company you work for), and your gender. Your age range, region where you live, and your gender will be used for statistical purposes only. For example, there were 50 Participants with 25 being male and 25 being female with the following regional and age range breakout; standard statistical methods will be used such as the mean, the standard deviation, and the standard error.

The study consists of three distinct and disconnected databases. The first database contains your UID and the stories you create and has Internet access for the experiment. The UID is the manual link between the experiment database and the personal information database. The third database is on the Internet and contains your responses to the questionnaire. The personal information database is not connected at all to the Internet - it has no wireless, wired, or other capability. It contains your UID to manually link between the experiment and user information databases, your name, your age range, the region where you live, and your gender. No one will have access to your name and personal email address except, as noted above, the principle investigator, the IRB and the committee chair. The experimental KMS will not ask you for any personal information. Linkage between the experiment and personal information databases is purely manual using the UID, i.e. the principle investigator takes your UID from the experiment database and manually searches the personal information database.

All study data will be maintained for 36 months following the end of the study. Following the study, all data, except for the stories themselves, will be encrypted for 36 months. At the end of the 36-month period, all encrypted data will be deleted using a deletion program that places 0 s and Xs three times to ensure the data cannot be 
recovered. However, stories will be retained. The stories cannot be linked to any individual as there are no names or email addresses, etc. in the experiment database only a meaningless numerical UID. The stories may be utilized in future research. All information obtained in this study is strictly confidential unless disclosure is required by law. The IRB, regulatory agencies, or Dr. Liu may review research records.

\section{What if I do not want to participate or I want to leave the study?}

You have the right to leave this study at any time or refuse to participate. If you decide to leave or you decide not to participate, you will not experience any penalty. If you choose to withdraw, any information collected about you before the date you leave the study will be kept in the research records for 36 months from the conclusion of the study and may be used as a part of the research. Should you decide to quit the study, simply send an email to the principle investigator and say you are quitting. There is no requirement to state why and the principle investigator will not query you further. You will simply be marked as dropped from the study.

\section{Other Considerations:}

If the researcher learns anything which might change your mind about being involved, you will be told of this information. This should not be considered as information to keep you in the study but potential information that may lead you to quit.

\section{Voluntary Consent by Participant:}

By continuing to the experiment and questionnaire, you indicate that

- You have read the above and understand the nature of the study

- Your questions about this research study have been answered

- You understand that you may ask the researchers any study related questions in the future

- You understand that you may ask Institutional Review Board (IRB) personnel questions about your study rights

- You understand that you are entitled to a copy of this form

- You voluntarily agree to participate in the study entitled A Knowledge Management System (KMS) Using a Storytelling Approach to Collect Tacit Knowledge 


\section{Appendix B Study Information Sheet}

I am Nicholas Shaw, a Doctoral Candidate at Nova Southeastern University in the Computer Information Systems program within the College of Engineering and Computing. I have completed my Proposal and am in the experiments stage of my dissertation. My research is in knowledge management systems (KMS'). Specifically, my research is in the collection of tacit knowledge from participants who place their knowledge into a KMS using stories.

This information sheet explains the study. The study uses a Waiver of Consent to Informed Consent. When you enter the experiment web site, you will be provided a link to view the Waiver of Consent to Informed Consent. You can read it or not but it is always available to you. Think of the consent form as a study FAQ of your rights as a participant in the study - I highly recommend reading it. The consent form provides additional contacts should you wish additional information. If you choose not to read the Waiver of Consent, then you will be taken directly to the experiment. If you choose to read the Waiver of Consent, then you will be taken to the experiment afterwards. You can always go back to the Waiver of Consent; you will be asked if you wish to view it each time you enter the program. This study implemented a limited-use, web-based, KMS designed specifically for the study. Limited-use means it isn't production ready and can't really be used in a non-study environment; its sole purpose is to answer the study propositions. You can begin creating stories now. I suggest reading the User Guide (it's very short) as there are some quirks in the system and this will explain any workarounds. For the experiment, you are only asked to complete one story; however, you may complete as many as you wish. Completing more than one story will ensure 
that learning the KMS interface is not a detractor. The user interface and the creation of stories is fairly straightforward. After you complete one story, you can create more if you wish or if you are done with the experiment, you simply select 'Done' in the experiment and you will be taken to the questionnaire. When you are done with the questionnaire, you are done as a participant and I will send you an email thanking you for your participation. The questionnaire covers three areas - stories and tacit knowledge, forums, and other aspects of the experiment. With the exception of one question that is a yes/no question, all questions are multiple choice with only one answer.

\section{Overview}

There are two types of knowledge - explicit and tacit. Explicit knowledge is that which you can read, see, feel, touch, and print. Explicit knowledge is that type of knowledge that exists in SharePoint, on your hard drive, or a book - you can go back and reference it. Everything on the Internet is Explicit knowledge. Tacit knowledge, on the other hand, is knowledge that you have learned over time, it is your experiences and it is stored in your head. As you go through life, you encounter situations and learn from them. Companies want to tap into what you have learned in order to make that knowledge available to others. Research supports what you already know - in general, people are willing to pass their knowledge to others who ask (direct knowledge transfer) but are less willing to provide that same knowledge into a KMS (indirect knowledge transfer).

Most people have, at one time or another, used stories to convey a point. You use stories to teach lessons to others that you've learned whether for the job or in your personal lives. The fundamental problem with $\mathrm{KMS}^{\prime}$ is the approach. KMS' typically use a problem/resolution format, i.e. what was the problem and how was it resolved. 
This study considers the transference of tacit knowledge into a KMS differently the approach uses stories that are input directly into the KMS by the holders of the information. The use of stories in KMS' is not new. In the past, stories were collected through interviews and the data placed into a KMS by the interviewers. This is neither cost effective or efficient.

The creation of stories is controlled through a framework to ensure that the participant provides as much information as possible and that the reader gains sufficient knowledge from the story to determine if the solution or lesson in the story is applicable to their needs. The start of a story is the selection of a domain/subdomain pair. An example of a domain/subdomain pair is decommissioning (domain) and servers (subdomain) - a very broad topic. Once a participant selects the domain/subdomain pair for the story, i.e. the area in which the story is about, they then answer 'guiding questions' that are based upon the domain and subdomain pair. 'Guiding questions' provide information that might otherwise be left out, i.e. information that a participant might assume that a member of the same Community of Practice (CoP) would understand. A CoP is a grouping of people with a mutual shared interest such as systems administrators or database administrators. For this limited-use KMS, the CoP is Information Technology which is, again, very high level. An example of a guiding question is a story about migrating servers from one location to another. The participant might not mention that the migration occurred across multiple data centers. Thus, in anticipation of this potential scenario, one guiding question might be how many data centers were involved. Guiding questions simply help put a story into a frame of reference and context for the user. In real life, it is anticipated that a Contributor will provide their knowledge soon after an event has occurred thus resulting in potentially 
more extensive guiding questions; however, in this study, it is likely that the events are not current. As a result, the guiding questions are limited to what Participants will hopefully remember.

The lessons learned and problems of a KMS are not typical of what is provided in, for example, a forum. Forums typically deal with what I term 'micro' or 'point' knowledge, i.e. very narrow or short-term knowledge such as helping someone with a piece of code or buying something that does x. Some data in forums can be considered 'macro' knowledge that others may wish as well but it is generally shorter term. Other challenges with forums are searching for usable information and the discussion style of forums that often degrades or moves off topic. 'Macro' knowledge is what is typically captured within KMS', i.e. the knowledge is long-term.

What companies desire from their KMS' is to successfully get employees to want to place their tacit knowledge into a KMS thereby making the knowledge explicit and available to others. Sharing of your tacit knowledge makes you valuable. You will never provide all of your tacit knowledge; you will only tap into a very small amount as situations occur.

The study KMS is a web-based application. Once you are provided the URL, you will have immediate access and up to 120 days to enter, review, and post stories; however, you can complete the experiment and questionnaire in less than an hour with one story. In fact, you can complete a story in less than thirty minutes depending upon the topic. The questionnaire will help my study determine, based upon your responses, if the storytelling approach is viable. You may wonder why the stories are written versus audible. There were pros and cons to each but ultimately, I felt it was better to use writing as it is easier for the user to correct and update their contributions. 
There are three databases - the experiment and questionnaire databases that are Internet-connected and the personal information database that is non-Internet-connected, i.e. no access to the Internet through wired, wireless, or other means. The questionnaire database stores your responses to the questionnaire. The User ID (UID) is used to manually link between the experiment and personal information databases. The experiment database is used for your stories. I collect and store in the personal information database your name, personal email address, an age range such as 18-30, a region where you reside, how many years you have worked at your company (I do not want to know what company you work for), and your gender for statistical purposes, i.e. I'll break down participants in the study by age groups, by region, and by gender. An example is there were 50 Participants of which 30 were males and 20 were females with an age breakdown range of 20-30, 30-40, etc. Your personal email address is only stored in the non-Internet-connected database. The purpose of names and email addresses is to enable the Institutional Review Board (IRB) and my committee to validate that participants are real; the IRB may also check to ensure that no one in the study was coerced. Congress, in order to prevent abuse with human subjects, created in law certain protections for subjects in experiments. Universities implement these protections through IRB's.

An internal system email address will be used for collaboration between you and me while in the KMS experiment - it cannot be used outside the KMS. The email addresses stored in the KMS are fake. An example is $\underline{123 @ \mathrm{kms} . c o m}$. The 123 would be your UID.

There are no interviews for this study and, thus, no recordings made of any type. 


\section{Appendix C Participant Data and Survey}

The following participant information is only this one page and is used strictly for statistical purposes, i.e. providing in the research a breakout of participant data. An example is of 70 participants, 50 were male and 20 were female. 40 participants came from the northeast, etc. While I am not interested in what company you work for, how long you have worked at your current company is of interest. An example might be of 70 participants, $82 \%$ have been at their current company for less than 5 years while $15 \%$ have been at their current company 5 years or more, and $3 \%$ have been at their current company for less than 1 year. Will this affect the outcome of the research? No, however, it may be of interest in future research on the same topic, e.g. perhaps the next researcher will seek participants with a different mix.

For one story, please complete the entire participant information followed by the survey.

For multiple stories, please put in your participant number only then complete the survey.

Participant Number: (the number you were given when you were signed up)

Participant Profile: $\quad$ Age Range: $\quad 18-30 \_31-40 \_41-50 \_51-60 \_$_ $61+$ Gender: Male Female

Region:

(1) Northwest (Washington, Oregon, Idaho, Montana, and Wyoming)

(2) West (California, Nevada, Utah, and Colorado)

(3) Southwest (Arizona and New Mexico)

(4) North Central (North Dakota, South Dakota, Minnesota, and Wisconsin)

(5) Central __ (Nebraska, Iowa, Illinois, Kansas, and Missouri)

(6) South Central ___ (Oklahoma, Arkansas, Texas, and Louisiana) 
(7) Northeast __ (Maine, Vermont, New Hampshire, Massachusetts, New York, Connecticut, Pennsylvania, New Jersey, Delaware, Maryland, Ohio, Indiana, and Michigan)

(8) East Central __ (Kentucky, Tennessee, West Virginia, Virginia, and North Carolina)

(9) Southeast ___ (Mississippi, Alabama, Georgia, South Carolina, and Florida)

Years at company: 


\section{SHARING OF KNOWLEDGE and STORYTELLING}

1-1. Based upon this limited study, my opinion regarding my willingness to provide my tacit knowledge into a KMS has improved.

I significantly agree

I somewhat agree

My opinion has not changed

I somewhat disagree

I significantly disagree

1-2. The storytelling-based approach contributed to my willingness to provide my tacit knowledge into a KMS.

I significantly agree

I somewhat agree

My opinion has not changed

I somewhat disagree

I significantly disagree

1-3. The storytelling-based approach is a better mechanism to communicate information into a KMS than the problem/resolution format typically used in KMS.

I significantly agree

I somewhat agree

My opinion has not changed

I somewhat disagree

I significantly disagree

1.4. I enjoyed the process of creating stories.

I significantly agree

I somewhat agree

My opinion has not changed

I somewhat disagree

I significantly disagree

1.5. I felt like the storytelling-based approach allowed me the ability to tell it like it happened. 
I significantly agree

I somewhat agree

My opinion has not changed

I somewhat disagree

I significantly disagree

1.6. After reviewing my story, I felt like it needed a lot of work and I didn't want to put that time in.

I significantly agree

I somewhat agree

My opinion has not changed

I somewhat disagree

I significantly disagree

1-7. I would prefer to use audio to tell my stories versus writing my stories out.

I significantly agree

I somewhat agree

My opinion has not changed

I somewhat disagree

I significantly disagree

1-8. The storytelling-based approach allowed me more flexibility to tell what happened in my own way, in a way that my peers will understand.

I significantly agree

I somewhat agree

My opinion has not changed

I somewhat disagree

I significantly disagree 


\section{SCENARIOS, SOLUTIONS, and COPS}

2-1. I like a KMS that is based upon scenarios and solutions. A KMS that uses solutions is one where you are providing a solution to a specific issue that is likely to be encountered by others in the future. A scenario is the background that led to the issue.

I significantly agree

I somewhat agree

My opinion has not changed

I somewhat disagree

I significantly disagree

2.2. I like using domains and subdomains to segment/catalog data in a KMS

I significantly agree

I somewhat agree

My opinion has not changed

I somewhat disagree

I significantly disagree

2-3. The use of multiple levels of domains and subdomains reduces the need to perform searches.

I significantly agree

I somewhat agree

My opinion has not changed

I somewhat disagree

I significantly disagree

2-4. Guiding questions help improve the clarity of a story. Guiding questions provide the reader more information about something to help them place something into context or provide greater insight into what was done or why. An example is provisioning 10 servers - were they all provisioned in the same data center or in multiple data centers. Each has different issues and the reader may want to know which so they can place the solution into context.

I significantly agree

I somewhat agree

My opinion has not changed

I somewhat disagree

I significantly disagree

2-5. I like the use of communities of practice (CoP) as they help me go to an area of shared interests and where it is more likely that I'll find answers to my questions. 
I significantly agree

I somewhat agree

My opinion has not changed

I somewhat disagree

I significantly disagree

2-6. Solutions and scenarios work well with a storytelling-based approach.

I significantly agree

I somewhat agree

My opinion has not changed

I somewhat disagree

I significantly disagree 
3-1. Have you ever participated in a forum? $\quad$ Yes $\square$ No $\square$

If you have never participated in a forum, you are done!

3-2. I enjoy providing my tacit knowledge into a forum.

I significantly agree

I somewhat agree

My opinion has not changed

I somewhat disagree

I significantly disagree

3-3. I like providing my tacit knowledge in a forum more than a KMS.

I significantly agree

I somewhat agree

My opinion has not changed

I somewhat disagree

I significantly disagree

3-4. The freeform writing structure of providing tacit knowledge in a forum is better than the problem/resolution format of a KMS.

I significantly agree

I somewhat agree

My opinion has not changed

I somewhat disagree

I significantly disagree

3-5. The quality of information in a KMS is higher than the quality of information usually found in forums.

I significantly agree

I somewhat agree

My opinion has not changed

I somewhat disagree

I significantly disagree 


\section{Appendix D Story Guiding Questions}

Most of the questions are logical tests, i.e. yes or no. Ergo, so questions must be answered while others depend upon the previous answer, i.e. if/then constructs.

\section{DOMAIN: Migration}

\section{Subdomain: Application and/or Database}

- The application and/or database was mission critical, i.e. it was in some form of high availability: Yes/No

- The type of redundancy was:

○ Failover Cluster

○ Load-Balanced(LB) Cluster

- High Performance Computing (HPC)

- Internal Database High Availability (such as Oracle RACK)

○ N/A

- RAID was implemented: Yes/No

- The type of RAID was:

- RAID 0 (Stripping)

- RAID 1 (Mirroring

- RAID 5 (Software Mirroring)

- RAID 10 (Mirroring and Striping)

- RAID 50 (Software Mirroring and Striping)

- The database implemented encryption: Yes/No

- The database was migrated to on premise servers: Yes/No

- The database was migrated to the cloud: Yes/No

- Migration was to production: Yes/No 


\section{Subdomain: Data Center Migration ${ }^{7}$}

- Number of total Data Centers:

- Number of Data Centers going away:

- Mission Criticality Questions and Failover:

- Swing Servers were Required: Yes/No/Unknown

- Disaster Recovery (DR) sites had to be realigned (closing DC's had DR at the to-be DC): Yes/No/Unknown

- DC consolidation was to Owned data centers: Yes/No/Unknown

- DC Consolidation was to commercial cloud: Yes/No/Unknown

- Server/Mainframe numbers (as best you recall):

○ Number of UNIX servers migrated:

- Number of UNIX servers eliminated:

○ Number of Linux servers:

- Number of Linux servers eliminated:

○ Number of Windows servers:

○ Number of Windows servers eliminated:

○ Number of mainframes:

○ Number of mainframes eliminated:

- Number of other operating systems (such as real-time operating systems (RTOS)):

○ Number of storage enclosures:

\footnotetext{
${ }^{7}$ Migrate existing hardware and/or application systems to one or more different data centers such as a result of a data center consolidation effort.
} 
- Number of storage enclosures eliminated:

- Vendor Support Questions

○ Vendor packaged the servers: Yes/No/Unknown

○ Vendor shipped the servers: Yes/No/Unknown

○ Vendor parts were on-site in case of need: Yes/No/Unknown

○ Did vendor install in new data center: Yes/No/Unknown

\section{Subdomain: Servers}

- The servers were considered mission critical: Yes/No/Unknown

- Servers were migrated from a development to a test environment: Yes/No/Unknown

- Servers were migrated from a test to a production environment: Yes/No/Unknown

- Servers were physical servers: Yes/No/Unknown

- Servers were virtual servers: Yes/No/Unknown

- Servers were migrated to on premise data centers: Yes/No/Unknown

- Servers were migrated to the commercial cloud: Yes/No/Unknown

- Number of UNIX servers migrated:

- Number of Linux servers migrated:

- Number of Windows servers migrated:

- Number of other operating systems (such as RTOS) migrated:

- Vendor parts were on-site in case of need: Yes/No N/A Unknown

\section{Subdomain: Storage}

- Primary storage use was for:

- Storage Area Network (SAN) 
○ Network Attached Storage (NAS)

○ Direct Attached Storage (DAS)

○ Tape backup

○ Unknown

\section{Subdomain: System Software}

- The software was installation of a new operating system: Yes/No

- The software was an operating system update: Yes/No

- The software was installation of tools to monitor/manage systems: Yes/No

- The software was an update of tools to monitor/manage systems: Yes/No

- The software was installation of a database instance: Yes/No

- The software was installation of a database update: Yes/No

- The software was installation of a virtual server: Yes/No

- Migration was to system software on premise: Yes/No/Hybrid

- Migration was to system software in the cloud: Yes/No/Hybrid

- A backup was performed if the migration was an update, upgrade, or patch: Yes/No/Unknown

\section{DOMAIN: Provisioning}

\section{Subdomain: Cloud}

- Cloud Service Model: IaaS/PaaS/SaaS

- Type of Cloud: Public/Private/Community/Hybrid

- Data contained sensitive information (PII and/or PCI): Yes/No/Unknown

- An alternate disaster recovery (DR) site was included: Yes/No/Unknown

- Had a broker: Yes/No/Unknown 
- Number of cloud service providers:

- Defined availability requirements/service level requirements (SLA): Yes/No/Unknown

\section{Subdomain: Networks}

- Make of network device is:

- Model of network device is (if you know it):

- Device purpose is: Router/Switch/Hub/Access Point (AP)/Other

- Network Protocol is: IPv4/IPv6/Both

- Network speed is: $100 \mathrm{Mb} / 1 \mathrm{~Gb} / 10 \mathrm{~Gb} / 100 \mathrm{~Gb} / \mathrm{Other}$

- Network wireless type is: $802.11 \mathrm{a} / 802.11 \mathrm{~b} / 802.11 \mathrm{~g} / 802.11 \mathrm{n} / 802.11 \mathrm{ac} / \mathrm{N} / \mathrm{A}$

- Network topology is: Bus/Star/Ring/Hub/Mesh/Tree

- Auto provisioned? Yes/No

\section{Subdomain: Servers}

- Server make is:

- Server model is (if you know it):

- Servers were auto-provisioned: Yes/No/Unknown

- Default credentials were changed: Yes/No/Unknown

- Server was provisioned with a database image: Yes/No/Unknown

- Server was provisioned with an application image: Yes/No/Unknown

- Server was provisioned with a developer's image: Yes/No/Unknown

- Server was provisioned with a web-server image: Yes/No/Unknown

- Server was provisioned with a web-client image: Yes/No/Unknown

- Server was provisioned with a different (other) image: Yes/No/Unknown 
- Server was a VM: Yes/No/Unknown

\section{Subdomain: Storage}

- Make of storage:

- Model of storage (if you know it):

- Storage was auto-provisioned: Yes/No/Unknown

- Default credentials were changed: Yes/No/Unknown

- Storage was configured as storage attached network (SAN): Yes/No

- Storage was configured as network attached storage (NAS): Yes/No

- Storage was configured as direct attached storage (DAS): Yes/No

\section{Subdomain: Virtualization}

- Virtual technology: VMware/KVM/Hyper-V/Xen/Other

- Installed as bare metal server: Yes/No

- VM type: Server/Client

- Users can create virtual machines (VM): Yes/No

- Users can manage virtual machines (VM): Yes/No

\section{DOMAIN: Design System}

\section{Subdomain: Hardware/Software}

- Written requirements were provided: Yes/No

- A meeting with all potential participants occurred to discuss the requirements: Yes/No

- This project was a: In-house Build/Contractor Build/Commercial-off-the-shelf (COTS)

- Requirements led to a Request for Proposal (RFP): Yes/No/Unknown 
- A production pilot was performed prior to going into production: Yes/No/Unknown

- A separate analysis step occurred after requirements gathering: Yes/No/ N/A if external contractor or COTS

- Following analysis, detailed design occurred that included models, design instructions, etc.: Yes/No/ N/A if external contractor or COTS

- Choose the primary development model used: Waterfall model/Prototyping model/ Rapid application development (RAD) model/Incremental model/Spiral Model/ Agile Model/Formal methods model/ N/A if external contractor or COTS

- A non-production test environment was developed: Yes/No/Unknown

\section{DOMAIN: Decommission}

\section{Subdomain: Application}

- The application processed sensitive data such as personally identifiable information (PII): Yes/No

- Sensitive data was scrubbed from storage devices: Yes/No/ N/A

- The application was on a virtual server: Yes/No

- The application was on a physical server: Yes/No

- Number of data centers involved:

\section{Subdomain: Servers}

- A license recovery search was done for potential reutilization: Yes/No/Unknown

- A virtual server (VM) was decommissioned: Yes/No

- A physical server was decommissioned: Yes/No

- How many servers were decommissioned?

- Number of data centers involved:

- All interfaces were identified: 


\section{Subdomain: Storage}

- A license recovery search was done for potential reutilization: Yes/No/Unknown

- Sensitive data was scrubbed from storage devices: Yes/No/ N/A

- SAN storage was decommissioned: Yes/No

- NAS storage was decommissioned: Yes/No

- DAS storage was decommissioned: Yes/No

- Number of data centers involved:

- Backup processes were deregistered: Yes/No/Unknown 


\title{
Appendix E Actual Story Example
}

\section{This is an approximately $85 \%$ screen capture of an actual story that was created}

\author{
during the testing of the KMS. At the top are the questions and answers to the guiding \\ questions followed by the story.
}

The application processed sensitive data such as Personally Identifiable Information (PII): Yes

Sensitive data was scrubbed from storage devices: Yes

The application was on a virtual server: Yes

The application was on a physical server: No

Number of data centers involved: 1

An application was no longer necessary. We weren't replacing it with something else, technology just overcame the need to have the application. This application processed sensitive PII data so we needed to make sure that no data remained on any of the storage devices that house the data for the application and we needed to make sure that all backup data that contained the sensitive information was also scrubbed. Our backup data resided both on our local backup systems (local and DR) as well as at the Iron Mountain facility for redundancy. We also had to notify all of the users of the application that it was going away as well as ensure that there were no other applications running within the virtual server (VM) where the application resided. These efforts took us quite a bit of time.

Since this wasn't a real problem but a decommissioning, we didn't really have to try anything; however, once we got rid of all the data on disk and on tape, we discovered that Federal law required that we keep the data for seven years. There was no way to unscrub the data as we over wrote the disks and tapes with ones and zeros thus completely destroying all data on the media.

There were no obstacles to accomplishing this decommissioning except time. We wanted to decommission the application and remove the VM server so we could free up resources to install another application and VM. Thus, we didn't necessarily do all of our due diligence (like ensuring we maintained the data for seven years in accordance with Federal law).

The negative impact was we are in violation of Federal law. We had to prepare a memo to the Federal agency responsible for oversight and explain what we did and why. Investigators came to our facility and inspected everything. They then considered what punishment our Agency would receive for failing to follow law. In the end, we were penalized $\$ 1,000,000.00$ which was a significant financial impact to us. Our Agency turned around and fired the manager, senior systems administrator, and senior storage administrator.

The key lesson learned was know your data, i.e. know what data is protected data by law. The second lesson was don't let time be the driver of your activities, i.e. if you're in a rush, it's likely that you will miss something and it could lead to your dismissal. What we did following that decommissioning was to establish strict processes and procedures for decommissioning. One of the key requirements we instituted was to check with the records manager before any data is removed from any system. The second thing we did was separate the Iron Mountain data from the local and DR data. What this meant was we weren't allowed to touch the Iron Mountain data until another party did an assessment on the data it contained. This was, again, to ensure we didn't violate some Federal law and had no way of coming back from it. 


\section{Appendix F Participant Response Scoring}

Table 6 below is data that was captured into a Microsoft Excel spreadsheet and stored in this table for easy inclusion into the report. Appendix F data maps precisely to the data contained in the Appendix $\mathrm{H}$ code book. This appendix shows all questions to include the participant number (P \#). Data for the six participants who dropped is not included as they did not do the survey. Table 7 is the demographic data.

Table 6 - Participant Survey Response Table

\begin{tabular}{|c|c|c|c|c|c|c|c|c|c|c|c|c|c|c|c|c|c|c|c|}
\hline \multirow{3}{*}{ P \# } & \multicolumn{19}{|c|}{ Question Responses } \\
\hline & \multicolumn{8}{|c|}{ Sharing of Knowledge and Storytelling } & \multicolumn{6}{|c|}{ Scenarios, Solutions, and COPS } & \multicolumn{5}{|c|}{ Forums } \\
\hline & $1-1$ & $1-2$ & $1-3$ & $1-4$ & $1-5$ & $1-6$ & $1-7$ & $1-8$ & $2-1$ & $2-2$ & $2-3$ & $2-4$ & $2-5$ & $2-6$ & 3-1 & 3-2 & 3-3 & $3-4$ & 3-5 \\
\hline 65 & 5 & 5 & 4 & 5 & 5 & 4 & 4 & 5 & 5 & 5 & 5 & 4 & 3 & 4 & 0 & 3 & 3 & 3 & 3 \\
\hline 67 & 5 & 5 & 5 & 5 & 3 & 4 & 3 & 5 & 2 & 2 & 1 & 4 & 5 & 5 & 1 & 3 & 4 & 3 & 3 \\
\hline 69 & 3 & 4 & 2 & 1 & 4 & 4 & 5 & 1 & 5 & 4 & 5 & 4 & 3 & 4 & 1 & 5 & 3 & 3 & 3 \\
\hline 73 & 4 & 5 & 5 & 2 & 2 & 2 & 5 & 5 & 5 & 5 & 3 & 4 & 5 & 4 & 1 & 4 & 3 & 4 & 3 \\
\hline 74 & 5 & 5 & 4 & 4 & 5 & 1 & 1 & 5 & 4 & 4 & 3 & 5 & 5 & 4 & 1 & 5 & 3 & 2 & 5 \\
\hline 75 & 4 & 4 & 4 & 4 & 5 & 2 & 2 & 4 & 4 & 4 & 4 & 5 & 4 & 4 & 1 & 3 & 3 & 4 & 4 \\
\hline 77 & 4 & 5 & 5 & 5 & 5 & 3 & 4 & 4 & 4 & 2 & 3 & 4 & 4 & 5 & 0 & 3 & 3 & 3 & 3 \\
\hline 78 & 4 & 4 & 4 & 3 & 3 & 2 & 2 & 4 & 3 & 3 & 3 & 4 & 4 & 4 & 1 & 3 & 4 & 3 & 3 \\
\hline
\end{tabular}




\begin{tabular}{|c|c|c|c|c|c|c|c|c|c|c|c|c|c|c|c|c|c|c|c|}
\hline \multirow{3}{*}{ P \# } & \multicolumn{19}{|c|}{ Question Responses } \\
\hline & \multicolumn{8}{|c|}{ Sharing of Knowledge and Storytelling } & \multicolumn{6}{|c|}{ Scenarios, Solutions, and COPS } & \multicolumn{5}{|c|}{ Forums } \\
\hline & $1-1$ & $1-2$ & $1-3$ & $1-4$ & $1-5$ & $1-6$ & 1-7 & $1-8$ & $2-1$ & $2-2$ & $2-3$ & $2-4$ & $2-5$ & $2-6$ & 3-1 & $3-2$ & 3-3 & 3-4 & $3-5$ \\
\hline 84 & 3 & 5 & 5 & 4 & 5 & 2 & 2 & 4 & 3 & 3 & 4 & 4 & 4 & 4 & 1 & 5 & 2 & 5 & 3 \\
\hline 85 & 2 & 4 & 4 & 4 & 4 & 2 & 1 & 5 & 5 & 3 & 2 & 3 & 3 & 4 & 1 & 3 & 1 & 3 & 5 \\
\hline 86 & 2 & 3 & 3 & 1 & 1 & 5 & 1 & 1 & 3 & 3 & 3 & 3 & 3 & 3 & 1 & 1 & 1 & 1 & 1 \\
\hline 89 & 3 & 4 & 5 & 4 & 5 & 2 & 2 & 5 & 2 & 4 & 4 & 5 & 4 & 4 & 1 & 4 & 2 & 1 & 5 \\
\hline 91 & 5 & 5 & 5 & 5 & 5 & 3 & 2 & 5 & 5 & 4 & 4 & 5 & 5 & 5 & 1 & 4 & 2 & 2 & 4 \\
\hline 92 & 3 & 5 & 5 & 5 & 4 & 4 & 5 & 4 & 4 & 5 & 4 & 4 & 5 & 4 & 1 & 4 & 3 & 3 & 3 \\
\hline 93 & 1 & 2 & 2 & 2 & 2 & 2 & 2 & 2 & 3 & 2 & 2 & 3 & 3 & 2 & 0 & 3 & 3 & 3 & 3 \\
\hline 94 & 3 & 2 & 2 & 3 & 4 & 2 & 2 & 3 & 3 & 2 & 2 & 2 & 3 & 2 & 0 & 3 & 3 & 3 & 3 \\
\hline
\end{tabular}

Table 7 - Demographics \& Participant Status

\begin{tabular}{|c|c|c|c|c|c|}
\hline $\begin{array}{c}\text { Completed } \\
\text { Participant } \\
\text { Number }\end{array}$ & \multicolumn{5}{|c|}{ Demographics and Participant Status } \\
\hline & P \# & Age Range & Region & Dropped & Outliers \\
\hline 1 & 64 & $51-60$ & SE & & \\
\hline 2 & 65 & $41-50$ & C & & \\
\hline & 66 & $51-60$ & E & 1 & \\
\hline 3 & 67 & $18-30$ & NW & & \\
\hline 4 & 69 & $41-50$ & NW & & \\
\hline 5 & 72 & $61+$ & SE & & \\
\hline 6 & 73 & $18-30$ & NW & & \\
\hline 7 & 74 & $51-60$ & NE & & \\
\hline 8 & 75 & $51-60$ & SW & & \\
\hline & 76 & $41-50$ & W & 1 & \\
\hline 9 & 77 & $61+$ & C & & \\
\hline 10 & 78 & $61+$ & SW & & \\
\hline & & & & & \\
\hline
\end{tabular}




\begin{tabular}{|c|c|c|c|c|c|}
\hline $\begin{array}{c}\text { Completed } \\
\text { Participant } \\
\text { Number }\end{array}$ & \multicolumn{5}{|c|}{ Demographics and Participant Status } \\
\hline & P \# & Age Range & Region & Dropped & Outliers \\
\hline 11 & 79 & $18-30$ & SW & & \\
\hline & 80 & $41-50$ & NE & 1 & \\
\hline 12 & 81 & $41-50$ & E & & \\
\hline & 82 & $18-30$ & NW & 1 & \\
\hline 13 & 83 & $51-60$ & C & & \\
\hline 14 & 84 & $31-40$ & NE & & \\
\hline 15 & 85 & $51-60$ & W & & \\
\hline 16 & 86 & $41-50$ & NE & & 1 \\
\hline & 87 & $41-50$ & SE & 1 & \\
\hline & 88 & $18-30$ & W & 1 & \\
\hline 17 & 89 & $51-60$ & E & & \\
\hline 18 & 91 & $51-60$ & SW & & \\
\hline 19 & 92 & $61+$ & W & & \\
\hline 20 & 93 & $18-30$ & SE & & 3 \\
\hline 21 & 94 & $31-40$ & C & & 1 \\
\hline & & & TOTAL & 6 & 3 \\
\hline
\end{tabular}




\section{Appendix G KMS Screen Captures}

Figure 13 is the initial screen that participants saw. If a participant had never been to the site and registered, they had to do this prior to proceeding.

\section{Figure 13 - KMS Home Screen}

\section{Knowledge Management Online System}

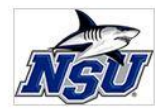

Welcome to KMOS (Knowledge management online system) a simple knowledge management system (KMS)

This is the starting point for contributing stories, reviewing stories, and finding stories. KMOS contains two fundamental uses - problem sets (lesson learned) and solution sets. Solution sets are, in the way, template based upon the solutions of others. Like problems sets, solutions sets are lesson learned but a different level. Use the menu to the top and make a selected based upon the role you wish to use during this lesson.

Should you have any difficulties or have questions relating to this study. You can contact me via email Nicholas Shaw

Dissertation in Knowledge Management

Nova Southern University

College of Engineering and Computing (CEC)

Nicholas Shaw (Doctoral Candidate) 
Once registration was complete (which collected the demographic information and where the participant created a password), they were then taken to the login screen (Figure 14) to use their credentials (email address and password).

Figure 14 - Contributor Password Screen

HOME LOGIN

\section{Welcome to KMOS.}

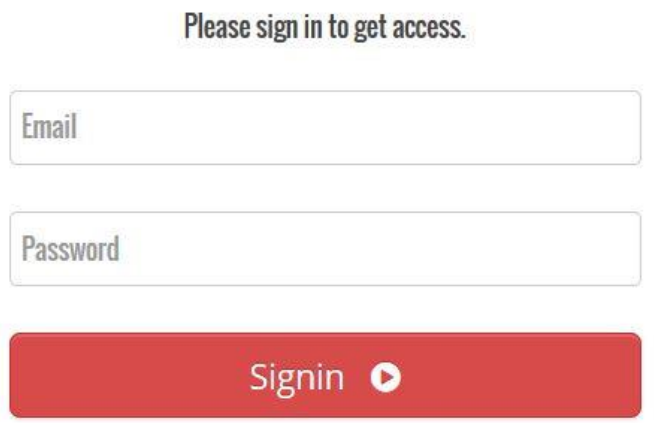


Once a contributor logged in, they were presented Figure 15 that provided them with a status of stories they had completed and the ability (under Stories) to create another story (ADD STORY), or to review all of their stories (MANAGE MY STORIES). They could also search for particular stories based upon the domain/subdomain pair, a pulldown menu. Participants log out of the system by selecting 'Log Out' in the upper right corner.

Figure 15 - Contributor Initial Screen

\section{KMOS}

Hi, (TESTER) Nicholas Shaw $\rightarrow$ Log Out

MANAGE MYSTORIES ADD STORY

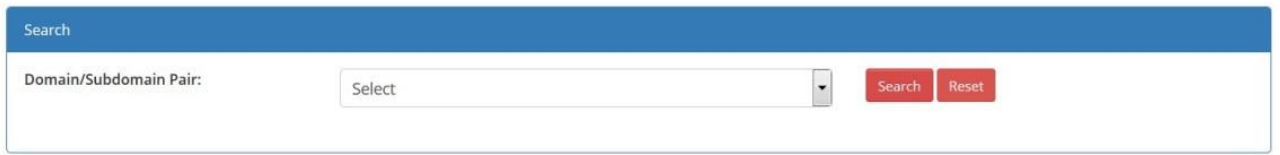

Stories

Domain Subdomain Pair

Story

Status

Search:

No data available in table 
Figure 16 is the 'MANAGE STORIES' screen where the contributor could see the status of their stories, where they could 'Edit' stories that have not been 'Published' or just view the stories they submitted.

Figure 16 - Contributor Status/Edit/View Stories Screen Capture

\begin{tabular}{|l|l|l|l|l|l|l|l|}
\hline Search & Search & Reset \\
\hline Domain/Subdomain Pair: & Select & - & \\
\hline
\end{tabular}

Stories

\begin{tabular}{|l|l|l|}
\hline Domain Subdomain Pair & Story & What is here and what is there. \\
\hline Provisioning/Servers & $\begin{array}{l}\text { We were told that we needed to provision } 15 \text { web servers for a high priority project and that the } \\
\text { servers needed to be ready within four hours. This was a major issue as there weren't enough } \\
\text { administrators to provision that many servers. I estimated, based upon past performance, that it } \\
\text { would take us about a week to provision that many servers. I briefed the Director and he said "get it } \\
\text { done". This is a priority of the CEO in order for us to compete against our major competitor. }\end{array}$ \\
\hline Provisioning/Servers & $\begin{array}{l}\text { This was a mission critical database. We implemented RAID o stripping for performance but forgot to } \\
\text { implement any form of redundancy. One night, the physical server crashed during a period when the } \\
\text { financial audits were occurring. The physical server failed over to the backup server but the } \\
\text { application data was never replicated. Thus, we had to do a complete restore of the data from tape. }\end{array}$ \\
\hline Migration/Database & $\begin{array}{l}\text { This was a time and attendance system. We thought we understood the requirements based upon a } \\
\text { written requirements document and we held meetings before preparing the request for proposal } \\
\text { (RFP); however, we failed to meet with everyone who might have valuable input, i.e. we met with the } \\
\text { non-IT customer but we didn't meet with the IT Architecture and Engineering organization and we } \\
\text { didn't meet with the network organization. As a result. we didn't consider have the reauirement that }\end{array}$ \\
\hline Design System/Software & \begin{tabular}{l} 
Vublished \\
\hline
\end{tabular} \\
\hline
\end{tabular}


Once a contributor selected to add (create) a new story, they were presented with the selection of a domain/subdomain pair. Stories relate to the selected domain/subdomain pair. For example, if a participant selected 'Decommission/Storage' then the story is about decommissioning some amount/type of storage. Figure 17 also shows the other sections in the story that are grayed out until selected.

Figure 17 - Selecting a domain and subdomain pair of a story

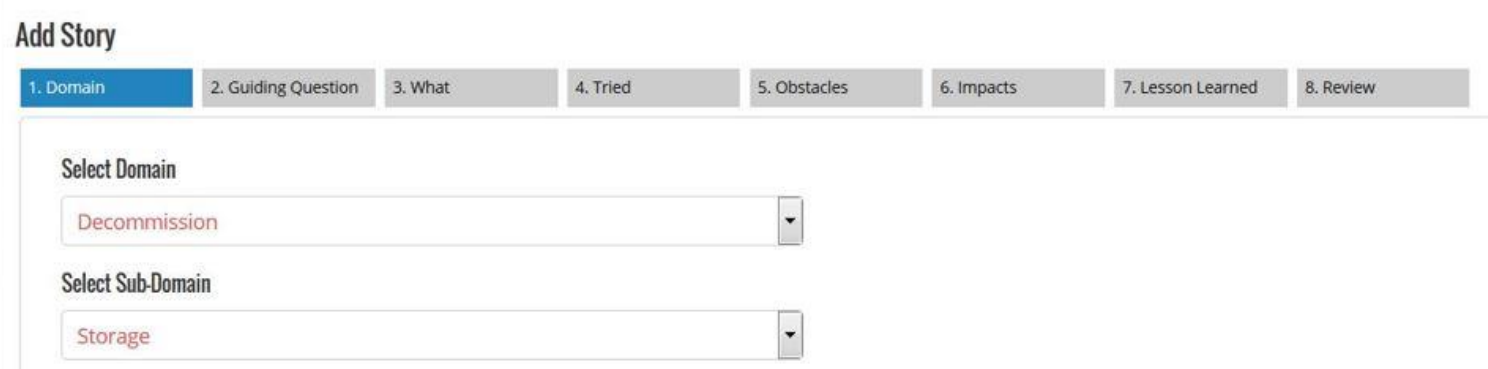


After selecting the domain/subdomain in which the story is about, the contributor will be taken to Guiding Questions (Figure 18). Guiding Questions directly relate to the chosen domain/subdomain pair. In the example below, the domain/subdomain pair is 'Provision/Servers'. As noted earlier, the amount of questions presented during the study was based upon the assumption that while the stories were true, they were not likely recent. Thus, the guiding questions were based upon what a contributor would likely remember. Note that completed tabs (sections) for creating a story are light blue while the current tab is highlighted.

Figure 18 - Answering guiding questions screen capture

\section{Add Story}

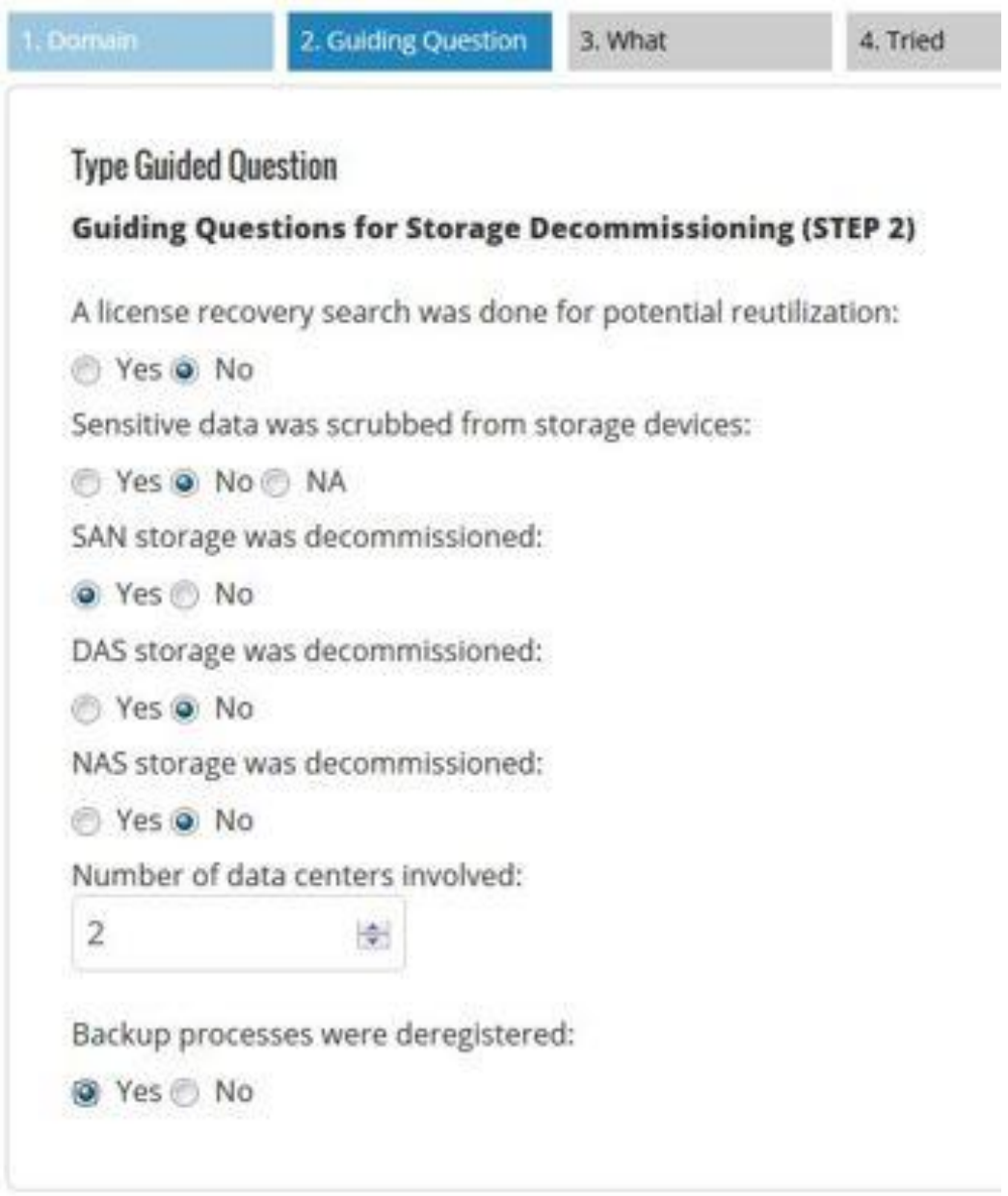


Figure 19 is an example of a participant who has gone through all of the previous tabs and is now working on 'Impacts'.

Figure 19 - Continuing the creation of a story screen shot

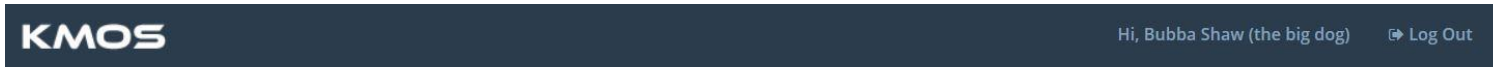

MANAGE MYSTORIES ADDSTORY

Add Story

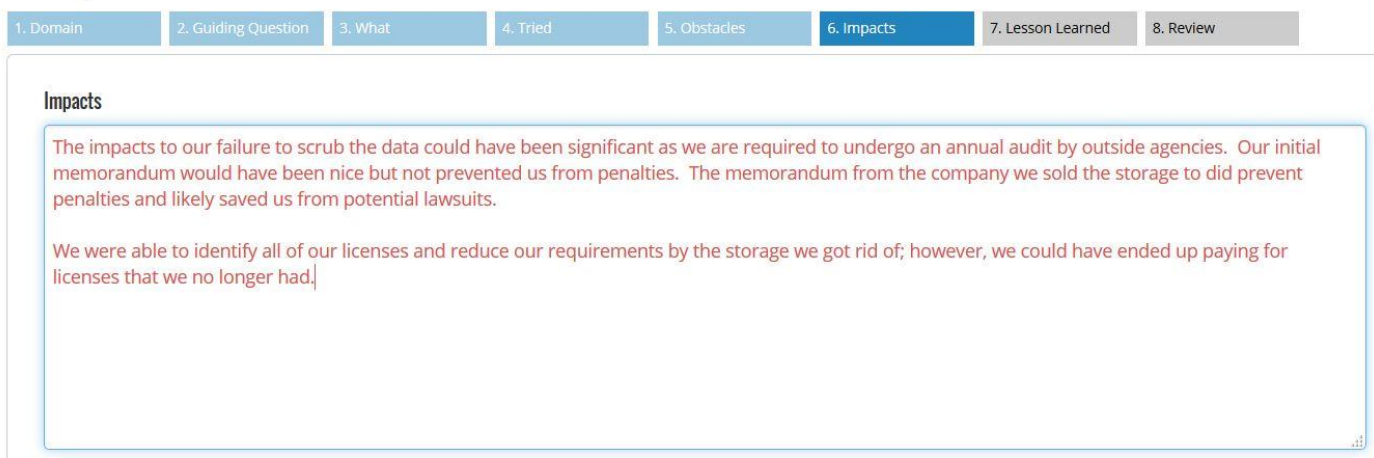


Figure 20 is an example of a contributor who has entered lessons learned.

Lessons learned are critical to this process as it provides readers with information on

what not to do, i.e. to learn from the mistakes and errors experienced by others.

Figure 20 - Lessons learned screen shot

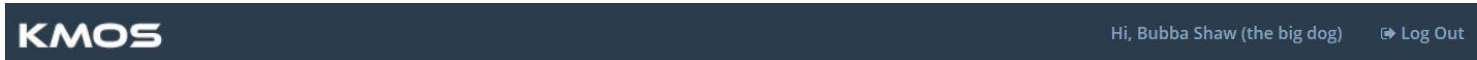

MANAGE MY STORIES ADDSTORY

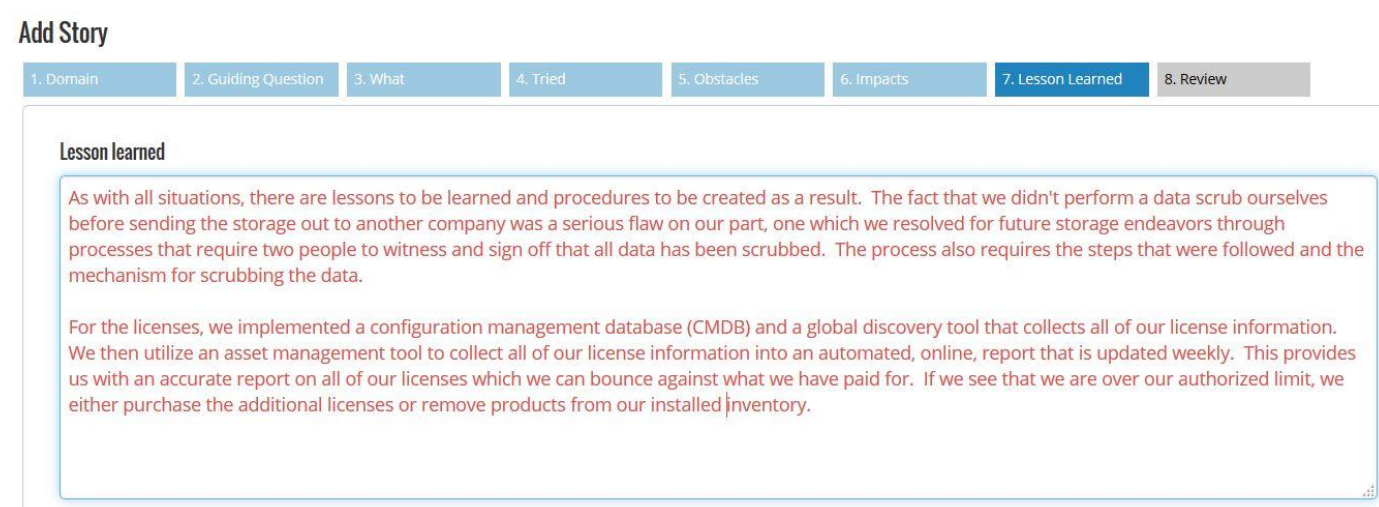


Where collaboration occurs between the contributor and the principle investigator (Reviewer), the information is in a text box next to the story. Figure 21 is an example of collaboration prior to the system being made available for external testing.

\section{Figure 21 - Collaboration between contributor and reviewer screen shot}

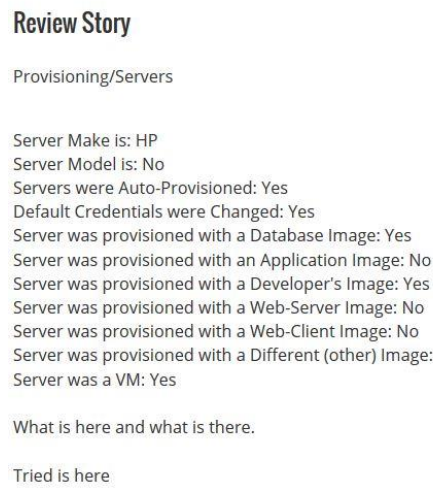

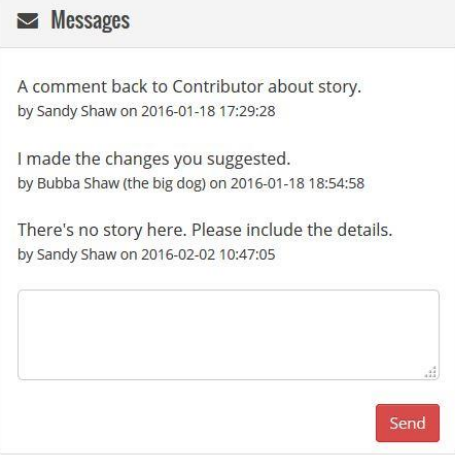


This portion of a story (Figure 22) includes the domain/subdomain pair title as

well as the guiding questions. This is what the contributor sees upon completion of a

story.

Figure 22 - Completed story being reviewed screen shot

MANAGE MYSTORIES ADDSTORY

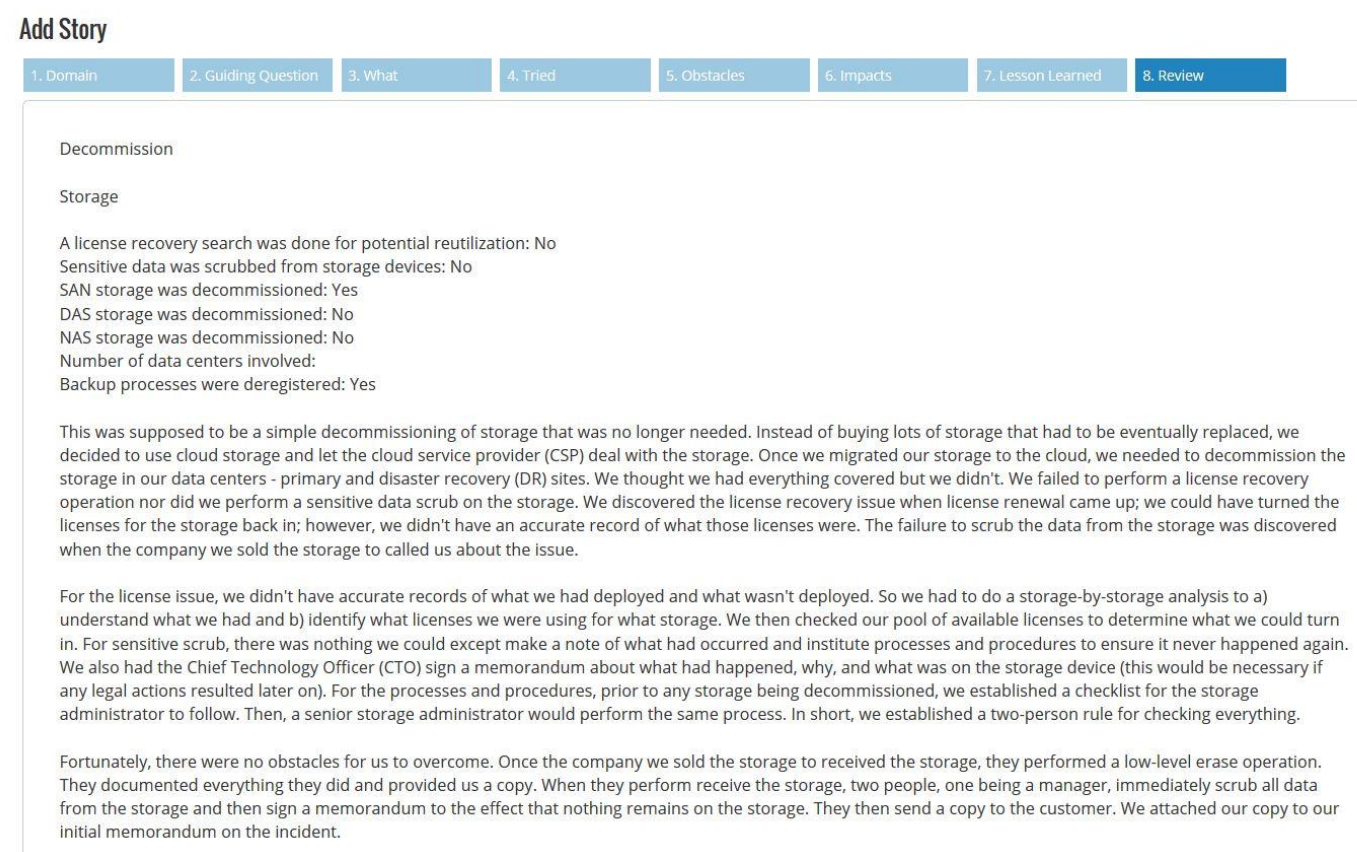


Once a story has been reviewed by the principle investigator (Reviewer), the story can be accepted (Published), or declined (Figure 23). When a story is declined, a message block to the contributor comes up and collaboration between the contributor and reviewer begins.

\section{Figure 23 - Reviewer Accept or Decline Story screen shot}

scrubbed. The process also requires the steps that were followed and the mechanism for scrubbing the data. For the licenses, we implemented a configuration management database (CMDB) and a global discovery tool that collects all of our license information. We then utilize an asset management tool to collect all of our license information into an automated, online, report that is updated weekly. This provides us with an accurate report on all of our licenses which we can bounce against what we have paid for. If we see that we are over our authorized limit, we either purchase the additional licenses or remove products from our installed inventory.

\section{Back to List Accept Decline Story}


When a participant or the principle investigator was finished within the

Knowledge Management Online System (KMOS), they logged out (Figure 24, upper right corner of screen).

Figure 24 - Logging out of the KMOS system

KMOS

MANAGE MYSTORIES ADDSTORY

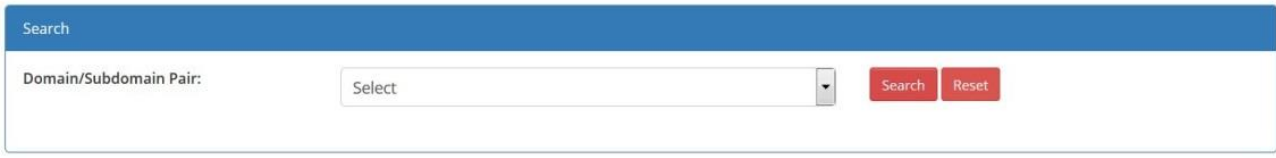

Stories

$\begin{array}{lll}\text { Search: } & \\ \text { Domain Subdomain Pair } & \text { If Story If Actions }\end{array}$

No data available in table 


\section{Appendix H Survey Code Book}

This Appendix contains the code book. The code book is a set of rules for assigning numerical values to responses obtained participants. The code book was prepared in accordance with "Research Methodology", $2^{\text {nd }}$ Edition by Kumar (2005) and "Research Design", $3{ }^{\text {rd }}$ Edition by Creswell (2009). The format used for the code book is a fixed format. This format stipulates that a piece of information obtained from a participant is entered into a specific column. Each column has a number and the 'Col.no.' in the code book which refers to the column in which a specific type of information is to be entered (Kumar, 2005).

Table 8 - Survey Code Book

\begin{tabular}{|c|c|c|c|c|}
\hline $\begin{array}{c}\text { COL \# } \\
1\end{array}$ & $\begin{array}{c}\text { Ques. } \\
\# \\
2\end{array}$ & $\begin{array}{c}\text { Variable Name } \\
3\end{array}$ & $\begin{array}{c}\text { Response Pattern } \\
4\end{array}$ & $\begin{array}{c}\text { Code } \\
5\end{array}$ \\
\hline 1 & Part \# & PNO & Participant number & Code Actual \\
\hline \multirow[t]{5}{*}{2} & $1-1$ & TACIT & Significantly disagree & 1 \\
\hline & & & Somewhat disagree & 2 \\
\hline & & & No change & 3 \\
\hline & & & Somewhat agree & 4 \\
\hline & & & Significantly agree & 5 \\
\hline \multirow[t]{5}{*}{3} & $1-2$ & CONTRIB & Significantly disagree & 1 \\
\hline & & & Somewhat disagree & 2 \\
\hline & & & No change & 3 \\
\hline & & & Somewhat agree & 4 \\
\hline & & & Significantly agree & 5 \\
\hline \multirow[t]{5}{*}{4} & $1-3$ & STORCOMM & Significantly disagree & 1 \\
\hline & & & Somewhat disagree & 2 \\
\hline & & & No change & 3 \\
\hline & & & Somewhat agree & 4 \\
\hline & & & Significantly agree & 5 \\
\hline \multirow[t]{5}{*}{5} & $1-4$ & CREATESTORY & Significantly disagree & 1 \\
\hline & & & Somewhat disagree & 2 \\
\hline & & & No change & 3 \\
\hline & & & Somewhat agree & 4 \\
\hline & & & Significantly agree & 5 \\
\hline 6 & $1-5$ & MYWAY & Significantly disagree & 1 \\
\hline
\end{tabular}




\begin{tabular}{|c|c|c|c|c|}
\hline $\begin{array}{c}\text { COL \# } \\
1\end{array}$ & $\begin{array}{c}\text { Ques. } \\
\# \\
2\end{array}$ & $\begin{array}{c}\text { Variable Name } \\
3\end{array}$ & $\begin{array}{c}\text { Response Pattern } \\
4\end{array}$ & $\begin{array}{c}\text { Code } \\
5\end{array}$ \\
\hline & & & Somewhat disagree & 2 \\
\hline & & & No change & 3 \\
\hline & & & Somewhat agree & 4 \\
\hline & & & Significantly agree & 5 \\
\hline \multirow[t]{5}{*}{7} & $1-6$ & TOOMUCHTIME & Significantly disagree & 1 \\
\hline & & & Somewhat disagree & 2 \\
\hline & & & No change & 3 \\
\hline & & & Somewhat agree & 4 \\
\hline & & & Significantly agree & 5 \\
\hline \multirow[t]{5}{*}{8} & $1-7$ & AUDIO & Significantly disagree & 1 \\
\hline & & & Somewhat disagree & 2 \\
\hline & & & No change & 3 \\
\hline & & & Somewhat agree & 4 \\
\hline & & & Significantly agree & 5 \\
\hline \multirow[t]{5}{*}{9} & $1-8$ & OWNWAY & Significantly disagree & 1 \\
\hline & & & Somewhat disagree & 2 \\
\hline & & & No change & 3 \\
\hline & & & Somewhat agree & 4 \\
\hline & & & Significantly agree & 5 \\
\hline \multirow[t]{5}{*}{10} & $2-1$ & SCENSOL & Significantly disagree & 1 \\
\hline & & & Somewhat disagree & 2 \\
\hline & & & No change & 3 \\
\hline & & & Somewhat agree & 4 \\
\hline & & & Significantly agree & 5 \\
\hline \multirow[t]{5}{*}{11} & $2-2$ & DOMSUB & Significantly disagree & 1 \\
\hline & & & Somewhat disagree & 2 \\
\hline & & & No change & 3 \\
\hline & & & Somewhat agree & 4 \\
\hline & & & Significantly agree & 5 \\
\hline \multirow[t]{5}{*}{12} & $2-3$ & MULTILEVEL & Significantly disagree & 1 \\
\hline & & & Somewhat disagree & 2 \\
\hline & & & No change & 3 \\
\hline & & & Somewhat agree & 4 \\
\hline & & & Significantly agree & 5 \\
\hline \multirow[t]{5}{*}{13} & $2-4$ & GUIDEQUES & Significantly dislike & 1 \\
\hline & & & Somewhat dislike & 2 \\
\hline & & & Neither like nor dislike & 3 \\
\hline & & & Somewhat like & 4 \\
\hline & & & Significantly like & 5 \\
\hline \multirow[t]{3}{*}{14} & $2-5$ & COPS & Significantly disagree & 1 \\
\hline & & & Somewhat disagree & 2 \\
\hline & & & No change & 3 \\
\hline
\end{tabular}




\begin{tabular}{|c|c|c|c|c|}
\hline $\begin{array}{c}\text { COL \# } \\
1\end{array}$ & $\begin{array}{c}\text { Ques. } \\
\# \\
2\end{array}$ & $\begin{array}{c}\text { Variable Name } \\
3\end{array}$ & $\begin{array}{c}\text { Response Pattern } \\
4\end{array}$ & $\begin{array}{c}\text { Code } \\
5\end{array}$ \\
\hline & & & Somewhat agree & 4 \\
\hline & & & Significantly agree & 5 \\
\hline \multirow[t]{4}{*}{15} & $2-6$ & STORYSOL & Significantly disagree & 1 \\
\hline & & & No change & 3 \\
\hline & & & Somewhat agree & 4 \\
\hline & & & Significantly agree & 5 \\
\hline \multirow[t]{2}{*}{16} & $3-1$ & PARTFORUM & Yes & 1 \\
\hline & & & No & 2 \\
\hline \multirow[t]{5}{*}{17} & $3-2$ & TACITFORUM & Significantly disagree & 1 \\
\hline & & & Somewhat disagree & 2 \\
\hline & & & No change & 3 \\
\hline & & & Somewhat agree & 4 \\
\hline & & & Significantly agree & 5 \\
\hline \multirow[t]{5}{*}{18} & $3-3$ & KMSFORUM & Significantly disagree & 1 \\
\hline & & & Somewhat disagree & 2 \\
\hline & & & No change & 3 \\
\hline & & & Somewhat agree & 4 \\
\hline & & & Significantly agree & 5 \\
\hline \multirow[t]{5}{*}{19} & $3-4$ & FREEFORM & Significantly disagree & 1 \\
\hline & & & Somewhat disagree & 2 \\
\hline & & & No change & 3 \\
\hline & & & Somewhat agree & 4 \\
\hline & & & Significantly agree & 5 \\
\hline \multirow[t]{5}{*}{20} & $3-5$ & QUALITY & Significantly disagree & 1 \\
\hline & & & Somewhat disagree & 2 \\
\hline & & & No change & 3 \\
\hline & & & Somewhat agree & 4 \\
\hline & & & Significantly agree & 5 \\
\hline \multirow[t]{2}{*}{21} & 4 & GENDER & Male & 1 \\
\hline & & & Female & 2 \\
\hline \multirow[t]{5}{*}{22} & 5 & AGE & $18-30$ & 1 \\
\hline & & & $31-40$ & 2 \\
\hline & & & $41-50$ & 3 \\
\hline & & & $51-60$ & 4 \\
\hline & & & $60+$ & 5 \\
\hline \multirow[t]{7}{*}{23} & 6 & REGION & Northwest & 1 \\
\hline & & & West & 2 \\
\hline & & & Southwest & 3 \\
\hline & & & North Central & 4 \\
\hline & & & Central & 5 \\
\hline & & & South Central & 6 \\
\hline & & & Northeastern & 7 \\
\hline
\end{tabular}




\begin{tabular}{|c|c|c|l|c|}
\hline COL \# & Ques. & Variable Name & \multicolumn{1}{|c|}{ Response Pattern } & Code \\
$\mathbf{1}$ & $\#$ & $\mathbf{4}$ & & $\mathbf{5}$ \\
& $\mathbf{2}$ & & & 8 \\
\hline & & & East & 9 \\
\hline & & & Southeast \\
\hline
\end{tabular}




\section{Appendix I BPMN KMS Framework Model}

Figure 25 - BPMN KMS Framework Model

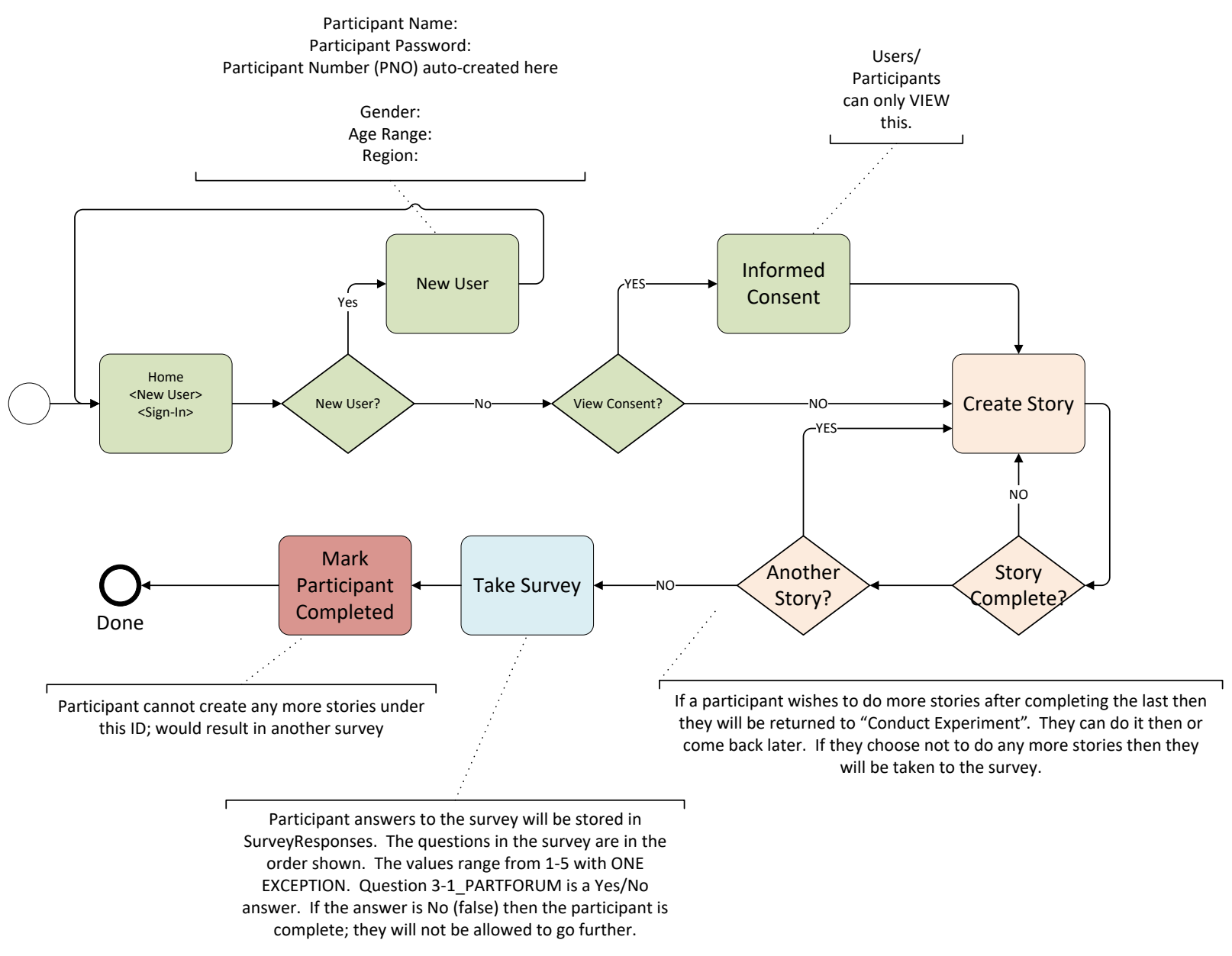




\section{References}

Abdullah, R., Eri, Z. D., \& Talib, A. M. (2011). A Model of Knowledge Management System for Facilitating Knowledge as a Service (KaaS) in Cloud Computing Environment. Paper presented at the 2011 International Conference on Research and Innovation in Information Systems (ICRIIS), Kuala Lumpur.

Abecker, A., S., D., \& Maurer, F. (2000). Organizational Memory and Knowledge Management. Information Systems Frontiers, 2(3-4), 251-252.

Anantatmula, V., \& Kanungo, S. (2007). Modeling Enablers for Successful KM Implementation. Paper presented at the 40th Hawaii International Conference on system Sciences (HICSS '07).

Ariffin, M. M., Arshad, N. I., Shaarani, A. R., \& Shah, S. U. (2007). Implementing Knowledge Transfer Solution through Web-based Help Desk System. Paper presented at the World Academy of Science, Engineering and Technology 2007.

Azudin, N., Ismail, M. N., \& Taherali, Z. (2009). Knowledge Sharing among Workers: A Study on Their Contribution through Informal Communication in Cyberjaya, Malaysia. Knowledge Management and E-Learning: An International Journal, 1(2), 139-163.

Becerra-Fernandez, I. (2000). The Role of Artificial Intelligence Technologies in the Implementation of People-Finder Knowledge Management Systems (SS-00-03). Retrieved from http://www.aaai.org

Benbya, H., \& Alstyne, M. V. (2008). Eliciting and Validating Knowledge in Knowledge Management Systems. Paper presented at the 41st Hawaii International Conference on Systems Sciences (HICSS).

Boulila, N., Hoffmann, A., \& Herrmann, A. (2011). Using Storytelling to Record Requirements: Elements for an Effective Requirements Elicitation Approach Paper presented the Fourth International Workshop on Multimedia and Enjoyable Requirements Engineering - Beyond Mere Descriptions and with More Fun and Games (MERE) Trento.

Burrows, G. r., Drummond, D. L., \& Martinsons, M. G. (2005). Knowledge Management in China. Communications of the ACM, 48(4), 73-76.

Buttler, T., \& Lukosch, S. (2012a). Exploring the Use of Stories in Patterns of Collaboration. Paper presented at the 2012 45th Hawaii International Conference on System Sciences, Hawaii.

Buttler, T., \& Lukosch, S. (2012b). Rethinking Lessons Learned Capturing - Using Storytelling, Root Cause Analysis, and Collaboration Engineering to Capture Lessons Learned about Project Management. Graz, Austria.

Cerulo, L., \& Distante, D. (2013). Topic-Driven Semi-Automatic Reorganization of Online Discussion Forums: A Case Study in an E-Learning Context. Paper presented at the IEEE Global Engineering Education Conference (EDUCON), Technische Universität Berlin, Berlin, Germany.

Chakraborty, B., Nayek, P., Basak, S., D.Ghosh, \& Debnath, N. (2010). A Performance Comparison between Data-Based KMS and Ontology based KMS for e-Tourism Services. Paper presented at the 8th IEEE International Conference on Industrial Informatics (INDIN), Osaka.

Chatti, M. A., Schroeder, U., \& Jarke, M. (2012). LaaN: Convergence of Knowledge Management and Technology-Enhanced Learning. IEEE Transactions on Learning Technologies, 5(2), 177-189. doi:10.1109/TLT.2011.33 
Chen, Y., Xiao, X., Ren, H., \& Shi, M. (2011). Application Research of Knowledge Management and Engineering for Production Design Organization. Paper presented at the 2011 International Conference on Electronic \& Mechanical Engineering and Information Technology.

Chun, M., Sohn, K., Arling, P., \& Granados, N. (2008). Systems Theory and Knowledge Management Systems: The Case of Pratt-Whitney Rocketdyne. Paper presented the 41st Hawaii International Conference on System Sciences, Hawaii.

Coffey, J., \& Hoffman, R. (2003). Knowledge Modeling for the Preservation of Institutional Memory. Journal of Knowledge Management, 7(3), 38-53. doi:10.1108/13673270310485613

Creswell, J. W. (2009). Research Design: Qualitative, Quantitative, and Mixed Methods Approaches ( 3 ed.). Thousand Oaks, CA: Sage Publications, Inc.

Dictionaries, O. L. (2017). database management systems. Retrieved from https://en.oxforddictionaries.com/definition/database management system

Dingsoyr, T., Djarraya, H. K., \& Røyrvik, E. (2005). Practical Knowledge Management Tool Use in a Software Consulting Company. Communications of the ACM, 48(12), 97-100. doi:10.1145/1101779.1101783

Disterer, G. (2001). Individual and Social Barriers to Knowledge Transfer. Paper presented at the 34th Hawaii International Conference on System Sciences, Hawaii.

Eales, R. T. J. (2004). A Knowledge Management Approach to User Support. Paper presented at the Fifth Conference on Australasian User Interface (AUIC '04).

Fanfan, Y. (2012). Knowledge management: making a core competency in today's business world. Paper presented at the 2012 3rd International Conference on System Science, Engineering Design and Manufacturing Informatization (ICSEM).

Frost, A. (2013). Knowledge Management Systems. Retrieved from http://www.knowledgemanagement-tools.net/knowledge-management-systems.html

Gruber, T. (1995). Toward Principles for the Design of Ontologies Used for Knowledge Sharing. International Journal of Human-Computer Studies, 43(4-5), 907-928.

Gruber, T. R. (1993). A Translation Approach to Portable Ontology Specifications. Knowledge Acquisition, 5(2), 199-220. doi:10.1006/knac.1993.1008

Guechtouli, W., Rouchier, J., \& Orillard, M. (2012). Structuring knowledge transfer from experts to newcomers. Journal of Knowledge Management, 17(1), 47-68. doi:10.1108/13673271311300741

Haller, H., \& Abecker, A. (2010, June 13-16, 2010). iMapping - A Zooming User Interface Approach for Personal and Semantic Knowledge Management. ACM SIGWEB Newsletter, 119-128.

Hsu, I.-C., \& Sabherwal, R. (2011). From Intellectual Capital to Firm Performance: The Mediating Role of Knowledge Management Capabilities. IEEE Transactions on Engineering Management, 58(4), 626-642. doi:10.1109/TEM.2011.2111455

Jimenez-Jimenez, D., Martinez-Costa, M., \& Sanz-Valle, R. (2014). Knowledge management practices for innovation: a multinational corporation's perspective. Journal of Knowledge Management, 18(5), 905-918. doi:http://dx.doi.org/10.1108/JKM-06-2014$\underline{0242}$

Kalid, K. S., \& Mahmud, A. K. B. (2008). A Proposed Organization Storytelling Conceptual Framework for the Purpose of Transferring Tacit Knowledge Paper presented at the International Symposium on Information Technology (ITSim), Kuala Lumpur

Kankanhalli, A., Tan, B. C. Y., \& Wei, K.-K. (2005). Contributing Knowledge to Electronic Knowledge repositories: An Empirical Investigation. MIS Quarterly, 29(1), 113-143. 
Khalid, S., Shehryar, T., \& Arshad, S. (2015). The Role of Knowledge Management in Global Software Engineering. Paper presented at the Proceedings of the 2015 International Conference on Industrial Engineering and Operations Management, Dubai, United Arab Emirates (UAE).

Khan, S., Prasad, B. V. N., Selvi, S., Rani, U., Srivastava, A. K., \& Gautam, D. K. (2015). Document Management System: An Explicit Knowledge Management System. Paper presented at the 2nd International Conference on Computing for Sustainable Global Development (INDIACom).

Ko, D.-G., Kirsch, L. J., \& King, W. R. (2005). Antecedents of Knowledge Transfer from Consultants to Clients in Enterprise System Implementations. MIS Quarterly - Special Issue, 29(1), 59-85.

Kroenke, D. M. (2011). Experiencing MIS (3 ed.): Prentice Hall.

Kulkarni, U. R., Ravindran, S., \& Freeze, R. (2007). A Knowledge Management Success Model: Theoretical Development and Empirical Validation. Journal of Management Information Systems, 23(3), 309-347. doi:10.2753/MIS0742-1222230311

Kumar, R. (2005). Research Methodology: A Step-by-Step Guide for Beginners (2 ed.). London, U.K.: SAGE Publications, Inc.

Lee, J., \& Fink, D. (2012). Knowledge mapping: encouragements and impediments to adoption. Journal of Knowledge Management, 17(1), 16-28. doi:10.1108/13673271311300714

Linde, C. (2001). Narrative and Social Tacit Knowledge. Journal of Knowledge Management, 5(2), 160-171.

Ling, C. W., Sandhu, M. S., \& Jain, K. K. (2009). Knowledge Sharing in an American Multinational Company based in Malaysia. Journal of Workplace Learning, 21(2), 125-142. doi:10.1108/13665620910934825

Liu, L., \& Ozsu, M. T. (2009). Encyclopedia of Database Systems: Spring-Verlag.

Maalel, A., Mejri, L., Mabrouk, H. H., \& Ghezela, H. B. (2012). Toward a Knowledge Management Approach Based on an Ontology and Case-based Reasoning (CBR) Application to Railroad Accidents. Paper presented at the Sixth International Conference on Research Challenges in Information Science (RCIS), Valencia.

Makolm, J., Weiß, S., \& Reisinger, D. (2007). Proactive Knowledge Management: The DYONIPOS Research and Use-Case Project. Paper presented at the 1st International Conference on Theory and Practice of Electronic Governance (ICEGOV 2007), Macao, China.

Marczyk, G., DeMatteo, D., \& Festinger, D. (2005). Essentials of Research Design and Methoodology (1 ed.): John Wiley \& Sons.

Marshall, B., Yiwen Zhang, Chen, H., Lally, A., Shen, R., Fox, E., \& Cassel, L. N. (2003). Convergence of Knowledge Management and E-Learning: the GetSmart Experience. Paper presented at the 2003 Joint Conference on Digital Libraries, 2003.

McDermott, R., \& O'Dell, C. (2001). Overcoming Cultural Barriers to Sharing Knowledge. Journal of Knowledge Management, 5(1), 76-85.

Minitab-Product-Support. (2016). What is a test statistic. Retrieved from http://support.minitab.com/en-us/minitab/17/topic-library/basic-statistics-andgraphs/hypothesis-tests/basics/what-is-a-test-statistic/

. Minitab 17 (Version 17.3.1). (2016) [Statistical Software]: Minitab, Inc.

Morzy, M. (2010). An Analysis of Communities in Different Types of Online Forums. Paper presented at the International Conference on Advances in Social Networks Analysis and Mining.

Nasir, \& Noor. (2010). Integrating ontology-based approach in Knowledge Management System (KMS): construction of Batik Heritage Ontology. Paper presented at the 2010 
International Conference on Science and Social Research (CSSR), Kuala Lumpur, Malaysia.

$\mathrm{Ni}, \mathrm{N} .$, \& Li, Y. (2012). User interests modeling in online forums. Paper presented the International Conference on Advances in Social Networks Analysis and Mining.

Okoroji, O. C., Velu, C., \& Sekaran, C. (2014). Knowledge Sharing Strategies and Knowledge Sharing Attitudes: Empirical Evidence from Ophthalmology Hospital. International Journal of Global Education, 3(1), 14.

Orth, A., Smolnik, S., \& Jennex, M. (2009). The Relevance of Integration for Knowledge Management Success: Conceptual and Empirical Findings. Paper presented at the Hawaii International Conference on System Sciences, Hawaii.

Patalas-Maliszewska, J., Krebs, I., \& Dudek, A. (2017, 28-31 Aug. 2017 ). An approach to automated tacit-knowledge acquisition and transformation in manufacturing companies. Paper presented at the 22nd International Conference on Methods and Models in Automation and Robotics (MMAR), 2017, Miedzyzdroje, Poland

Pumareja, D., \& Sikkel, K. (2005). The Role of Dissonance in Knowledge Exchange: A Case Study of a Knowledge Management System Implementation. 38th Hawaii International Conference on System Sciences, 1, 42b.

Purcell, R., \& O'Brien, J. (2015). Unitas: Towards a Holistic Understanding of Knowledge in Organisations - A Case Based Analysis. The Electronic Journal of Knowledge Management, 13(2), 142-154.

Qiu, J., Want, Z., \& Nian, C. (2014). An approach to filling firms' knowledge gaps based on organisational knowledge structure. Journal of Knowledge Management, 18(1), 1-18.

Rance, S., \& Hanna, A. (2007). ITIL V3 Glossary v3.1.24. In ITIL (Ed.), (pp. 58).

Riege, A. (2005). Three-dozen Knowledge-Sharing Barriers Managers Must Consider. Journal of Knowledge Management, 9(3), 18-35. doi:10.1108/13673270510602746

Rumanti, A. A., Hidayat, T. P., \& Saputro, Y. D. (2015, 06-09 December 2015). Tacit Knowledge Transfer and it Implementation on Small and Medium Enterprises. Paper presented at the IEEE International Conference on Industrial Engineering and Engineering Management (IEEM), Singapore, Singaport.

Rumsey, D. (2003). Statistics. USA: Wiley Publishing.

Saenz, J., Aramburu, N., \& Blanco, C. E. (2012). Knowledge sharing and innovation in Spanish and Colombian high-tech firms. Journal of Knowledge Management, 16(6), 919-933. doi:10.1108/13673271211276191

Sandhu, M. S., Jain, K. K., \& Ahmad, I. U. K. b. (2011). Knowledge Sharing among Public Sector Employees: Evidence from Malaysia. International Journal of Public Sector Management, 24(3), 206-226. doi:10.1108/09513551111121347

Sani, M. R. F., Kardan, A. A., \& Cohan, A. (2013). A Supporting tool in Online Learning Forums based on Multi-Documents Summarization. Paper presented at the 4th International Conference on e-Learning and e-Teaching, ICELET 2013.

Schank, R. C. (2010). Learning Through Storytelling, Not Documents: Knowledge Management Meets Al. eLearn, 2010, 2.

Smuts, H., Merwe, A. v. d., Loock, M., \& Kotzé, P. (2009). A Framework and Methodology for Knowledge Management System Implementation. Paper presented at the 2009 Annual Research Conference of the South African Institute of Computer Scientists and Information Technologists (SAICSIT '09).

Sole, D., \& Wilson, D. G. (2002). Storytelling in Organizations: The power and traps of using stories to share knowledge in organizations. Harvard University: Learning Innovations Laboratory. HARVARD Graduate School of Education. 
Sugathan, S. K., \& Kalid, K. S. (2009). An Exploratory Study of Storytelling Approach as an Instructional Tool from Educators' Perspective. Paper presented at the International Conference on Computer Technology and Development, Kota Kinabalu.

Swap, W., Leonard, D., Shields, M., \& Abrams, L. (2001). Using Mentoring and Storytelling to Transfer Knowledge in the Workplace. Journal of Management Information Systems, 18(1), 95-114.

Taherparvar, N., Esmaeilpour, R., \& Dostar, M. (2014). Customer knowledge management, innovation capability, and business performance: a case study of the banking industry. Journal of Knowledge Management, 18(3), 30.

Tanenbaum, \& Wetherall, D. (2011). Computer Networks (5th ed., pp. 75-82): Prentice Hall.

Thalmann, S., Peinl, R., Hetmank, L., Kruse, P., Seeber, I., Maier, R., . . Bick, M. (2010). Ontologybased Standardization on Knowledge Exchange in Social Knowledge Management Environments. Paper presented at the 12th International Conference on Knowledge Management and Knowledge Technologies (i-KNOW '12).

Thomas Berry, J., \& Nelson, G. (2009). Storytelling: Improving Technical Communication Through Organizational Change. Paper presented at the IEEE International Professional Communication Conference (IPCC) Waikiki, $\mathrm{HI}$

Vizcaino, A., Soto, J. P., Portillo, J., \& Piattini, M. (2007). A Multi-agent Model to develop KMS. 40th Annual Hawaii International Conference on system Sciences (HICSS '07), 203b.

Wasko, M. M., \& Faraj, S. (2005). Why Should I Share? Examining Social Capital and Knowledge Contribution in Electronic Networks of Practice. MIS Quarterly, 29(1), 35-57.

Weber, R., \& Gunawardena, S. (2008). Designing Multifunctional KMS. Paper presented at the 41st Hawaii International Conference on System Sciences, Hawaii.

Weber, R. O. (2007). Addressing Failure Factors in Knowledge Management. The Electronic Journal of Knowledge Management, 5(3), 333 - 346.

Whyte, G., \& Classen, S. (2012). Using storytelling to elicit tacit knowledge from SMEs. Journal of Knowledge Management, 16(6), 950-962. doi:10.1108/13673271211276218

Wilson, E. B. (1990). An Introduction to Scientific Research (1 ed.): Dover.

WU, Y.-L., \& ZHOU, B. (2008). A Management Object Oriented Solution of Knowledge Management System. Paper presented at the 4th International Conference Wireless Communications, Networking and Mobile Computing, 2008. WiCOM '08, Dalian.

Xinxiang, J., \& Xiaohui, Z. (2011). Application of Knowledge Management in Modern Enterprise Paper presented at the 2011 International Conference on E -Business and E Government (ICEE).

Yao, L. J., Kam, T. H. Y., \& Chan, S. H. (2007). Knowledge sharing in Asian public administration sector: the case of Hong Kong. 2005 ACM SIGPLAN conference on Programming language design and implementation, 1(51-69). doi:10.1108/17410390710717138

Yordanova, K. (2007). Integration of Knowledge Management and E-learning - Common Features. Paper presented at the International Conference on Computer Systems and Technologies (CompSysTech'07). 